University of Redlands

\title{
Monitoring Trails and Disturbance in Joshua Tree National Park
}

\author{
A Major Individual Project submitted in partial satisfaction of the requirements \\ for the degree of Master of Science in Geographic Information Systems \\ by \\ Jennifer K Lee \\ Fang Ren, Ph.D., Committee Chair \\ Mark Kumler, Ph.D.
}

August 2009 
Monitoring Trails and Disturbance in Joshua Tree National Park

Copyright (C) 2009

by

Jennifer K Lee 
The report of Jennifer K Lee is approved.

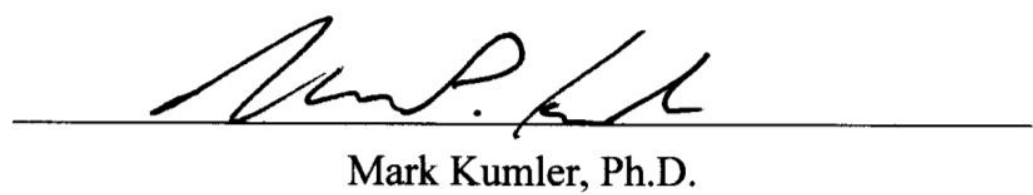

Mark Kumler, Ph.D.

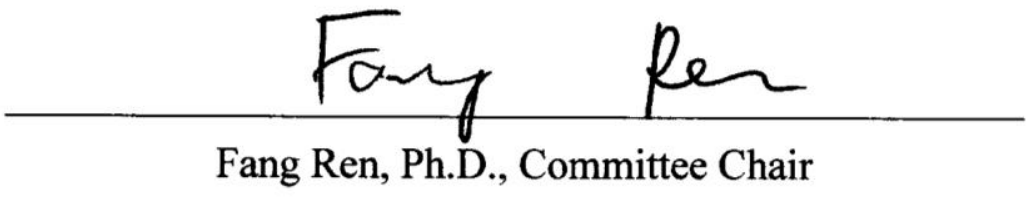

August 2009 



\section{Acknowledgements}

I would like to thank the many people that have supported me throughout this project and program.

First, none of this would have been possible without the support of my home office and co-workers in Virginia. Specific thanks go out to Mr. Gunnar Radel and Ms. Alice Danby for giving me this opportunity.

I want to acknowledge my advisor Dr. Fang Ren, for her ceaseless attention to detail, instruction, and support throughout the year. Dr. Ruijin Ma for tirelessly providing his remote sensing expertise, and special thanks to the rest of the MS GIS faculty and ESRI instructors we worked with throughout the year. Lynn Flewelling for her amazing editing skills and quick turn-around times - thanks. I also want to thank Rubin Ortiz for putting in so much extra time to keep our computers from exploding.

Thank you to my client Dr. Alice Miller and Technical Liaison Sean Murphy at Joshua Tree National Park. Their expertise and guidance was greatly appreciated.

Special thanks and admiration goes to everyone in Cohort 14. Our Cohort - the selfless Cohort. Each person brought a unique talent and strength to our group and from beginning to end your generosity and support never wavered. Thank you Anas, Johnson, Renee, Alyssa, Mike, David, Doti, Bernard, Sean, Laura, Joyce, Tia, and Gerry. I also want to acknowledge our supporters from the sidelines Olga, Gabriel, Jasper, Rick, Cleo, and Pepper.

And finally, I would like to thank my parents, sister, Kim, Norm, and Terri for their continued support throughout this past year. Your phone calls and cards kept me going through the most trying of times - thanks! 



\begin{abstract}
Monitoring Trails and Disturbance in Joshua Tree National Park

by

Jennifer K Lee

Joshua Tree National Park, well known for its recreation activities, is in need of improved vegetation and trail monitoring programs. Specifically, social trails, or trails created by users that deviate from designated paths, are major contributors to vegetation disturbance and loss. Current activity levels are beginning to negatively affect surrounding landscapes. This project was developed to enable staff to monitor large regions of the park without expending significant man-hours or costs. With this in mind, the project was developed using QuickBird satellite imagery as the main component for feature extraction from an ESRI system with the Feature Analyst (FA) and Spatial Analyst extensions. The deliverables for this project were a master geodatabase, vegetation index, and a feature class containing all the social trails within a given region. A customized ArcToolbox and model were developed, in addition to a complete processflow highlighting the steps required to process and analyze the data. The implemented tools and methods in the project enabled the client to monitor large regions of the park
\end{abstract} with less effort than field data collection. 



\section{Table of Contents}

CHAPTER 1 - INTRODUCTION .................................................................................... 1

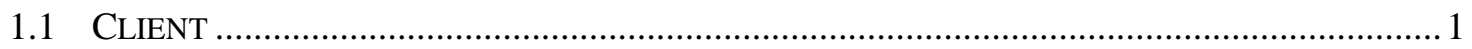

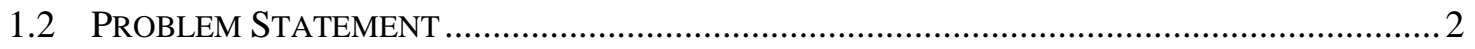

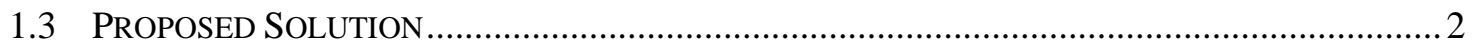

1.3.1 Goals and Objectives...................................................................................

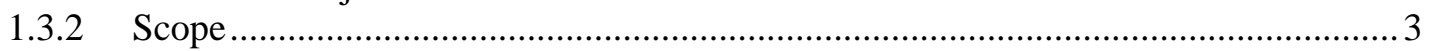

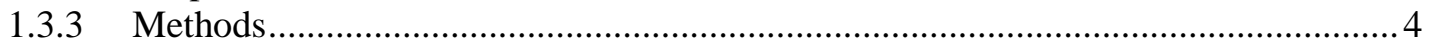

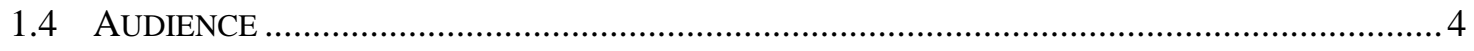

1.5 OVERVIEW OF THE REST OF THIS REPORT ………………………………………….... 4

CHAPTER 2 - BACKGROUND AND LITERATURE REVIEW ................................ 7

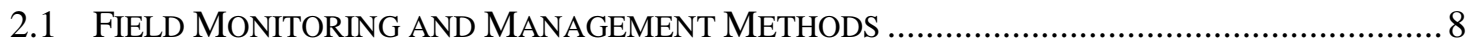

2.2 Monitoring METHOdS IMPLEMENTING REMOTE SENSING AND GIS .............................. 10

2.2.1 Image Classification and Interpretation ……………………………………..... 10

2.2.2 Spectral Transformation Applications ………………………………………….... 10

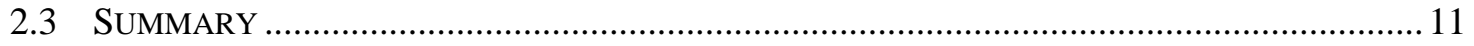

CHAPTER 3 - SYSTEMS ANALYSIS AND DESIGN ……........................................ 13

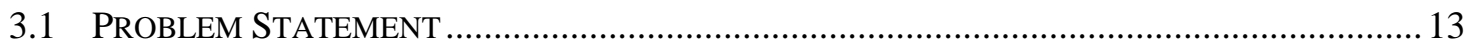

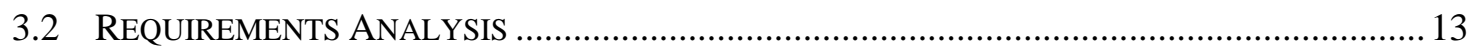

3.2.1 Functional Requirements ................................................................................ 14

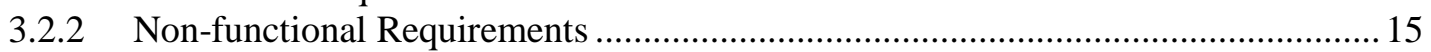

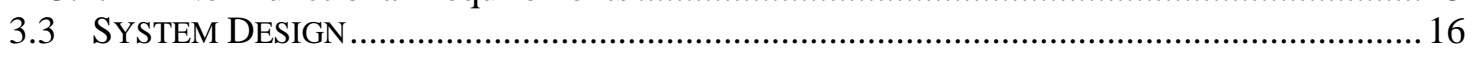

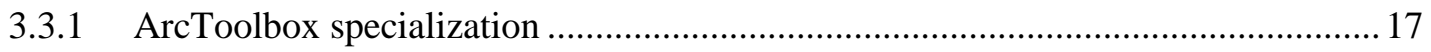

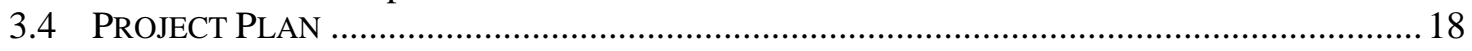

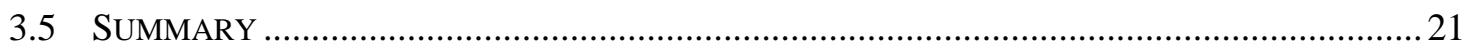

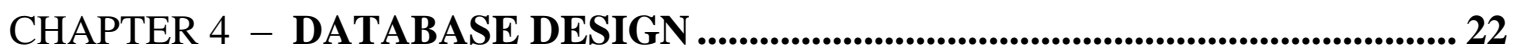

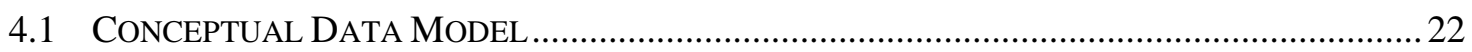

4.2 LOGICAL DATA MODEL …………………………………………………………. 23

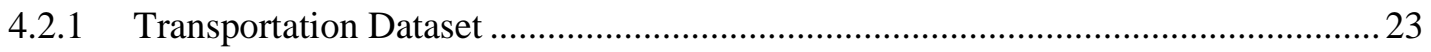

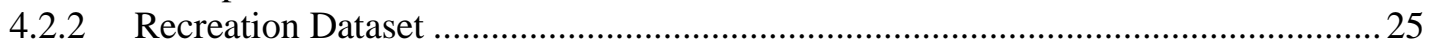

4.2.3 Hydrology Dataset ……………………………………………………. 25

4.2.4 Remaining Feature Classes ..........................................................................2

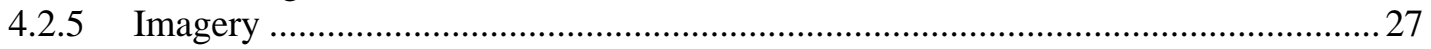

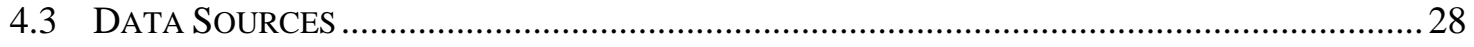

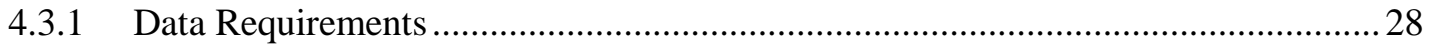

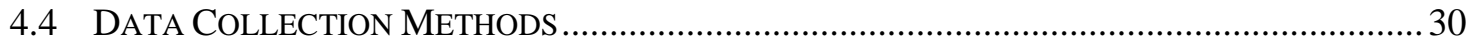

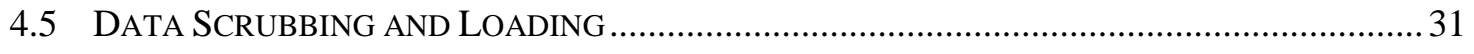

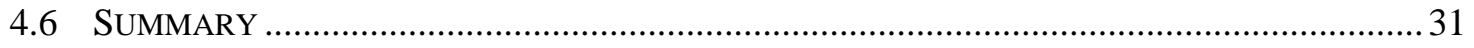

CHAPTER 5 - IMPLEMENTATION ........................................................................... 33

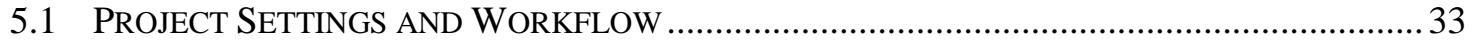

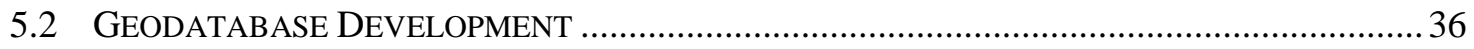

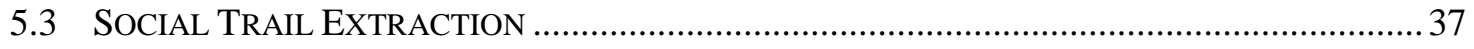

5.3.1 Image and Vector Data Setup ………………………………………………...... 37

5.3.2 Image Registration .......................................................................................... 41 


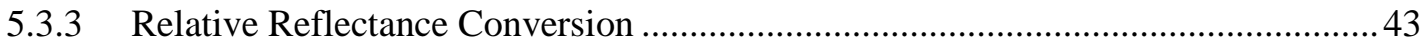

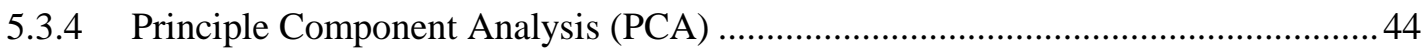

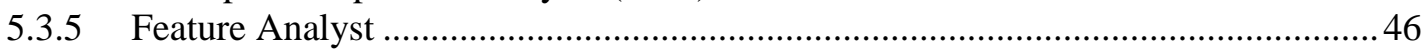

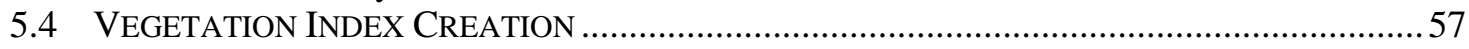

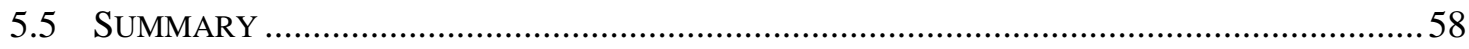

CHAPTER 6 - RESULTS AND ANALYSIS ................................................. 59

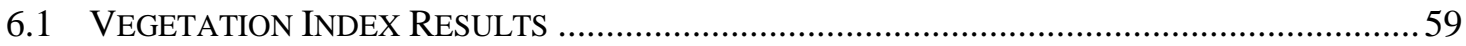

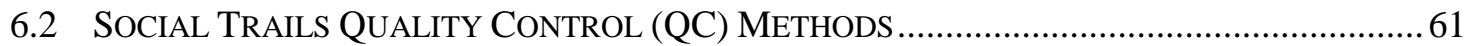

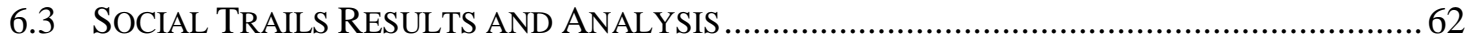

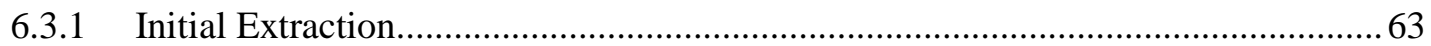

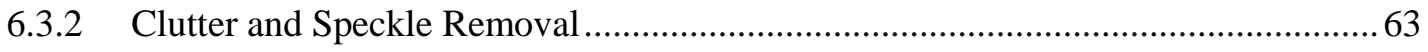

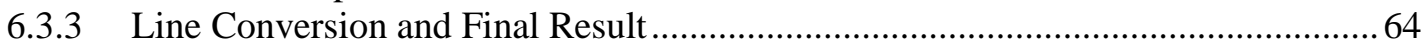

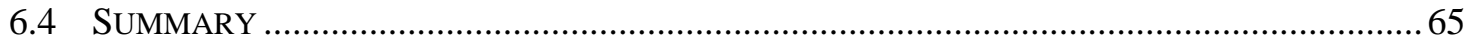

CHAPTER 7 - CONCLUSIONS AND FUTURE WORK.................................... 67

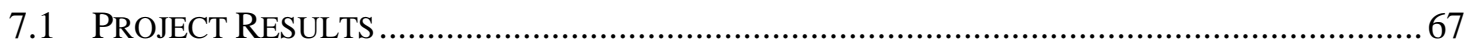

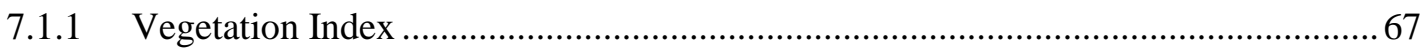

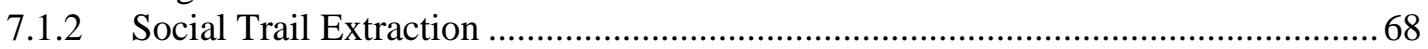

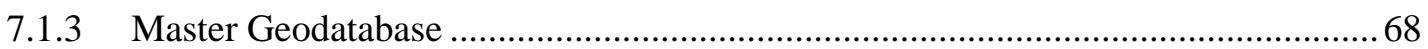

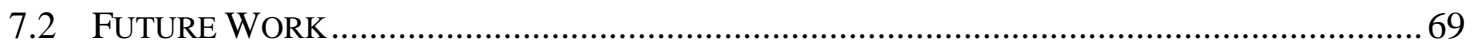

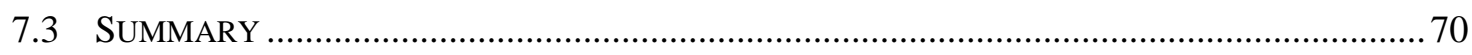

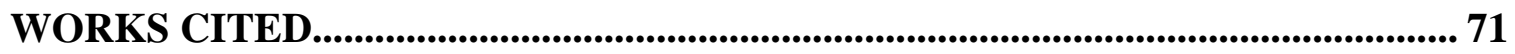

APPENDIX A：VECTOR LAYER REQUIREMENTS......................................... 75

APPENDIX B: GEODATABASE SCHEMA...................................................................... 76

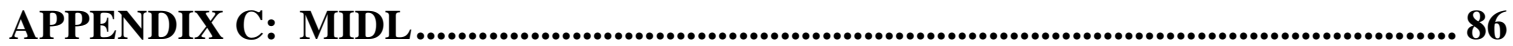




\section{Table of Figures}

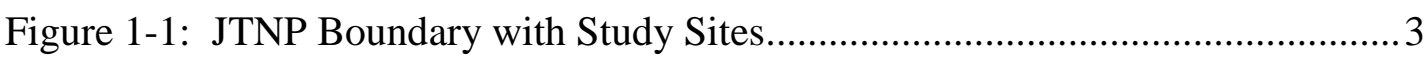

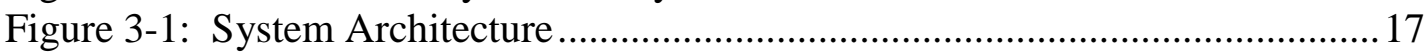

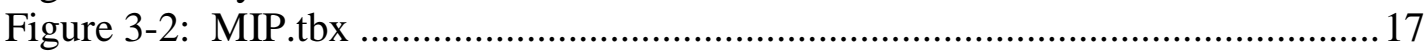

Figure 3-3: Mean Calculation Model................................................................. 18

Figure 3-4: Workflow Diagram (Original) …………………………………......... 19

Figure 4-1: Conceptual Model ...........................................................................22

Figure 4-2: Master File Geodatabase …………………......................................23

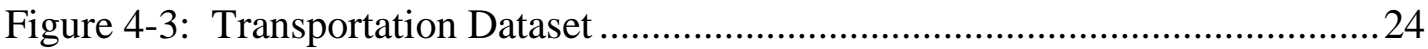

Figure 4-4: Transportation Domain Types ………………………………….....2

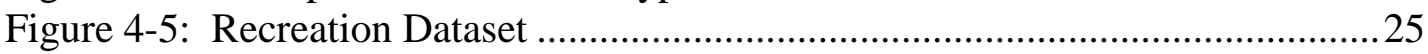

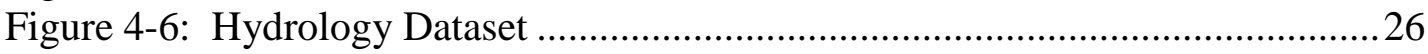

Figure 4-7: Original Hydrologic Table ............................................................2

Figure 4-8: Final Streams Table ……………………...................................2

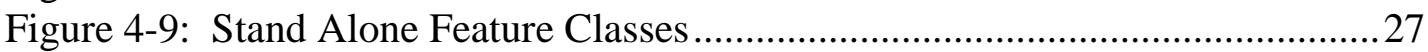

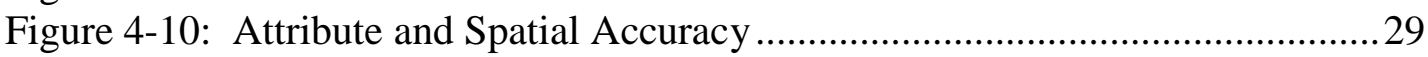

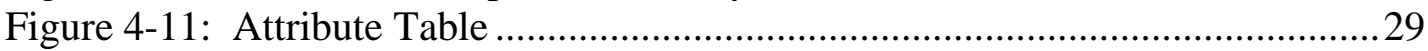

Figure 4-12: Spatial Accuracy and Precision Examples..............................................30

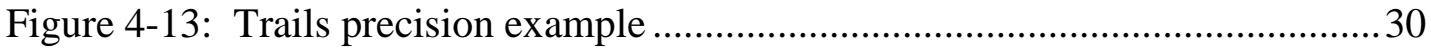

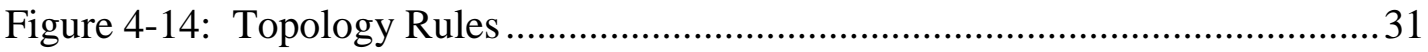

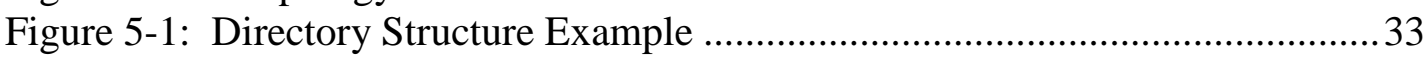

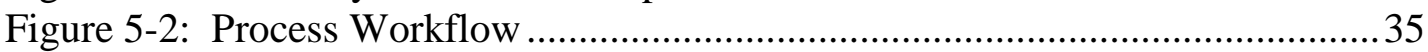

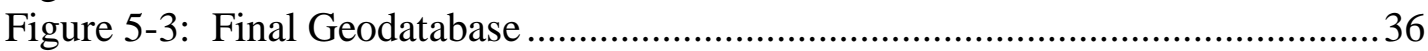

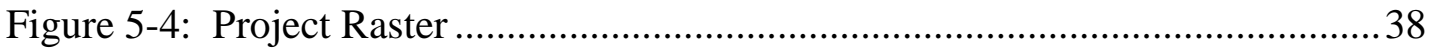

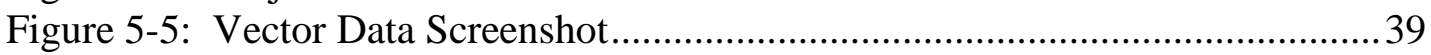

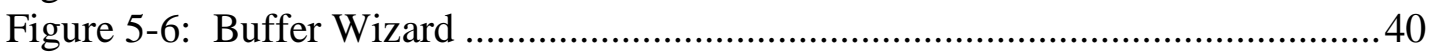

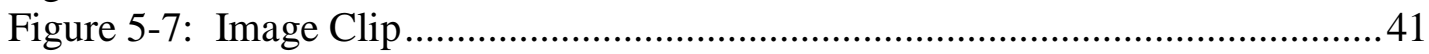

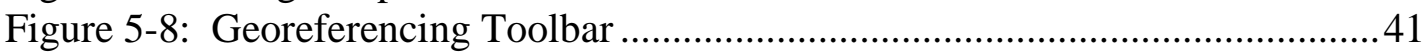

Figure 5-9: Control Point Registration ................................................................. 42

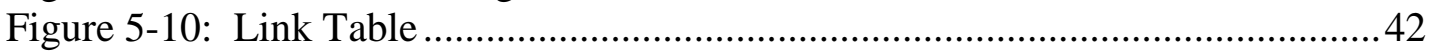

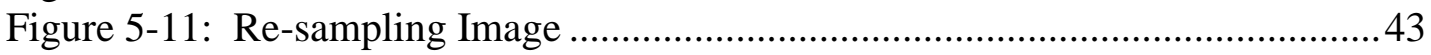

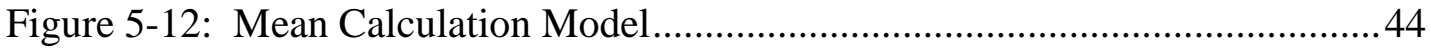

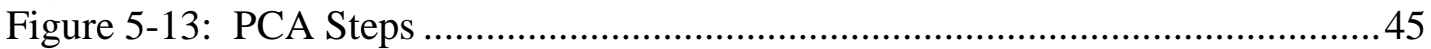

Figure 5-14: Raster to Other Format Tool ........................................................... 45

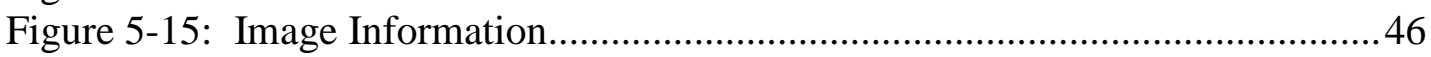

Figure 5-16: Feature Analyst 4.2 Toolbar............................................................. 47

Figure 5-17: Create New Feature Class ................................................................ 47

Figure 5-18: Feature Analyst Progress Window..................................................... 47

Figure 5-19: Training Sample Extraction ............................................................4

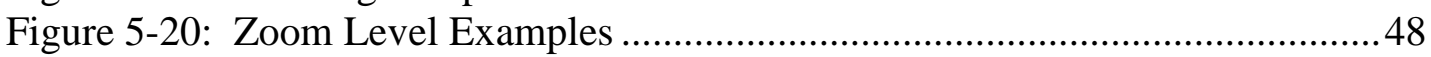

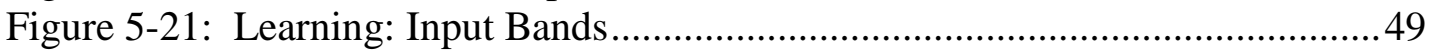

Figure 5-22: Learning: Input Representation.....................................................50

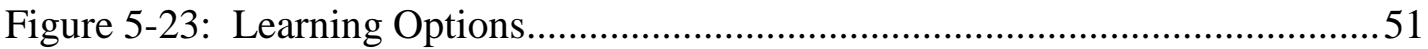

Figure 5-24: FA Remove Clutter Tools ………………….................................... 
Figure 5-25: Remove Clutter Selection Examples ............................................ 52

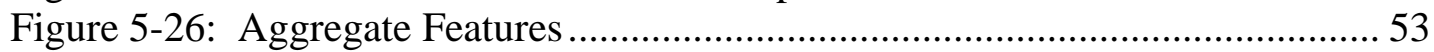

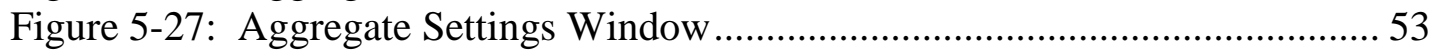

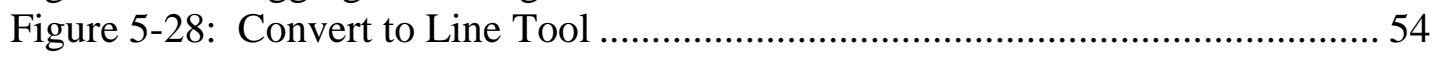

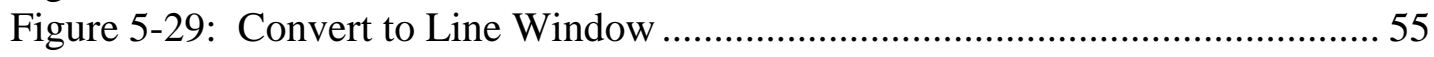

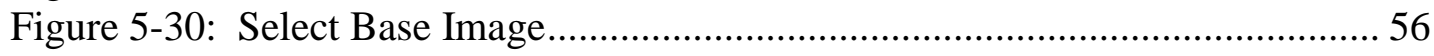

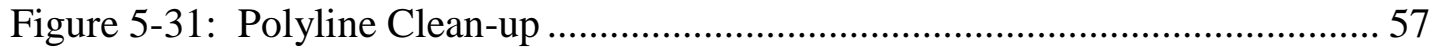

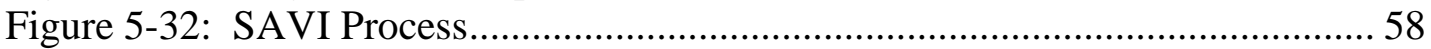

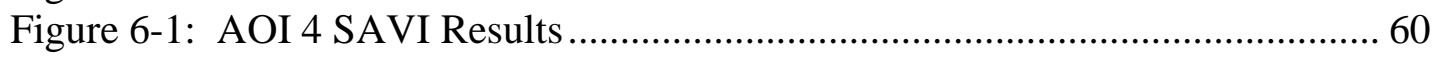

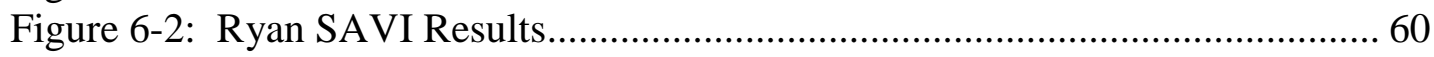

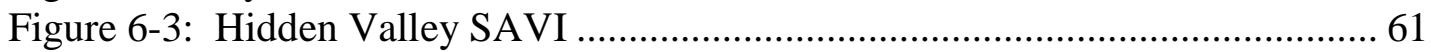

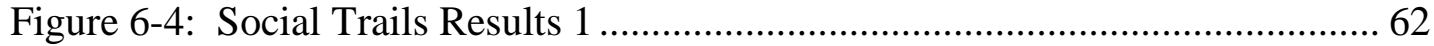

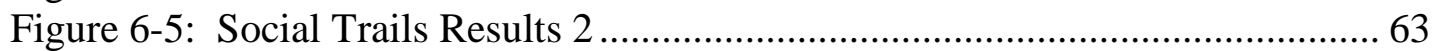

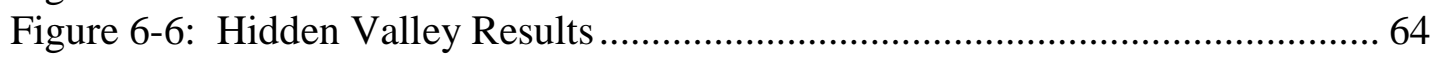

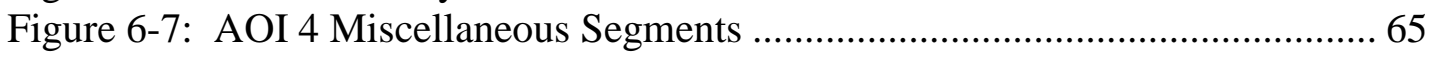




\section{List of Tables}

Table 1: Qualitative Trail Condition Classes ............................................................ 9

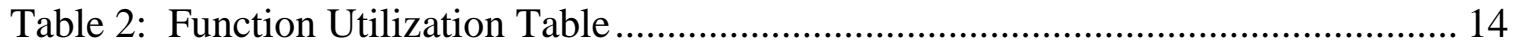

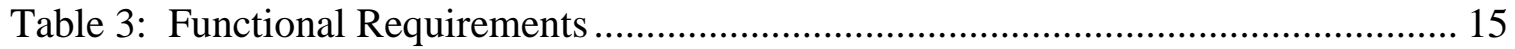

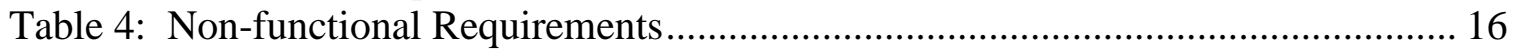

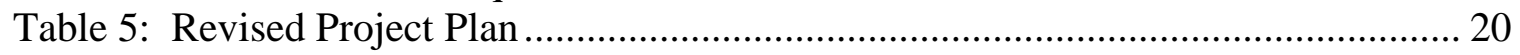

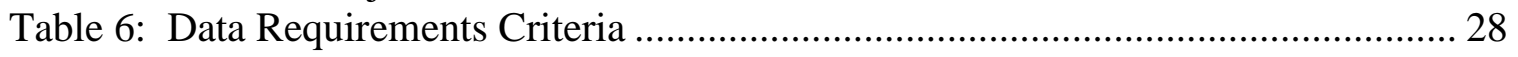

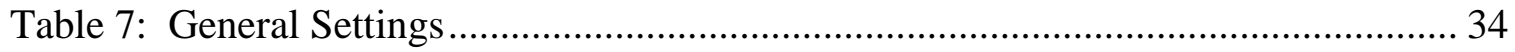





\section{List of Acronyms and Definitions}

$\begin{array}{ll}\text { DLG } & \text { Digital Line Graphic } \\ \text { DRG } & \text { Digital Raster Graphic } \\ \text { DOQ } & \text { Digital Orthophoto Quadrangle } \\ \text { FA } & \text { Feature Analyst extension } \\ \text { GIS } & \text { Geographic Information Systems } \\ \text { GPS } & \text { Global Positioning System } \\ \text { JTNP } & \text { Joshua Tree National Park } \\ \text { MIP } & \text { Major Individual Project } \\ \text { NAIP } & \text { National Agricultural Imagery Program } \\ \text { NDVI } & \text { Normalized Difference Vegetation Index } \\ \text { NPS } & \text { National Park Service } \\ \text { PCA } & \text { Principal Component Analysis } \\ \text { QC } & \text { Quality Control } \\ \text { SAVI } & \text { Soil Adjusted Vegetation Index } \\ \text { TOC } & \text { Table of Contents }\end{array}$





\section{Chapter 1 - Introduction}

Joshua Tree National Park (JTNP), California, spans almost 800,000 acres that include two separate desert ecosystems known as the Mojave and Colorado deserts (NPS, n.d.; Rahman, Park, \& La Doux, 2007). The park is well known for its rock climbing and hiking opportunities, but as annual visitation rates have increased to over one million people per year; these activities have begun to negatively impact the park (California Native Plant Society, 1999; Murdock, 2004). Unfortunately, staffing numbers and fiscal budgets have not kept pace with the popularity of the park, so the resource managers are left looking for more efficient and inexpensive methods to continue their work. In particular, to better maintain the park's natural state, managers need to be able to monitor the impact of recreational use on vegetation and trails within the park.

To address this issue, this project focused on examining recreation disturbance effects on vegetation and trails within JTNP using geographic information systems (GIS) and remote sensing techniques. Using imagery as the main component of analysis, a set of tools was developed to enable a user to monitor large regions of the park without requiring extensive field work. A baseline dataset was created allowing park staff to track vegetation and trail changes through time, to provide managers with a more accurate assessment of the health of specific regions within the park. These tools and methods would significantly reduce the time and funds required to monitor vast regions of the park.

This chapter is organized into five sections that include client background, the problem statement, the proposed solution including goals, scope, and methods, the audience, and an overview for the rest of this report.

\subsection{Client}

Dr. Alice Miller, the Vegetation Program Manager for JTNP is the client for this project, with Sean Murphy as the technical liaison. Dr. Miller manages all research and restoration efforts associated with the landscape of the park. Some of the challenges faced by Dr. Miller and her staff in their daily work include monitoring recreation use and effects, educating the public, and restoring or maintaining the park in its natural state.

Moving beyond traditional field-based monitoring, the staff at JTNP is adopting advanced technologies to aid in park management. For example, the staff has many geospatial resources at their disposal and they have explored GIS and remote sensing techniques for general queries, display, and mapping purposes. However, their use of GIS and remote sensing is currently limited to these basic operations and, therefore, the strength of the advanced technologies has not been fully utilized for park management. Dr. Miller was already aware of the utility of remotely sensed imagery and vector data, and proposed several projects that included the use of these data sources to the University of Redlands MSGIS Program. This project was developed with the expectation of delivering a prototype toolset and methodology that semi-automates the identification and extraction of vegetation disturbance as it relates to recreation and trail use. 


\subsection{Problem Statement}

Traditional field-based research and monitoring methods are time consuming and costly. The vegetation and soils within JTNP are highly variable and susceptible to disturbance events such as increased trail use (Murdock, 2004). Monitoring and management of these changes requires thorough baseline data and a methodology to assess the impacts of recreation (California Native Plant Society, 1999; Marion, Leung, \& Nepal, 2006). Of particular interest are the effects of increased recreational use or disturbance on designated and non-designated trails throughout the park. Non-designated trails, also called social trails, created by recreationists walking off designated trails and trampling vegetation, are usually used for shortcuts or access points to camping areas (Scott, 1998). At this time, the client does not have a complete inventory of designated and social trails and has no way to calculate or monitor the effects that different levels of use are having currently or in the future on the surrounding landscape and vegetation.

Current trail management practices at JTNP include mapping out the social trail networks by hiking the trails with GPS units (Miller, 2008). The mapping sites are selected based on visitor use, with the most popular visitor areas being mapped first. The problem with this method is the amount of time required and cost accrued to walk every social trail within the park. Until completion of this method the gaps in the data leave park staff with only a partial picture of the relative health of the landscape. Another question left unanswered is the rate of disturbance and its effect on the surrounding vegetation. The park staff needs an economic yet efficient method to monitor recreation activities, specifically social trails, and their impact throughout the park. Therefore, this project focused on identifying all designated and social trails, as well as the various types and levels of trail-based disturbance within the park and the impacts of this disturbance over time to the surrounding landscape.

\subsection{Proposed Solution}

Since the traditional methods of monitoring and managing through field-based research are not always financially feasible, new methods need to be developed. The proposed solution was an analytic model that would extract social trails from raster images using only Environmental Systems Research Institute (ESRI) software, as well as create a vegetation index that would highlight disturbance effects. This model would utilize multi-date pan-sharpened QuickBird imagery ( $0.6 \mathrm{~m}$ resolution), and associated vector data. The results of this model could be used as a tool to assess, monitor, and predict future management requirements associated with trails within JTNP.

\subsubsection{Goals and Objectives}

The goal for this project was to create a tool that would facilitate park staff monitoring current and future impacts of recreational trail-use on both designated and social trail networks, as well as surrounding vegetation. Using this tool, park staff could focus their wilderness management skills on developing solutions to the disturbances caused by recreational trail-use, rather than collecting and processing data. Under this general goal, three objectives were established for the project. The main objective was to create a set of tools and methods for extracting trails from remotely sensed data using ESRI software. 
The secondary objective was to develop a park-wide database to store and manage the park data. The final objective was to create a vegetation index for future monitoring of the impacts on vegetation.

\subsubsection{Scope}

The scope of this project was limited to inventorying and assessing designated and social trail networks, disregarding their association with other recreation activities such as camping or bouldering sites. Due to time constraints and the size of the park, the focus of this project was narrowed to three separate one kilometer square study areas, shown in Figure 1-1. The study areas were selected to include high-use and low-use areas, as well as to cover several different geographic landscapes within the park. However, because of budgetary concerns the three one kilometer square study sites were selected from one 28 square kilometer region with two years of coverage.

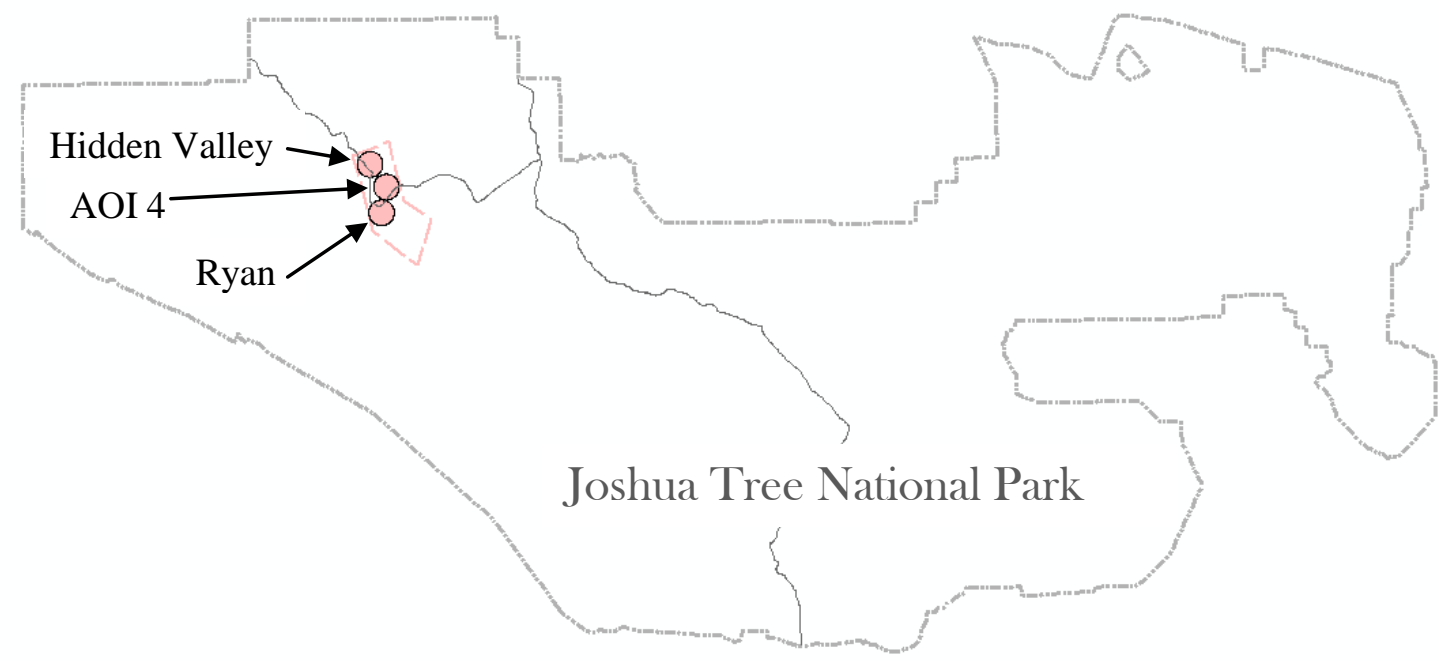

Figure 1-1: JTNP Boundary with Study Sites

Specifically, the project scope included the assessment and development of the current database infrastructure, and providing all data at completion in file geodatabase format. Raster and vector processing outputs were also provided at the completion of the project. The specific raster outputs delivered were vegetation indices of each image date and several iterative examples of the images as they were processed. The vector layer output included the new social trails feature class. An ArcToolbox extension compatible with ArcGIS 9.3 was created containing all appropriate tools and models used throughout the project. A detailed methodological approach document was also delivered at project completion, annotating all processes and steps required to duplicate this process throughout the park. 


\subsubsection{Methods}

Significant research was conducted to select appropriate techniques and methods that would ensure the success of this project. The main limiting factor in the selection of processes and techniques was the requirement for all work to be performed using ESRI software. The ESRI software extensions Feature Analyst and Spatial Analyst were also used for this project. The multi-faceted approach to this project included a combination of image processing and analysis in addition to vector creation and analysis.

This project tested the developed methods on QuickBird pan-sharpened imagery with a resolution of 0.6 meters. QuickBird pan-sharpened imagery is a fusion of high resolution panchromatic imagery $(0.6 \mathrm{~m})$ with moderate resolution multispectral imagery $(2.4 \mathrm{~m})$, which results in high resolution 4-band imagery (Aronoff, 2005a). All imagery was re-projected to North American Datum 1983 (NAD83) Universal Transverse Mercator Zone 11 North (UTM Zone 11N). Geometric rectification was applied to align multiple image dates to the original source image, which was 2005 National Agriculture Imagery Program (NAIP) imagery. Several strategies were reviewed to determine the most applicable method for this project, as well as for the client. The purpose for rectifying and re-projecting the imagery prior to analysis was in preparation for future temporal monitoring processes. Although performing these actions prior to analysis may introduce minor warping this method adequately met the needs of the client.

The images were clipped to one kilometer square regions based on study site location. To aid the trail extraction process, both unsupervised and supervised classification techniques were applied, including the spectral transform Principle Component Analysis (PCA) using the Spatial Analyst extension. The vegetation index used was the Soil Adjusted Vegetation Index (SAVI). For the purposes of this project the radiance values were converted to relative reflectance values and will be discussed in more detail in Chapter Five.

A master geodatabase was loaded with vector data covering the entire park boundary. Specific feature classes were selected based on accuracy, coverage, and relevancy. A separate geodatabase for each site was loaded with the clipped vector data. The Feature Analyst extension was used to analyze the imagery and extract trail features through hierarchical learning algorithms (Visual Learning Systems, Inc., 2007). Features were extracted through a series of steps that included spectral classification and object identification and then converted from raster to vector.

\subsection{Audience}

This project was designed for natural resource managers and scientists interested in monitoring or measuring recreation impacts to local environments, specifically arid environments, using remote sensing techniques. It is assumed that users of this product will have a basic knowledge of GIS, such as displaying data, spatial queries, map creation, and data loading.

\subsection{Overview of the Rest of this Report}

The rest of this report is organized as follows. Chapter Two, Background and Literature Review, highlights the studies related to traditional resource management and 
applications of GIS in resource management. In particular, commonly used methods for feature identification and extraction from imagery and spectral signatures are reviewed. The methods reviewed form the foundation for the approach applied in this project.

Chapter Three, Systems Analysis and Design, describes the functional requirements, including the hardware and software requirements of the project. A complete review of the project plan highlights the original plan and workflow, in addition to the final revised plan that accounted for necessary changes and alterations to the project. The system architecture and design, including a customized ArcToolbox, is also briefly discussed.

Chapter Four, Database Design, describes the conceptual and logical data models, data sources, and collection methods. This section also covers the processes used to scrub and load the data into the geodatabases, in addition to metadata requirements.

Chapter Five, Project Implementation, provides in detail what methods were used to process the imagery for analysis and how the imagery was analyzed. This section also covers the geoprocessing tools and models that were used.

Chapter Six, Results and Analysis, discusses the results of geoprocessing tasks that were run to extract trails from QuickBird imagery. Quality control methods and steps are explained in detail. Limitations and shortcomings of the methods used, as well as the results are also discussed.

Chapter Seven, Conclusions and Future Work, summarizes the results of the project with a concise explanation of what was done and why it worked. The three main objectives for this project-- baseline geodatabase, vegetation index, and social trails dataset--are briefly discussed. The future work portion of this chapter provides suggestions for future projects or analysis within JTNP, specifically regarding recreation, social trail networks, and the associated vegetation changes. 



\section{Chapter 2 - Background and Literature Review}

Located in southern California, Joshua Tree National Park (JTNP) encompasses regions of the Mojave Desert to the north and the Colorado Desert to the south (Rahman, Park, \& La Doux, 2007). Average annual rainfall within the park is about four inches. Daytime temperatures range from an average of 60 degrees Fahrenheit in the winter to over 100 degrees Fahrenheit in the summer months (NPS, n.d.). Joshua Tree was designated a National Monument in 1936 and later designated a National Park in 1994. Since 1994 visitation has reached over one million people per year. Increased recreation in the form of hiking, camping, and rock climbing has led to negative impacts on the park's natural state. Miller (n.d.) concluded that these "impacts include changes in species composition, loss of biodiversity, increases in exotic species, loss of biological and physical soil crust, and soil compaction" (p. 1). To better monitor these disturbances, an efficient and effective method is required by JTNP staff.

The staff at JTNP is tasked with managing the impact of more than one million visitors per year over a region spanning almost 800,000 acres (Murdock, 2004; NPS, n.d.). Multiple studies have looked at the impact of recreation at JTNP, with specific emphasis on social trail networks (California Native Plant Society, 1999; Miller, n.d.; Murdock, 2004; Rahman, Park, \& La Doux, 2007). Miller (n.d.) states that "ecosystem degradation caused by visitor-created informal or 'social' trail networks is a concern for resource managers throughout the National Park System" (p. 1). In desert environments such as JTNP, social trails are naturally created because of the lack of trees and dense vegetation that would normally keep users on the designated trails. The impact caused by social trails can take 50-100 years to recover from soil compaction and nutrient loss (Belnap, 1995; Rahman, Park, \& La Doux, 2007).

Social trail monitoring can be used as an indicator for future resource management projects (Marion, Leung, \& Nepal, 2006). Marion et al. (2006) suggested three primary monitoring questions in relation to social trails management:

- What are the alternative indicator measures and monitoring techniques?

- Are there efficient methods to monitor informal trails without field mapping them all?

- How do the methods compare with respect to accuracy, precision/consistency, and efficiency? (p. 44)

Centered on these questions, the following sections of this literature review will explore different monitoring techniques, discuss efficient alternatives to field mapping, and several methods based solely on accuracy and efficiency. Section 2.1 will focus on field monitoring and management methods and techniques. There will also be a description of assessment factors commonly used to rate trail degradation and their effects. Section 2.2 will present monitoring methods that use geospatial and remotely sensed data. Included in this section are two subsections: section 2.2.1 focusing on image classification and interpretation techniques, and section 2.2.2 discussing remote sensing techniques such as spectral transformation applications. 


\subsection{Field Monitoring and Management Methods}

Numerous studies have been conducted on the impact of recreation on wilderness and national parks from the management perspective (Leung \& Marion, 2000; Marion, Leung, \& Nepal, 2006; Nepal \& Nepal, 2004). In their review, Leung and Marion (2000) compared several approaches to conducting trail impact assessments, as well as methods for managing these impacts. Marion et al. (2006) also included the use of geospatial resources in their review of trail monitoring methods. Monitoring, maintaining, and planning trail networks have become important management objectives for the NPS in response to ever increasing park usage (Leung \& Marion, 1999; Leung \& Marion, 2000; Marion, Leung, \& Nepal, 2006).

Traditional methods for inventorying and assessing a trail network include visitor counters, user censuses and surveys, and manual trail assessments (Cole, 1983; Leung \& Marion, 2000; Lindsey, Wilson, Rubchinskaya, Yang, \& Han, 2007). Marion et al. (2006) found that these "sampling-based" and "census-based" methods proved very useful in assessing impact levels at the ground scale (p. 37). For instance, field collection methods can yield soil compaction data, discrete vegetation patterns and assessments, and accurate trail measurements including width, and erosion depth (Leung \& Marion, 2000; Marion, Leung, \& Nepal, 2006; Nepal \& Way, 2007). Some of the problems with the surveys include data collection points being too sparse or not being representative of the entire trail network (Leung \& Marion, 2000). Performing manual trail assessments or using visitor counters also tends to be cost prohibitive for long-term monitoring.

Several studies also highlighted trail assessment methods or indices, and descriptions (Jewell \& Hammitt, 2000; Marion, Leung, \& Nepal, 2006; Nepal, 2003). Nepal (2003) and Marion et al. (2006) ranked trail conditions into four qualitative classes summarized in Table 1. 


\section{Table 1: Qualitative Trail Condition Classes}

\begin{tabular}{ll}
\hline Condition class & Description \\
\hline & Lightly damaged trail. Either one or a combination of several impact features \\
& is present. Trail width is < $5 \mathrm{ft}$; no more than three treads apparent; low to \\
& moderate potential for trail expansion; some muddy spots may be present; \\
incision is $<0.5 \mathrm{ft}$; some exposed and loose soil may be present on the trail \\
Surface. Overall, a trail under this classification is stable and does not require \\
any maintenance as long as the conditions do not deteriorate further. \\
Moderately damaged trail. Trail segments clearly show deteriorating \\
conditions. Either a single impact feature with significant damage, or a \\
combination of more than two impact features is present: trail is wider than 5 \\
ft; incision between 0.5 and $1.0 \mathrm{ft}$ (incision of $1.5 \mathrm{ft}$ in the absence of any other \\
features will satisfy the condition itself); more than three treads are present; \\
muddiness and running water on trail; trail is displaced; and soil is \\
unconsolidated. The degree and magnitude of trail damage is significant \\
enough to prescribe some management actions.
\end{tabular}

Highly damaged trail. This is a potential hotspot, showing either one type of impact feature or a combination of several features. Both the magnitude and the extent of damage are significant. Basic impact features include trail width, multiple treads, and incision. Usually these are present in combined forms, for example, trail braiding leading to excessive width. In certain cases, trail width is less but several treads are present, some of which are deeply incised $(>1.5$ $\mathrm{ft}$ ). Frequently exposed bedrock and roots are present in addition to other impact features. A trail affected by landslides or localized slope failures also qualifies as a highly damaged trail.

Severely damaged trail or "hotspot." Either a single criterion or a combination of several impact features qualifies this category. The basic parameters are trail width, multiple treads, and trail incision, and are significantly damaged in extent and magnitude compared with Class III. Other impact features being satisfactory, if the basic parameters show heavy damage, it is considered as severely damaged. A trail under this classification exhibits

Class IV excessive width $(>10 \mathrm{ft})$, multiple treads $(>5)$, and incision $>1.5 \mathrm{ft}$. It may also exhibit signs of downhill sliding. Soil on the trail surface is unconsolidated, and no organic layer is present; exposed bedrock is frequent; trailside is highly eroded; root exposure is excessive; trail is very muddy requiring circumvention; trail outslope is $>10 \%$. Overall, a trail under this classification requires urgent repair, without which land degradation is inevitable in the near future. Damage is likely to spread out both vertically (depth) as well as horizontally.

Note. From "Monitoring Trail Conditions: New Methodological Considerations," by J. L. Marion, Y. Leung, and S. K. Nepal, 2006, The George Wright Forum, p. 36-49. Copyright 2006 by The George Wright Society. Reprinted with permission.

The premise behind these trail condition descriptions was used in numerous other articles as indicators for measurement (Nepal \& Way, 2007). Although the traditional descriptions and methods for trail network assessment have been carried out in practice 
for a long time, they are highly time-consuming and difficult to implement and therefore would not benefit JTNP in the long term.

\subsection{Monitoring Methods Implementing Remote Sensing and GIS}

Technological advances have made the use of Geographic Information Systems (GIS) and Global Positioning Systems (GPS) more readily available for resource managers (Marion, Leung, \& Nepal, 2006). The availability of free or low-cost geospatial data or remotely sensed imagery has also made the utility of GIS more realistic. One method currently used at JTNP is to map the social trails using hand-held GPS units (Miller, 2008). Other studies have also incorporated the use of GPS data to aid in the study and monitoring of social trails (Marion, Leung, \& Nepal, 2006; Morris \& Barnard, 2008). These studies also incorporated the use of aerial or satellite imagery to facilitate the analysis.

\subsubsection{Image Classification and Interpretation}

Several studies used digital orthophoto quadrangles (DOQs) with previously collected GPS data or other vector data layers to create maps or track changes of trail networks on the ground (Jewell \& Hammitt, 2000; Marion, Leung, \& Nepal, 2006; Morris \& Barnard, 2008). For example, Marion et al. (2006) found digitizing social trails directly from DOQs was more efficient than collecting trails via GPS data. Digitizing specific regions within JTNP from imagery could be possible, but digitizing the entire park would be a difficult task. The purpose of this project was to develop a semi-automated process to extract trails without requiring digitization or field work.

Another method of disturbance analysis using imagery focuses specifically on the objects of disturbance, primarily the trail networks, and their changes over time (Cao, Stow, Kaiser, \& Coulter, 2007; Klang, 1998; Morris \& Barnard, 2008). Klang (1998) and Morris et al. (2008) used different snake's algorithms in conjunction with GPS data or node points to delineate trails. Cao et al. (2007) used a feature extraction method that incorporated the ArcView extension Feature Analyst. These methods, however useful, all used some form of proprietary software (e.g., eCognition, or algorithms) that are not available to JTNP staff. Therefore, a similar approach with different implementation methods needs to be developed in this project.

\subsubsection{Spectral Transformation Applications}

Imagery has historically been used to detect changes in the environment through interpretation or spectral classification (Jewell \& Hammitt, 2000; Leung \& Marion, 2000). Additional studies also reviewed the applicability of using remotely sensed data to distinguish vegetation from arid landscapes using spectral signatures (Okin, Okin, Roberts, \& Murray, 1999). To date, several studies have demonstrated the effectiveness of spectral transformation techinques in detecting changes from mutli-spectral imagery (Cao, Stow, Kaiser, \& Coulter, 2007; Kim, Ednie, \& Daigle, 2006). These methods mainly include histogram equalization operations, the spectral transformations principal component analysis (PCA), and normalized difference vegetation index (NDVI). 
For example, Stow et al. (2008) used an object-based methodology to conduct habitat change analysis of shrubland habitat. Witztum and Stow (2004) focused their approach on using high spatial resolution multi-spectral imagery with spatial and spectral transforms to determine percent of bare ground in addition to identifying new trail features in coastal sage scrub. This study found that the spectral transform PCA with edge enhancement filters was able to detect social trails narrower than one meter.

Cao et al. (2007) also found that using a map-to-image differencing approach in conjunction with PCA or NDVI successfully extracted new trails from imagery. Specifically, it was noted that PCA was more effective with highly disturbed areas and more accurately delineated the trail centerlines (Cao, Stow, Kaiser, \& Coulter, 2007). This study used a combination of high resolution imagery collected from the Airborne Data Acquisition and Registration (ADAR) system and color infrared (CIR) aerial photographs for map deliniation and analysis.

\subsection{Summary}

The goal of this project was to create a series of tools and methods that would allow park staff to efficiently monitor and assess the impacts of social trail networks on the surrounding vegetation. Traditional field-based monitoring methods reviewed, such as user surveys, visitor counters, or manual trail assessments, proved to be too timeconsuming and costly for JTNP (Cole, 1983; Leung \& Marion, 2000; Lindsey, Wilson, Rubchinskaya, Yang, \& Han, 2007). The qualitative trail ranking methodology will be useful for adapting appropriate attributes to collected trails in collaboration with the methods currently used by JTNP (Jewell \& Hammitt, 2000; Marion, Leung, \& Nepal, 2006; Nepal, 2003).

Besides the traditional methods for collecting and describing trail networks, advanced technologies such as GPS, GIS, and remote sensing have been applied to natural resource management and monitoring (Jewell \& Hammitt, 2000; Marion, Leung, \& Nepal, 2006; Morris \& Barnard, 2008). In general, the use of GPS data, which is currently used in JTNP, appears to show an obvious limitation; though quite accurate, the time required to walk all trails within the park outweighs the benefit of the data. In this project, the GPS data may be a valuable source for ground truth testing.

Imagery has been widely used to enhance the efficiency of data collection and is now finding more uses in natural resource management. How to process and analyze the imagery data for trail extraction is the challenging task. To date, various attempts have been made to extract trail networks from imagery (Cao, Stow, Kaiser, \& Coulter, 2007; Kim, Ednie, \& Daigle, 2006; Witztum \& Stow, 2004). Among the image analysis techniques reviewed, combining the spectral transform PCA with the NDVI and classifying the results seems to be very promising for this project. It does not require commercial software that is not available to JTNP staff, and the methods used require very little remote sensing experience on the part of the user.

Therefore, this project used a combination of vegetation indices and spectral transformations to develop a tool that would efficiently and accurately identify social trails from high resolution multi-spectral imagery. The actual extraction component of the project was a challenge to avoid following the traditional standard of heads-up digitization, as used by Cao et al. (2007) and Witztum and Stow (2004). To keep with the necessity of efficiency and accuracy for JTNP, a raster-to-vector processing 
component took the place of heads-up digitizing. The vectorization process was completed using the Feature Analyst extension for ArcGIS. Although JTNP does not currently have a license for Feature Analyst, the inclusion of this software was necessary to complete the project. The implementation will be further discussed in Chapter Five. 


\section{Chapter 3 - Systems Analysis and Design}

A comprehensive project plan and system were designed based on the problem statement in Section 3.1, before further data collection and implementation was carried out. Section 3.2 discusses the requirements analysis phase of the project which included functional and non-functional requirements. Section 3.3 explains the system design and architecture, in addition to ArcToolbox specialization. Section 3.4 discusses the original project plan, as well as the changes that occurred throughout the project. Finally, a summary of the chapter will be found at the end.

\subsection{Problem Statement}

Trail management and monitoring practices at JTNP include mapping social trail networks by hiking the trails with Magellan Mobile Mapper 6 GPS units (Miller, 2008). Sites are selected for mapping based on visitor use, with the most popular visitor areas being mapped first. This method, although found to be quite accurate, is very inefficient. The park staff needs an economic yet efficient method of monitoring recreation activities, specifically social trails, and their impacts throughout the park. Therefore, this project attempted to identify all designated and social trails, as well as the various types and levels of trail-based disturbance within the park, using advanced GIS and remote sensing techniques.

\subsection{Requirements Analysis}

Performing a complete requirements analysis is important to project planning to ensure the success of a project. After several meetings with staff at JTNP, a series of functional and non-functional requirements were developed. A functional requirement is something that is required for the success of the project, while a non-functional requirement is something that isn't necessary, but desired, to accompany the project. These requirements were used by the client to determine the success of this project.

A function utilization table (Table 2) was created to assess what functions would be performed throughout the project and how many iterations each function would repeat per site. Based on these criteria, each requirement, regardless of type, was ranked into one of three tiers based on level of use and utility (Tomlinson, 2007). Tier 1 functions were used with maximum repetition throughout the project and were considered the most critical for the success of the project. Tier 2 functions were consistently used throughout the process, and needed to be efficient. Tier 3 functions were rarely used and may not be as efficient as the other Tiers. 
Table 2: Function Utilization Table

\begin{tabular}{ll}
\hline $\begin{array}{c}\text { Number } \\
\text { of } \\
\text { Iterations }\end{array}$ & \multicolumn{1}{c}{ Function } \\
\hline 1 & -Create Area of Interest (AOI) \\
& -Create trails feature class \\
\hline $1 *$ & -Image project/define projection \\
& -Image clip \\
& -Image reflectance conversion \\
& -SAVI using Map Algebra \\
& -PCA \\
& -Create training data feature \\
& class (FA) \\
\hline $1 * *$ & -Perform image training (FA) \\
& -Remove clutter (FA) \\
& - Aggregate data (FA) \\
& -Convert polygon to line (FA) \\
\hline \multirow{4}{*}{$\begin{array}{l}\text {-Image registration to Base } \\
\text { image (for each band) }\end{array}$} \\
\hline Note. * = repeated for number of images/dates; \\
$* *=$ repeated for highest accuracy in results
\end{tabular}

\subsubsection{Functional Requirements}

The system and methods developed in this project were chosen to maintain a userfriendly approach to the remote sensing processes used. The client needed the functionality of an efficient yet powerful system for use by staff members with little to no remote sensing or image interpretation experience. Therefore, the functional requirements included necessary software extensions, data processing capabilities, and deliverable products (Table 3 ). 


\section{Table 3: Functional Requirements}

\begin{tabular}{|c|c|c|}
\hline Number & Description & Tier \\
\hline \multicolumn{3}{|c|}{ Perform the following operations: } \\
\hline 1 & $\begin{array}{l}\text { The system will be able perform edits or updates to } \\
\text { vector data. }\end{array}$ & 3 \\
\hline 2 & The system will display raster and vector data. & 1 \\
\hline 3 & $\begin{array}{l}\text { The system will be able to define the projection of } \\
\text { or re-project data. }\end{array}$ & 2 \\
\hline 4 & $\begin{array}{l}\text { The system will be able to perform image } \\
\text { processing, to include: clip, reclassify, raster-to- } \\
\text { vector, reflectance conversion, registration, } \\
\text { rectification, and format conversion (i.e. GRID to } \\
\text { TIFF). }\end{array}$ & 1 \\
\hline 5 & The system will perform map algebra expressions. & 1 \\
\hline 6 & $\begin{array}{l}\text { The system will contain the Spatial Analyst and } \\
\text { Feature Analyst extensions for ArcMap. }\end{array}$ & 1 \\
\hline 7 & $\begin{array}{l}\text { The system will create new vector and raster data } \\
\text { layers. }\end{array}$ & 1 \\
\hline 8 & $\begin{array}{l}\text { The system will perform Principal Component } \\
\text { Analysis (PCA) and create Soil Adjusted } \\
\text { Vegetation Index (SAVI). }\end{array}$ & 1 \\
\hline 9 & $\begin{array}{l}\text { The system will "pull-out" social trail networks } \\
\text { from processed imagery. }\end{array}$ & 1 \\
\hline \multicolumn{3}{|c|}{ Create the following products: } \\
\hline 11 & The system will include a specialized toolset. & 2 \\
\hline 12 & $\begin{array}{l}\text { The system will produce vegetation indices for } \\
\text { each image date. }\end{array}$ & 2 \\
\hline 13 & $\begin{array}{l}\text { The system will produce new social trails vector } \\
\text { layers. }\end{array}$ & 1 \\
\hline 14 & $\begin{array}{l}\text { The products will have metadata in accordance } \\
\text { with National Park Service standards. }\end{array}$ & 3 \\
\hline
\end{tabular}

\subsubsection{Non-functional Requirements}

The non-functional requirements for this project ranged from including single-click functionalities to all processes running on one software suite (see Table 4). These requirements tended to be more superficial to the success of the project than absolutely necessary. 
Table 4: Non-functional Requirements

\begin{tabular}{clc}
\hline Number & \multicolumn{1}{c}{ Description } & Tier \\
\hline 1 & $\begin{array}{l}\text { The system will perform all operations within the } \\
\text { Environmental Systems Research Institute (ESRI) }\end{array}$ & 3 \\
& $\begin{array}{l}\text { ArcMap software suite. } \\
2\end{array}$ & $\begin{array}{l}\text { The system will include an electronic version of a } \\
\text { user tutorial. }\end{array}$ \\
3 & $\begin{array}{l}\text { The system toolbar/toolbox interface will include } \\
\text { tools that perform multiple operations with single- } \\
\text { click functionality. }\end{array}$ & 3 \\
\hline
\end{tabular}

\subsection{System Design}

The three major components in the project are a file geodatabase, a set of output raster and vector layers, and a customized toolbox. The file geodatabase was developed to contain two new feature classes (social trails and study site AOI), in addition to preexisting feature classes, and a project .MXD (ArcMap application). Second, a series of raster and vector outputs were produced that delineate the steps taken to extract the social trails from the imagery. Third, a project toolbox and toolbar was created that contains all models built in ModelBuilder and processes used in the project. All processing was performed on a Dell Precision M4300, Intel® ${ }^{\circledR}$ Core $^{\text {TM }} 2$ Duo CPU, 2.50GHz, 3.5 GB of RAM, Windows XP computer system. Required software included ArcGIS 9.3 at the ArcInfo-level license with the Spatial Analyst and Feature Analyst extensions. ArcToolbox and ModelBuilder were also important tools used.

The system architecture is outlined in Figure 3-1. The user process-flow included data-loading, image display and interpretation, rectification to base data layers, and image processing through Spatial Analyst. The resulting composite raster files were analyzed in Feature Analyst using its hierarchical learning algorithms. The completion of this analysis resulted in a new feature class. 


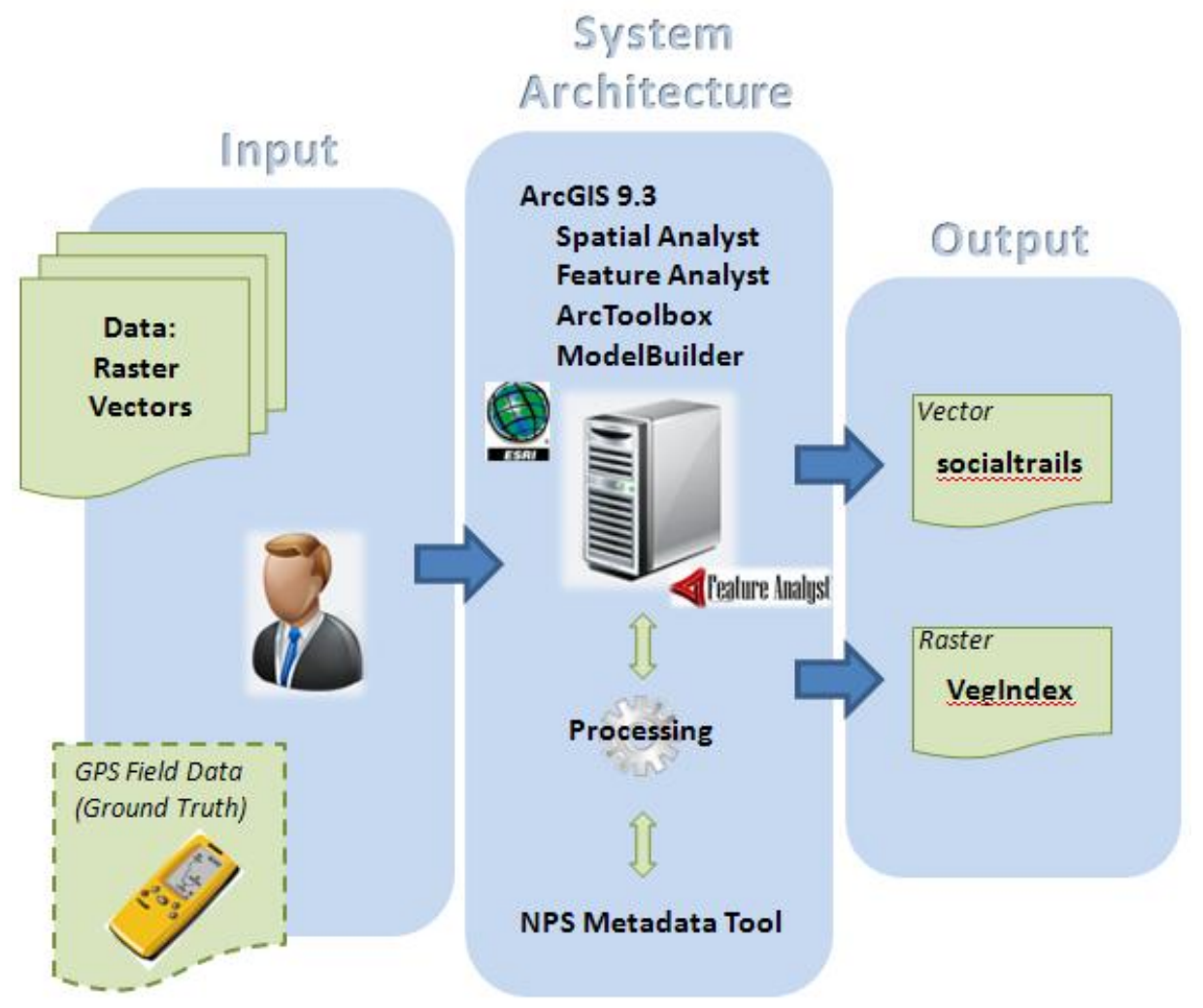

Figure 3-1: System Architecture

\subsubsection{ArcToolbox specialization}

In accordance with the system architecture displayed in Figure 3-1, a project toolbox (MIP.tbx) was created (see Figure 3-2).

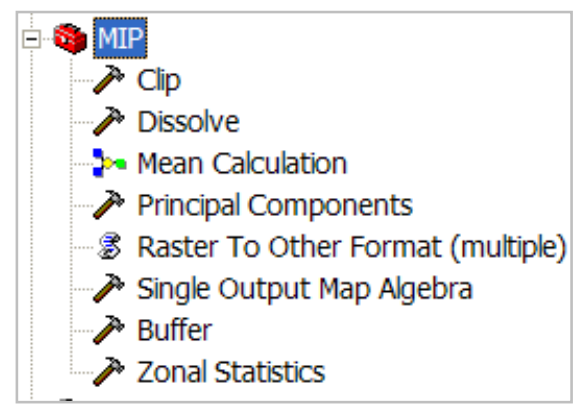

Figure 3-2: MIP.tbx

The toolbox contains the following tools:

1. Clip Tool: Used for clipping imagery to a specified boundary

2. Dissolve: This tool merges adjacent or connecting features

3. Principal Component: This tool transforms images into their principal components (PCA)

4. Raster To Other Format: Converts images from one format to another 
5. Single Output Map Algebra: This tool is used to perform map algebra processes

6. Buffer: This tool creates a buffer feature around designated features based on input values

7. Zonal Statistics: Used to calculate the mean statistics value of imagery within a specified zone

Also within the toolbox was the Mean Calculation Model (see Figure 3-3). This model calculates the mean value of the input image within the site boundary.

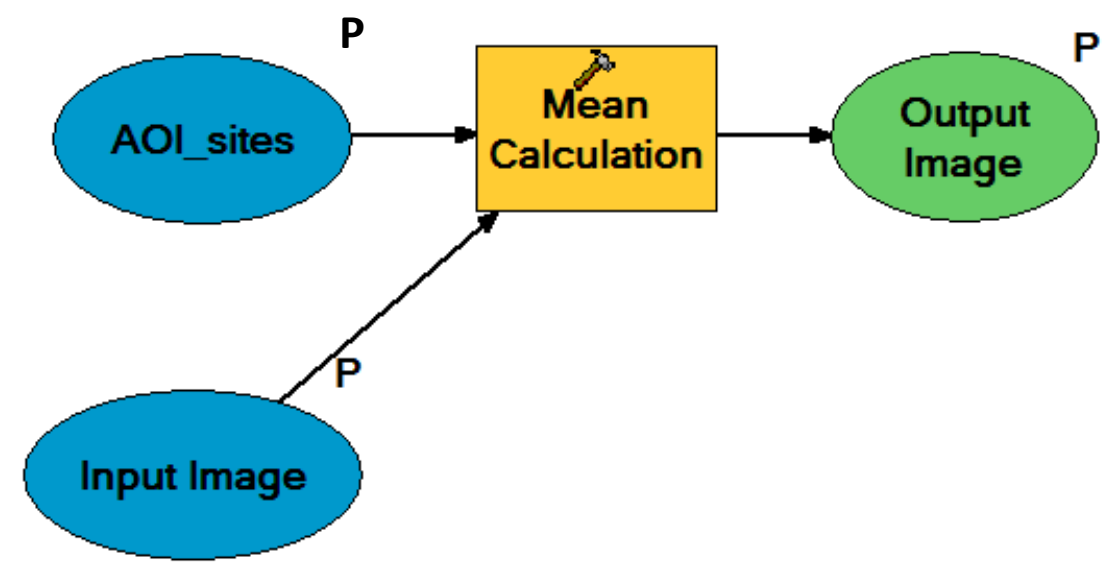

Figure 3-3: Mean Calculation Model

Within the Mean Calculation Model, Input Image, AOI_sites, and Output Image were parameters set in ModelBuilder. More details are provided in Chapter 5 about the MIP.tbx and Feature Analyst (FA) tools. It is also important to note that each of the input file locations can be changed by opening the model and using the browse button to the right of each input, rather than the drop-down menu. All other necessary settings were pre-set into the model and can be viewed by opening the Mean Calculation tool in edit mode.

\subsection{Project Plan}

The approach to this project was to inventory and assess the trail network, and define the levels of disturbance and their impacts over time to the associated vegetation. A workflow diagram (Figure 3-4) was created to graphically represent the flow of this project. This project was originally broken down into the following five steps:

1. Problem Analysis

2. Requirements Analysis

3. Development and Design

4. Integration and Testing

5. Delivery 


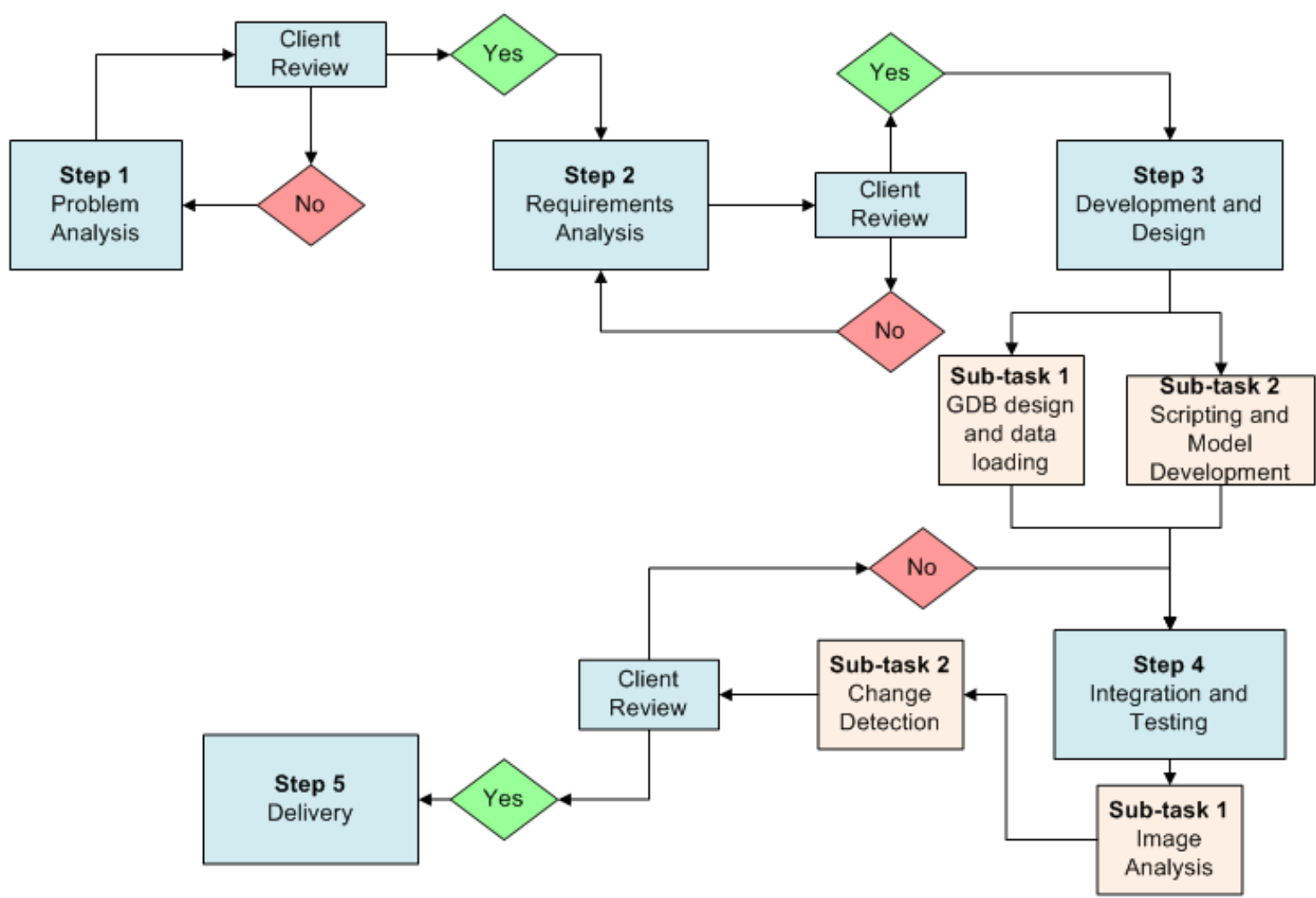

Figure 3-4: Workflow Diagram (Original)

Within each phase, there was an initial series of steps required to complete the designated tasks. However, the evolution of the project resulted in changing the order of steps and re-evaluating the products to be delivered. The following paragraphs will highlight how the methods planned in each phase changed. The revised project plan is summarized in Table 5. 
Table 5: Revised Project Plan

\begin{tabular}{|ll|}
\hline 1. Problem Analysis & $\begin{array}{l}\text { Literature review, problem scope assessment, AOI selection, and } \\
\text { client consultation }\end{array}$ \\
\hline $\begin{array}{l}\text { 2. Requirements } \\
\text { Analysis }\end{array}$ & $\begin{array}{l}\text { Data collection, inventory and assessment, metadata, system scope } \\
\text { assessment (software and hardware needs, Master Input Data List } \\
\text { (MIDL), functional and non-functional requirements }\end{array}$ \\
\hline 3. Preliminary Design & $\begin{array}{l}\text { Geodatabase design, implementation, data loading, vegetation index } \\
\text { requirements, and trail assessment methodology }\end{array}$ \\
\hline $\begin{array}{l}\text { 4. Detailed Development } \\
\text { and Design }\end{array}$ & $\begin{array}{l}\text { Script and model development, raster processing, image analysis and } \\
\text { interpretation, vegetation index creation }\end{array}$ \\
\hline $\begin{array}{l}\text { 5. Integration and } \\
\text { Testing }\end{array}$ & $\begin{array}{l}\text { Visual quality check of vegetation index and linear detection data, } \\
\text { possible ground truthing, performing data analysis, assessing model } \\
\text { validity and success rates }\end{array}$ \\
\hline 6. Delivery & \\
\hline
\end{tabular}

Note: Items in italics indicate changes to the original plan.

Step 1 included the literature review, problem scope assessment, AOI selection, and client consultation. The original problem scope assessment was almost completely rewritten to include a system scope assessment. The database requirements (including datasets), software and hardware needs, and functional requirements were included with the system scope assessment in the requirements analysis phase.

Step 2 originally included data collection and inventory, data assessment, metadata, vegetation index requirements, and a trail assessment methodology. The vegetation index and trail assessment methodologies, however, were tasks that were moved to the newly created preliminary design phase.

Step 3 included the geodatabase design and implementation, data loading, and script and model development. Several changes were made to this phase, some of which include the addition of the vegetation index and trail assessment methodology from step 2. The geodatabase design, implementation, and data loading were now positioned to occur in the preliminary design phase and the script and model development tasks were moved to the detailed development and design phase. The knowledge gained throughout the project, specifically for the database planning, led to an almost complete restructuring of how this portion of the project was completed.

Step 4 included raster processing, image analysis and interpretation, vegetation index creation, geostatistical accuracy assessment, possible ground truthing, visual quality control (QC) of vegetation index and linear detection data, performing data analysis, and assessing model validity and success rates. This was broken down into two separate phases that distinguished the raster processes from testing the models at completion (Phases 4 and 5 in Table 5). This section continued to evolve as the project progressed with the image processing due to the complexity of the raster analysis within ArcMap.

Step 5 consisted of packaging all the processed data and tools, metadata, geodatabase schema, analytic methods manual, MIP poster, and any miscellaneous written materials associated with the project. The tasks planned in this delivery phase 
remained the same, but were carried out throughout the entire course of the project instead of at the end of the project.

\subsection{Summary}

The staff at JTNP needs to maximize resources while at the same time minimizing fieldwork requirements. The functional and non-functional requirements displayed in Tables 3 and 4 represent their needs. The importance of these requirements is in their functional simplicity for the user, and a system architecture that is straightforward and easily understood. The flow of the process could be described as: images go in, data processing is conducted and analyzed, and the vectors come out. The original and revised project plans were discussed with explanations for many of the changes. 


\section{Chapter 4 - Database Design}

One of the deliverables for this project was a park-wide file geodatabase. Development of this geodatabase was fairly straightforward, because all the data came from JTNP in shapefile format. Section 4.1 briefly discusses the conceptual data model and what factors went into its development. Section 4.2 reviews in detail the feature classes and their relationships within the file geodatabase. Data requirements and sources are discussed in section 4.3, in addition to the metadata requirements. Sections 4.4 and 4.5 discuss data collection, scrubbing and loading methods. Finally, section 4.6 summarizes the details of this chapter.

\subsection{Conceptual Data Model}

The deliverables for this project were a master geodatabase, vegetation index, and a feature class containing all the social trails within a given region. A vector layer requirements table was created with source name, project name designation, and description, to provide more explanation of the layers used (see Appendix A). These data were selected not only for functional reasons, but also for analytic purposes. Vector data comprised all the feature data within the park, while raster data was processed for feature extraction. A conceptual model was created to assist with selecting and organizing the types of data necessary for this project.

For this project only specific features relevant to the study were included in the master geodatabase, but any park data could be loaded to the geodatabase in the future. The conceptual model for this project included a geodatabase with transportation, recreation, and hydrology feature datasets, in addition to feature classes for supporting data (see Figure 4-1). The feature datasets were created to group functionally related feature classes together, such as all transportation related features in the transportation feature dataset.

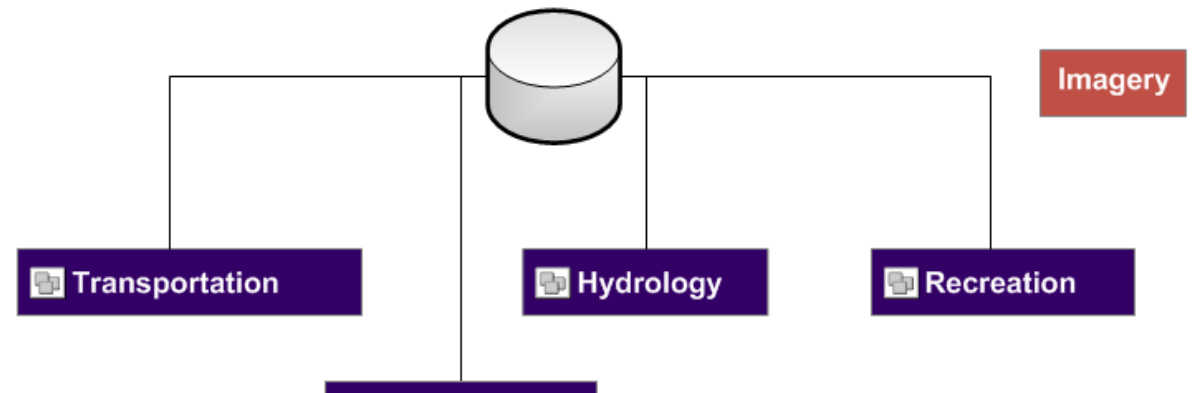

Supporting Data

Figure 4-1: Conceptual Model

Imagery, although not included in the database, was an important part to this project and the overall conceptual model. The raster data was left as a separate entity because of the nature of this project. Specifically, the imagery would undergo multiple processes that create new outputs, so keeping all the new raster outputs separate from the main database was important to minimize processing times. 


\subsection{Logical Data Model}

After evaluating the data provided by JTNP, it was apparent that a geodatabasespecifically an ArcGIS File Geodatabase - would need to be developed. The file geodatabase format was selected for its unlimited storage size and superior performance. The file geodatabase was comprised of three feature datasets and a total of fourteen feature classes (see Figure 4-2), including topologies. The vector data provided by JTNP was originally digitized from digital line graphic (DLG) and digital raster graphic (DRG) files, and later updated using DOQs. A majority of the feature classes were loaded directly from their original shapefile format into the geodatabase with no alterations to their table structure. The following subsections will discuss the criteria used to select and in some cases edit each feature class as well as the source in the geodatabase, including imagery. A detailed schema of the file geodatabase can be found in Appendix B.

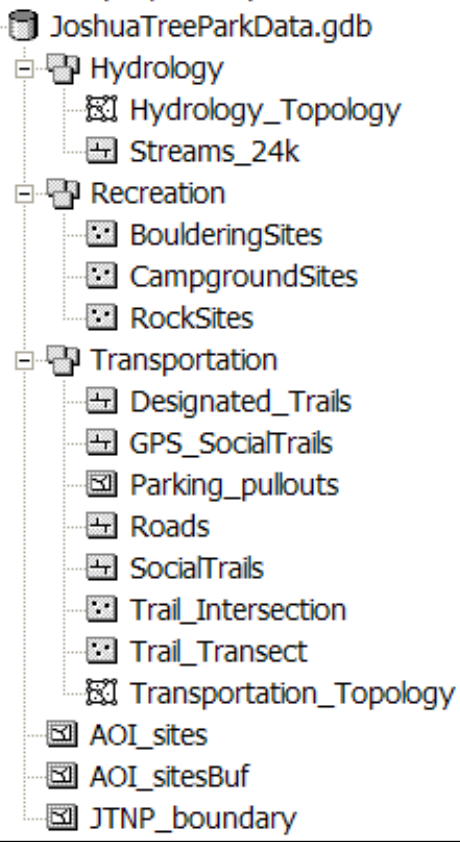

Figure 4-2: Master File Geodatabase

\subsubsection{Transportation Dataset}

The transportation dataset contains seven feature classes, in addition to the new SocialTrails feature class, as noted in Figure 4-3. This dataset was comprised of anything associated with the function of moving or traversing from one point to another. Within this dataset four feature classes (GPS_SocialTrails, Parking_pullouts, Trail_Intersection, and Trail_Transect) were loaded without any changes. Trail_Intersection and Trail_Transect were loaded into the geodatabase because they originated from the JOTR_SocialTrails08 geodatabase developed by staff at JTNP in a previous study. These two feature classes were included solely for the purpose of consistency between the file 
geodatabase created for this project and the geodatabase currently under use at the Park for GPS social trail collection.

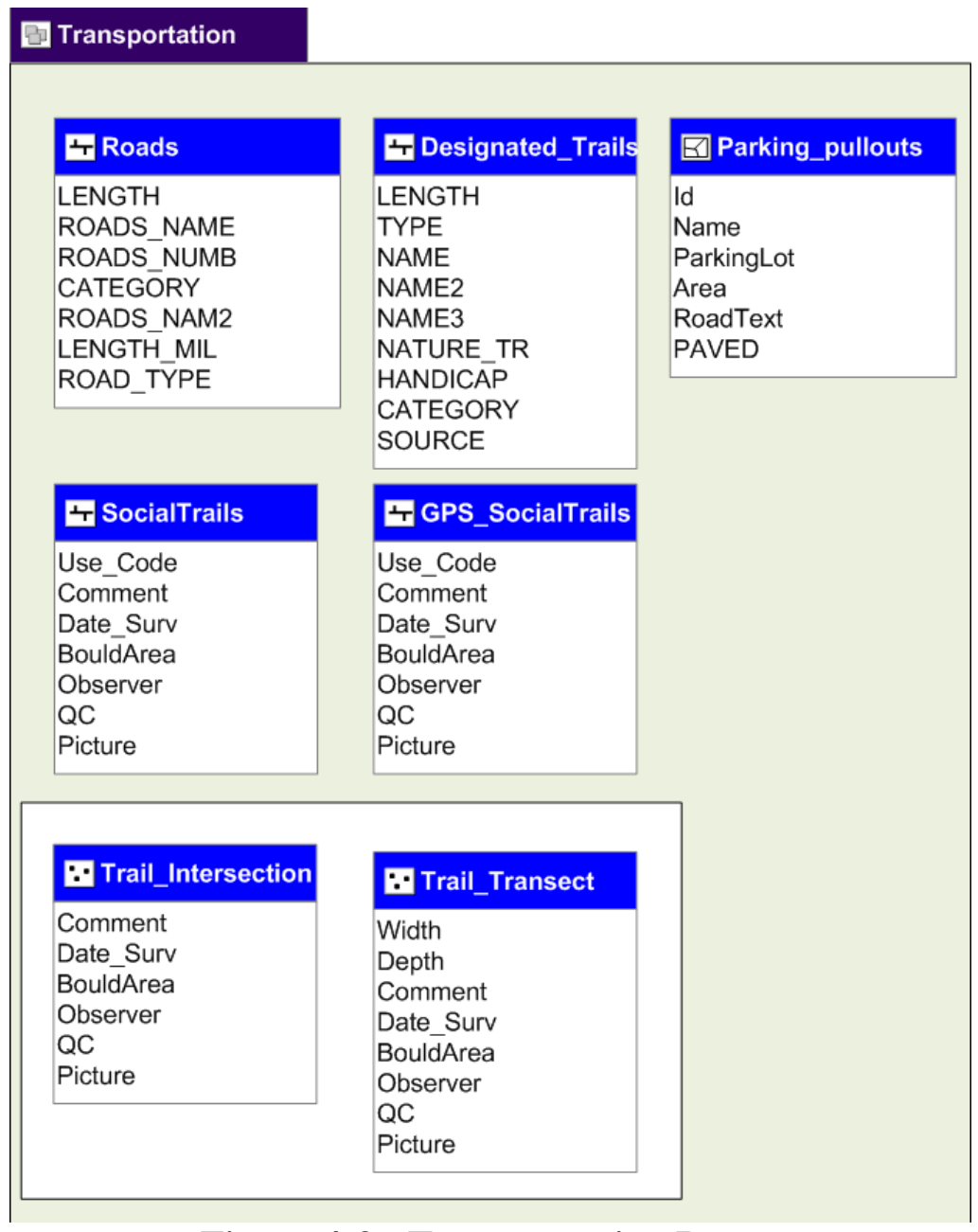

Figure 4-3: Transportation Dataset

Other feature classes from JTNP, including Designated_Trails and Roads, were modified to accommodate the required analysis in the later stage of the project. For example, a coded-value domain was added to Designated_Trails and Roads to aid future data entry tasks by creating a drop-down list. The domain for the Designated_Trails feature class designated trail type into five categories: foot, corridor, horse, bike, and bike-horse (see Figure 4-4). These categories were created from data already in the table. The Roads feature class domain was road types and was also created from current data in the table. 


\begin{tabular}{|c|c|c|c|}
\hline $\begin{array}{l}\text { Description } \\
\text { Domain Type } \\
\text { Field Type } \\
\text { Merge Policy } \\
\text { Split Policy }\end{array}$ & $\begin{array}{l}\text { Trail type } \\
\text { Coded Value } \\
\text { String } \\
\text { Default Value } \\
\text { Default Value }\end{array}$ & $\begin{array}{l}\text { Description } \\
\text { Domain Type } \\
\text { Field Type } \\
\text { Merge Policy } \\
\text { Split Policy }\end{array}$ & $\begin{array}{l}\text { Road types } \\
\text { Coded Value } \\
\text { String } \\
\text { Default Value } \\
\text { Default Value }\end{array}$ \\
\hline $\begin{array}{l}\text { Domain Members } \\
\text { Name }\end{array}$ & Value & $\begin{array}{l}\text { Domain Members } \\
\text { Name }\end{array}$ & Value \\
\hline Foot & Foot & PAVED & PAVED \\
\hline Corridor & Corridor & DIRT & DIRT \\
\hline Horse & Horse & DIRT_ $4 \times 4$ & DIRT_ $4 \times 4$ \\
\hline Bike & Bike & & \\
\hline Bike-Horse & Bike-Horse & & \\
\hline
\end{tabular}

Figure 4-4: Transportation Domain Types

In addition to being a deliverable, the SocialTrails feature class was also created for this project. The SocialTrails table contains the same fields as the GPS_SocialTrails feature class to maintain consistency with previous work by JTNP. Output trail features from the Feature Analyst process do not have any coding associated with use or interpretation of the images. However, these fields can be calculated as a user performs a visual quality control (QC) of the product. Further explanation of the SocialTrails feature class can be found in Chapter 6.

\subsubsection{Recreation Dataset}

There are three feature classes in the recreation dataset (see Figure 4-5). These feature classes were included in the geodatabase because of the relevance to this project.

According to JTNP, the majority of social trail disturbances are focused around camping areas, and bouldering or rock climbing sites (Miller, 2008).

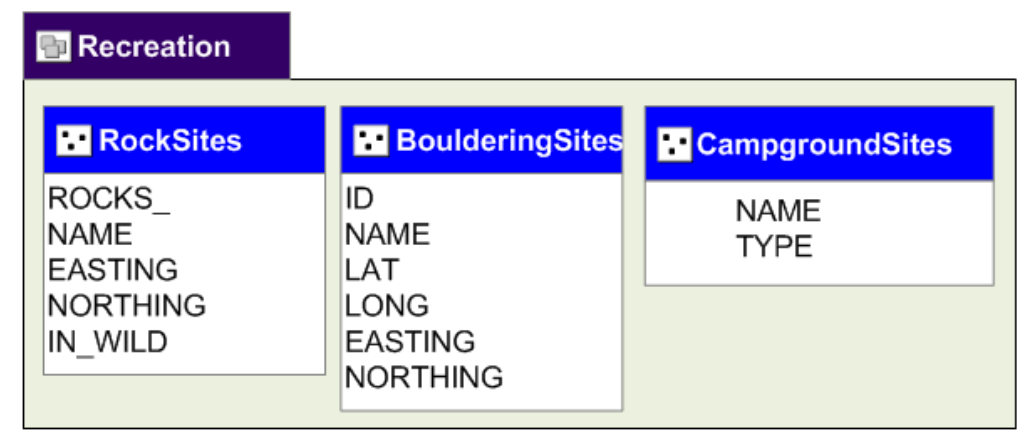

Figure 4-5: Recreation Dataset

\subsubsection{Hydrology Dataset}

The hydrology dataset contains one feature class called Streams_24k (see Figure 4-6). 


\section{囸Hydrology \\ 두 Streams_24. \\ LENGTH \\ MINOR2 \\ NAME \\ Figure 4-6: Hydrology Dataset}

The original data for this feature class was in the form of 28 individual shapefiles. According to the associated metadata, each shapefile is referenced to a 7.5 minute quadrangle map index that covers JTNP (Joshua Tree National Park, 2003). Several edits to the table needed to occur before the shapefiles could be loaded into the feature class. Each shapefile was named after its 7.5 minute quad map, in addition to each shapefile having two fields matching the name of the shapefile (see Figure 4-7).

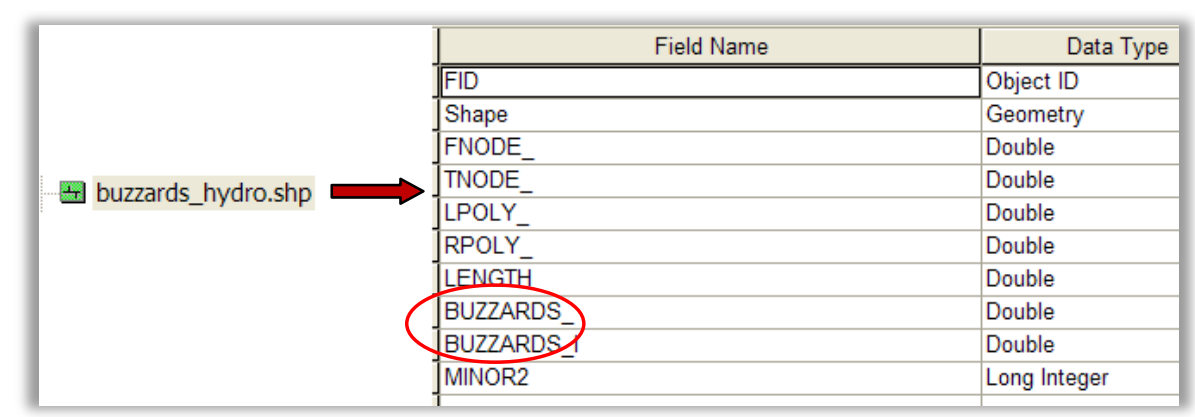

Figure 4-7: Original Hydrologic Table

A Name field was added and populated with the name of the shapefile. The fields FNODE_, TNODE_, LPOLY _, RPOLY_, and associated 'BUZZARDS_ and BUZZAR $\bar{R} D S$ I' were deleted from every shapefile. The associated 'BUZZZARDS_and BUZZARDS_I' fields were different for each shapefile, since they described the $7 . \overline{5}$ minute quad they were referencing. Finally, after deleting the extra fields the shapefiles could then be loaded into one feature class. The newly created Name field distinguishes each quad segment from the others (see Figure 4-8).

\begin{tabular}{|l|l|}
\hline \multicolumn{1}{|c|}{ Field Name } & \multicolumn{1}{|c|}{ Data Type } \\
\hline OBJECTID & Object ID \\
\hline Shape & Geometry \\
\hline LENGTH & Double \\
\hline MINOR2 & Long Integer \\
\hline NAME & Text \\
\hline Shape_Length & Double \\
\hline
\end{tabular}

Figure 4-8: Final Streams Table 


\subsubsection{Remaining Feature Classes}

The remaining feature classes that were not associated with a feature dataset were JTNP_boundary, AOI_sites, and AOI_sitesbuf (see Figure 4-9). The JTNP_boundary feature class was provided by JTNP, while the two AOI feature classes were created for this project. The AOI feature classes included a field referencing which camp area, if any, it was related to. The AOI_sitesbuf feature class was created solely for the purpose of the image rectification process, and otherwise is not used.

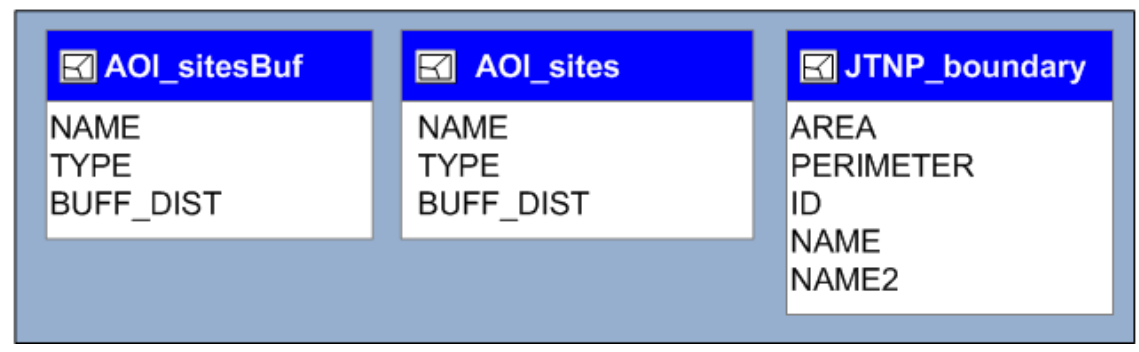

Figure 4-9: Stand Alone Feature Classes

\subsubsection{Imagery}

The project used DigitalGlobe's 4-band pan-sharpened QuickBird imagery with a spatial resolution of 0.6 meters. Initially, it was decided to use 1.0 meter spatial resolution multispectral NAIP imagery. However, after preliminary research it was determined that the optimum choice would be sub-meter resolution imagery for this prototype project. QuickBird imagery has the following band wavelengths: Blue $=450$ to $520 \mathrm{~nm}$; Green $=$ 520 to $600 \mathrm{~nm}$; Red $=630$ to $690 \mathrm{~nm}$; and Near IR (NIR) $=760$ to $900 \mathrm{~nm}$ (DigitalGlobe, 2009).

The necessity for multispectral imagery is two-fold. First, to create a vegetation index, specifically SAVI, the process requires the Red and NIR image bands. The Red and NIR image bands were particularly important because of their ability to distinguish vegetation from other features, based on reflectance values (Aronoff, 2005b). And second, for image interpretation, the multiple band combination possibilities make the multispectral imagery very useful. This project used two image dates for each siteDecember 12, 2005 and either May 10, 2008 or July 3, 2008 - for comparison purposes, in addition to noting any change detection possibilities. See the MIDL in Appendix C for more details about the imagery used.

The images were not loaded into the file geodatabase due to the nature of the current and future processing involved. For this project, each image was clipped twice, geo-rectified, converted to relative reflectance, converted to TIFF format, and processed for PCA and SAVI. Given the number of processes and resulting new images, it was deemed more appropriate and efficient to keep the images in a separate folder, rather than the geodatabase. 


\subsection{Data Sources}

All vector data came from JTNP, while the imagery was purchased from eMap International (www.emap int.com), a licensed DigitalGlobe reseller. Following practices recommended by Tomlinson (2007), a master input data list (MIDL) (see Appendix C) was created for this project containing identification information, storage size, basic characteristics, cost, and data availability. The features loaded into the geodatabase had metadata from text files imported via the NPS Metadata Editor, except for the features from JOTR_SocialTrails08.mdb, which did not have any metadata. The new SocialTrails and AOIsite feature classes were attributed using the NPS Metadata Editor in accordance with metadata requirements as determined by the NPS (National Park Service, n.d.).

\subsubsection{Data Requirements}

Each dataset was analyzed against a set of criteria to ascertain the overall fidelity of the database. The criteria looked at the completeness of each dataset in relation to the park boundary, attribution accuracy, spatial accuracy, spatial precision, and overall integrity (see Table 6) (Bolstad, 2008a). Since one of the deliverables was a master file geodatabase containing vector coverage of the park each dataset was checked for completeness.

\section{Table 6: Data Requirements Criteria}

\begin{tabular}{l|lllll}
\hline Feature class & $\begin{array}{l}\text { Completeness } \\
\text { (entire park) }\end{array}$ & $\begin{array}{l}\text { Attribute } \\
\text { Accuracy }\end{array}$ & $\begin{array}{l}\text { Spatial } \\
\text { Accuracy }\end{array}$ & $\begin{array}{l}\text { Spatial } \\
\text { Precision }\end{array}$ & $\begin{array}{l}\text { Data } \\
\text { Integrity }\end{array}$ \\
\hline Roads & $\mathrm{XXXX}$ & $\mathrm{XXXX}$ & $\mathrm{XXX}$ & $\mathrm{XXXX}$ & $\mathrm{XXXX}$ \\
Designated_Trails & $\mathrm{XXXX}$ & $\mathrm{XXX}$ & $\mathrm{XXX}$ & $\mathrm{XXX}$ & $\mathrm{XXX}$ \\
GPS_SocialTrails & $\mathrm{X}$ & $\mathrm{XXXX}$ & $\mathrm{XX}$ & $\mathrm{XXX}$ & $\mathrm{XX}$ \\
Parking_Pullouts & $\mathrm{XXXX}$ & $\mathrm{XXXX}$ & $\mathrm{XXXX}$ & $\mathrm{XXXX}$ & $\mathrm{XXXX}$ \\
Trail_Intersection & $\mathrm{UNK}$ & $\mathrm{UNK}$ & $\mathrm{UNK}$ & $\mathrm{UNK}$ & $\mathrm{UNK}$ \\
& & $\mathrm{NO}$ & $\mathrm{NO}$ & $\mathrm{NO}$ & $\mathrm{NO}$ \\
Trail_Transect & $\mathrm{NO} \mathrm{DATA}$ & $\mathrm{DATA}$ & $\mathrm{DATA}$ & $\mathrm{DATA}$ & DATA \\
BoulderingSites & $\mathrm{XXXX}$ & $\mathrm{XXXX}$ & $\mathrm{XXXX}$ & $\mathrm{XXXX}$ & $\mathrm{XXXX}$ \\
CampgroundSites & $\mathrm{XXXX}$ & $\mathrm{XXXX}$ & $\mathrm{XXXX}$ & $\mathrm{XXXX}$ & $\mathrm{XXXX}$ \\
RockSites & $\mathrm{XXXX}$ & $\mathrm{XXXX}$ & $\mathrm{XXXX}$ & $\mathrm{XXXX}$ & $\mathrm{XXXX}$ \\
JTNP_boundary & $\mathrm{XXXX}$ & $\mathrm{XXXX}$ & $\mathrm{XXXX}$ & $\mathrm{XXXX}$ & $\mathrm{XXXX}$ \\
\hline
\end{tabular}

Note: $\mathrm{XXXX}=$ Fulfills requirement; $\mathrm{XXX}=$ Satisfies requirement, but needs more work; $\mathrm{XX}=$ Incomplete, do not use for decision making analysis; $X=$ Does not meet requirement standards, do not use data

The attribution accuracy requirement was looking for consistency of attribution throughout each feature class, as well as accuracy to the true attribute. The metadata associated with the feature classes also addressed attribution and spatial accuracies, as noted in Figure 4-10. An example attribute table was provided in Figure 4-11 to highlight the consistency of the data. 


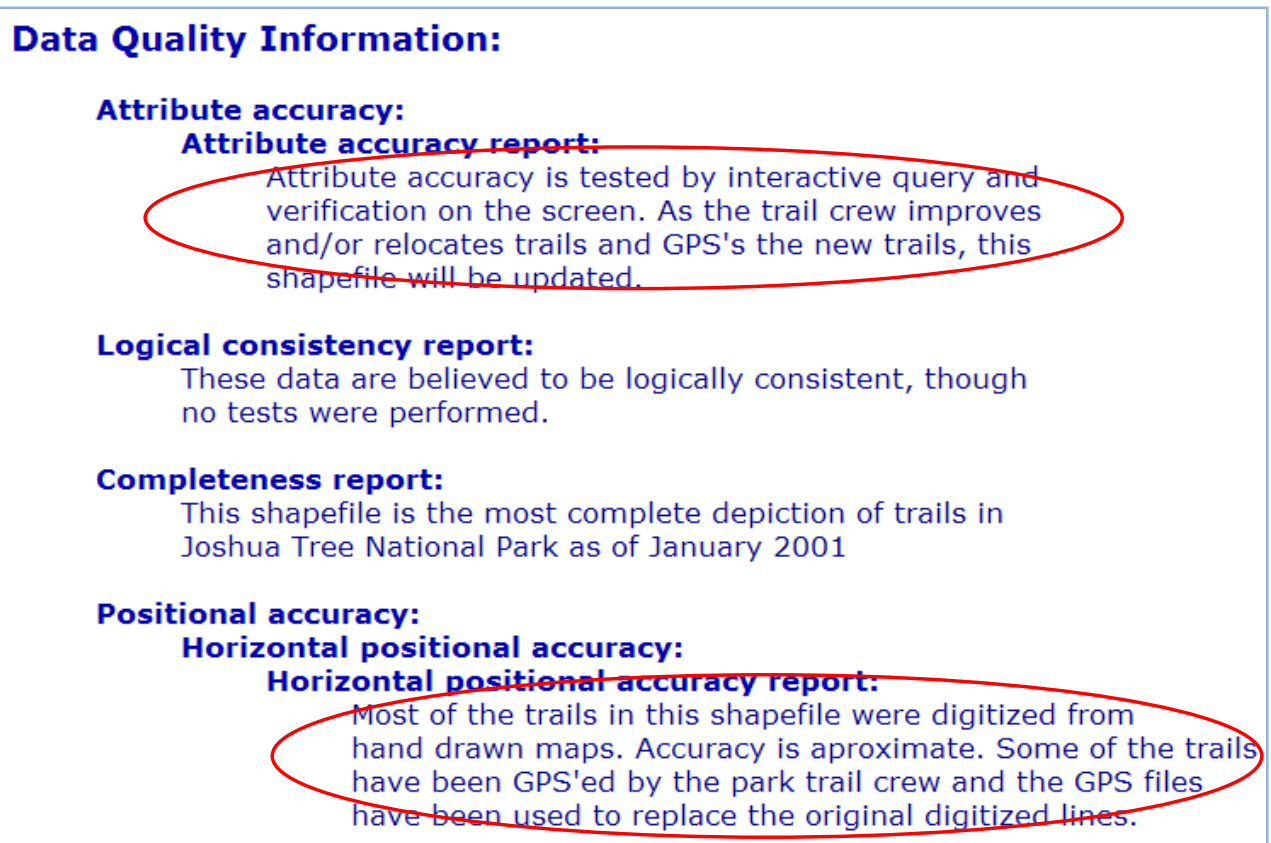

Figure 4-10: Attribute and Spatial Accuracy

\begin{tabular}{|c|c|c|c|c|c|c|c|}
\hline LENGTH & ROADS_NAME & ROADS_NUM & ROADS_TYPE & CATEGORY & ROADS_NAM & LENGTH_MIL & She \\
\hline 11779.6047 & Twentynine Palms Highway & SR 62 & PAVED & outside & & 7.319 & $\overline{5839}$ \\
\hline 2700.88252 & Indian Cove Road & RT212A & PAVED & open & RT5 & 1.687 & 4309. \\
\hline 878.12621 & Indian Cove Group Camp Ro & RT212B & PAVED & open & & 0.548 & 878.1 \\
\hline 409.03239 & Indian Cove Road & RT212A & PAVED & open & RT5 & 0.255 & 409.0 \\
\hline 455.76383 & Indian Cove Campground Ro & RT212C & PAVED & open & & 0.285 & 455.7 \\
\hline 281.74233 & Indian Cove Campground Ro & RT212C & PAVED & open & & 0.176 & 393.5 \\
\hline 5940.33487 & Joshua Lane & & PAVED & outside & & 3.691 & 558 \\
\hline 1013.5524 & Joshua Lane & & PAVED & outside & & 0.63 & 1013. \\
\hline 111.72933 & Santa Barbara Drive & & PAVED & outside & & 0.069 & 111.7 \\
\hline 404.91962 & Joshua Lane & & PAVED & outside & & 0.252 & 404. \\
\hline 759.79381 & San Marino Drive & & PAVED & outside & & 0.472 & 1248. \\
\hline 394.30476 & Black Rock Canyon Road & & PAVED & open & & 0.245 & 506.3 \\
\hline 91.9903 & Black Rock Campground Ro & RT214 & PAVED & open & & 0.057 & 154. \\
\hline 174.33777 & Black Rock Campground Ro & RT214 & PAVED & open & & 0.108 & 225.0 \\
\hline 9660.30522 & Twentynine Palms Highway & SR 62 & PAVED & outside & & 6.003 & 9660. \\
\hline 4511.52029 & Old Dale Road & & DIRT4X4 & outside & & 2.803 & 5954. \\
\hline 770.99881 & Lower Covington Flat Road & RT210 & DIRT4X4 & open & Old RT 5, Old & 0.479 & 770.9 \\
\hline 1188.72774 & Queen Valley Road & RT100 & DIRT & open & & 0.739 & 117 \\
\hline $10 n \ln 7 n 1$ & 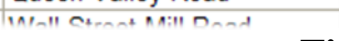 & OTnACA & דחוח & mon & & $n \cap 01$ & 1010 \\
\hline
\end{tabular}

Figure 4-11: Attribute Table

Spatial accuracy and precision are often mistaken for the true value of that information. As shown in Figure 4-12, spatial precision represents how closely a point strikes the same coordinates regardless of target, while spatial accuracy represents how closely a point strikes the desired target (Bolstad, 2008a). 


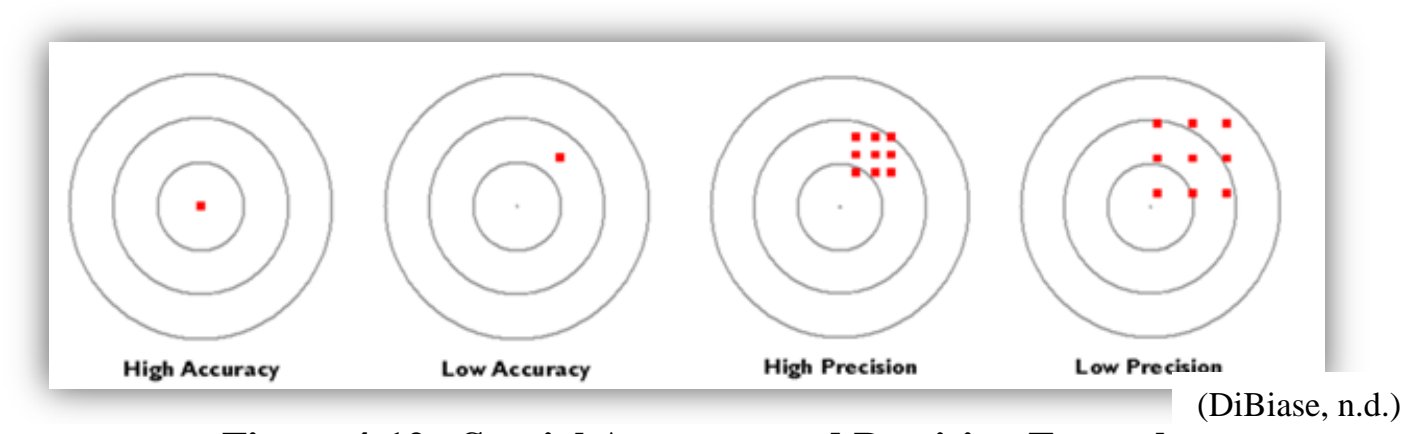

Figure 4-12: Spatial Accuracy and Precision Examples

The Designated_Trails feature class provides an excellent example of a high precision, high accuracy dataset. Although there is a noticeable shift between the vector data and the actual ground features in the left image of Figure 4-13, after rectification of the image the vector data is aligned almost perfectly, as seen in the rightmost image.
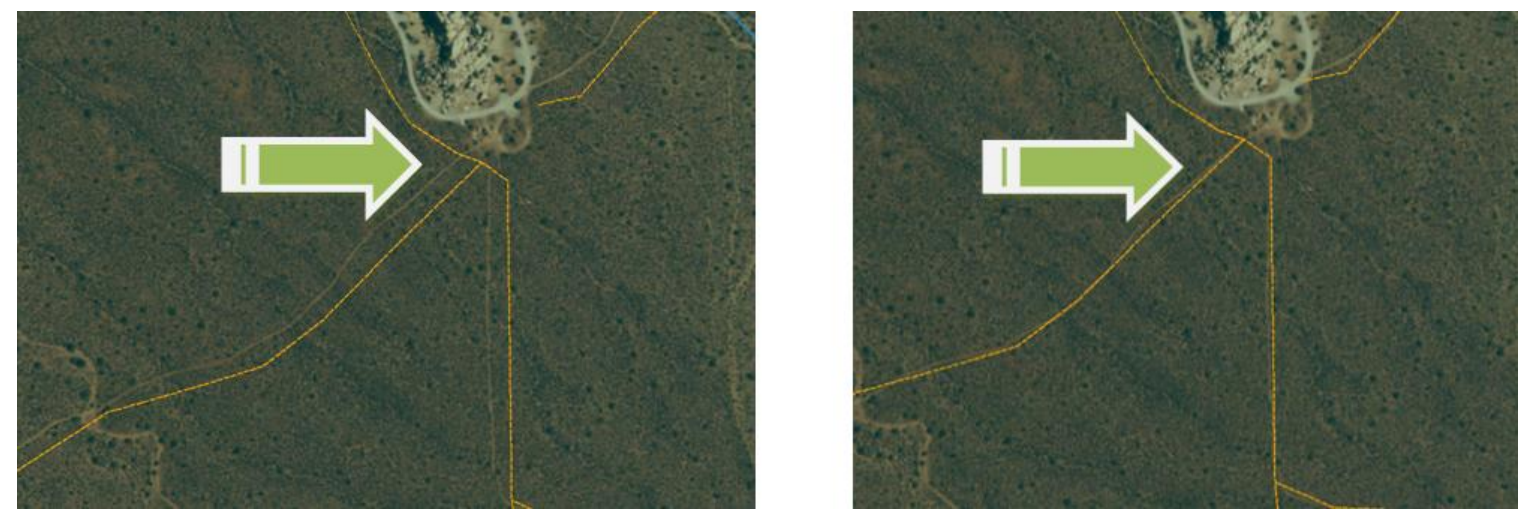

Figure 4-13: Trails precision example

\subsection{Data Collection Methods}

As mentioned earlier, all vector data was provided by JTNP. NAIP imagery was also provided, however, it was decided to use QuickBird imagery instead. Initially, an online search for free imagery through the many United States Geological Survey (USGS) websites was conducted, in addition to other federal and state websites that had GIS data for download. The location of JTNP is not an area of high interest for aerial or satellite imagery; consequently the results were too sporadic to be useful. Another constraint to the data collection problem, for imagery specifically, is that websites that offer free imagery for download are often so overloaded with requests that a single image download can take hours.

Once it was decided to purchase high resolution imagery, the two main image provider's websites (DigitalGlobe and GeoEye) were reviewed. Each website had several different methods for locating archived imagery; however, the sites were very cumbersome and rarely showed definitive images that matched the area of interest within JTNP. Consequently, an imagery reseller was contacted to determine what image dates were available, and how much they would cost. The lesson learned from this experience was to perform a web search under a predetermined timeline, and then contact an image 
reseller if the desired imagery was not able to be located within that given amount of time.

\subsection{Data Scrubbing and Loading}

Data provided by JTNP required very little editing prior to loading into the geodatabase (see Figure 4-2). All edits or changes to the tables or domains were discussed in section 4.2. Each shapefile was verified or reprojected into the North American Datum 1983 Universal Transverse Mercator Zone 11 North (NAD 83 UTM Zone 11N) and the metadata text files were loaded with the feature classes into the geodatabase.

Topologies were created and run on the hydrology, roads, and designated_trails feature classes. The topology rules were the same for each feature class to maintain consistency across the database (see Figure 4-14). The roads feature class had a significant number of topology errors involving dangles, overshoots, and pseudo nodes. The hydrology feature class had a large number of topology errors as well, but they were expected since the feature class was a result of merging multiple shapefiles.

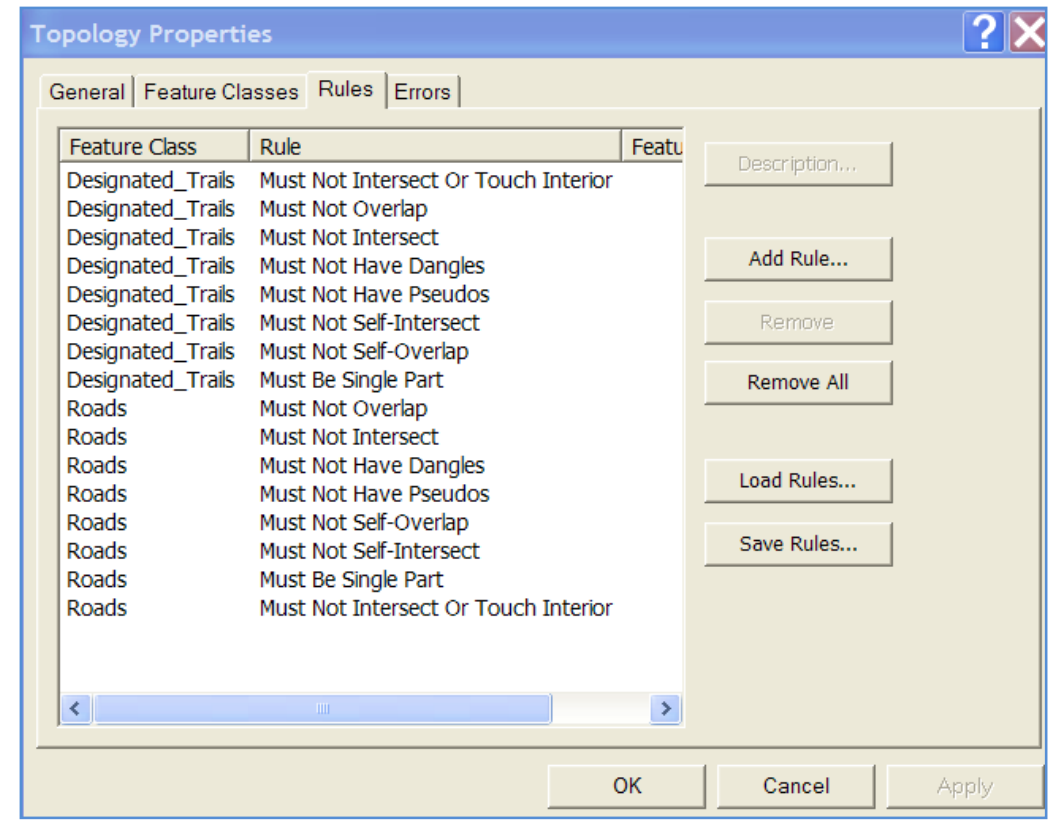

Figure 4-14: Topology Rules

The GPS_SocialTrails feature class, as noted in Table 7, had poor spatial integrity and mediocre accuracy, but was loaded into the geodatabase to be used as an immediate validator for the Feature Analyst output features. It was determined with the client that this feature class would be used as a quick validation and quality control of features being extracted.

\subsection{Summary}

The database design for this project was a very basic file geodatabase with a total of three feature datasets and fourteen feature classes. The conceptual model for this database 
grouped the feature classes functionally. Each feature class was loaded directly from shapefile format with little change being introduced to the tables. Section 4.2 introduced the logical model for this project. This section also included details highlighting each feature class and any edits that occurred prior to data loading.

Section 4.3, data sources introduced the MIDL in Appendix B. Data requirements, including spatial and attribute accuracy, precision, and integrity, were discussed in relation to data selection criteria. Data collection methods were reviewed with specific attention given to imagery acquisition. Data scrubbing and loading procedures were briefly discussed, including an explanation for the inclusion of the GPS_SocialTrails feature class despite its poor spatial quality. 


\section{Chapter 5 - Implementation}

The goal for this project was to create a tool that would facilitate park staff monitoring current and future impacts of recreational trail-use on both designated and social trail networks, as well as surrounding vegetation. There were three primary objectives to this goal. First, a park-wide file geodatabase would be created and loaded with vector data related to the social trails problem. Second, a set of tools and methods would be developed to enhance the extraction of trails from remotely sensed imagery using ESRI software. The final objective was to create a vegetation index for future monitoring of the impacts on vegetation.

This chapter discusses in detail the methods and tools developed or used to satisfy each of the objectives. Section 5.1 introduces the process workflow followed to meet each of the project objectives, as well as general recommendations. Section 5.2 details the steps taken to create and load the file geodatabase that includes a park-wide dataset of trail related features. Section 5.3 discusses the steps and tools required to create a new SocialTrails feature class from QuickBird imagery. Included in this section are a list of geoprocessing tools used, useful file management techniques, and detailed instructions to extract social trails from satellite imagery. Section 5.4 discusses the processes and steps required to produce a vegetation index. And finally, section 5.5 summarizes the methods and steps used for the implementation of this project.

\subsection{Project Settings and Workflow}

Prior to any analysis or image processing, multiple settings and directory structures needed to be set. A solid directory structure and was integral to keeping data organized. The directory structure used for this project is shown in Figure 5-1.

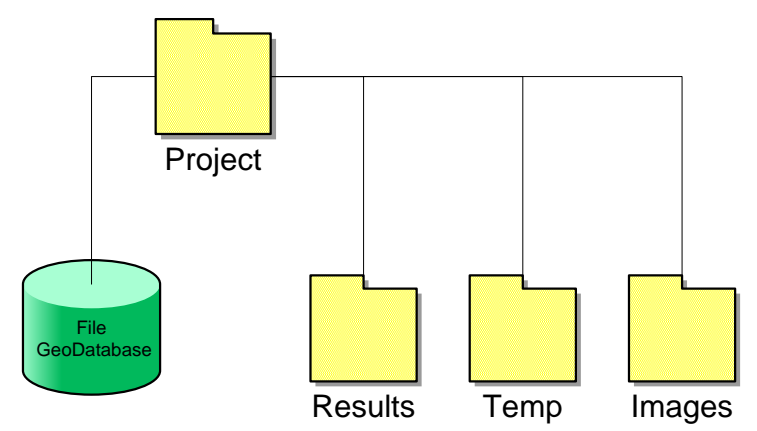

Figure 5-1: Directory Structure Example

It was also important to maintain a logical file naming structure, because with each process run in Feature Analyst (FA) new files were created, and it could quickly become confusing which file was used for which process. FA automatically attaches an abbreviation of the process being used to the end of the original filename in the newly created file as follows:

- Remove $\rightarrow \mathrm{Rmv}$ 


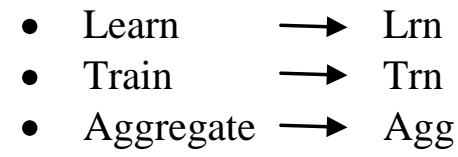

A template ArcMap document file (MIP.MXT) was provided with the digital project deliverables that contains the toolbars and toolboxes necessary to perform this analysis. The extensions for Spatial Analyst and Feature Analyst also needed to be activated when working in ArcMap. Table 7 displays the general settings required for this project.

\section{Table 7: General Settings}

\begin{tabular}{|c|c|c|}
\hline ArcMap & Location & Description \\
\hline Tool Extensions: & Tools $>$ Extensions $>$ & $\begin{array}{l}\text { Spatial Analyst: This extension is used for the } \\
\text { image processes PCA, NDVI, clip, and single } \\
\text { output map algebra }\end{array}$ \\
\hline \multirow{4}{*}{$\begin{array}{l}\text { Environment } \\
\text { Settings: }\end{array}$} & Tools $>$ Extensions $>$ & $\begin{array}{l}\text { Feature Analyst: This extension is used for } \\
\text { creating a training feature class (like a re- } \\
\text { classify), extracting polygon and line features } \\
\text { through a hierarchical learning process, and } \\
\text { feature conversion processes }\end{array}$ \\
\hline & $\begin{array}{l}\text { Tools }>\text { Options }> \\
\text { Geoprocessing }> \\
\text { Environments Button }\end{array}$ & $\begin{array}{l}\text { General Settings: Set the Current Workspace to } \\
\text { the designated project folder or geodatabase. } \\
\text { Scratch Workspace: Set to Temp folder }\end{array}$ \\
\hline & $\begin{array}{l}\text { ArcToolbox > right- } \\
\text { click }>\text { Environments }\end{array}$ & $\begin{array}{l}\text { Raster Storage Settings: Uncheck [build } \\
\text { pyramids] }\end{array}$ \\
\hline & $\begin{array}{l}\text { ArcToolbox > right- } \\
\text { click }>\text { Environments }\end{array}$ & $\begin{array}{l}\text { General Settings: Set the Current Workspace to } \\
\text { the designated project folder or geodatabase. } \\
\text { Scratch Workspace: Set to Temp folder }\end{array}$ \\
\hline MIP Toolbox: & $\begin{array}{l}\text { ArcToolbox > right- } \\
\text { click }>\text { Add Toolbox }\end{array}$ & $\begin{array}{l}\text { The MIP.tbx file is located in the Project Folder } \\
\text { from the project deliverable CD. }\end{array}$ \\
\hline ArcCatalog & Location & Description \\
\hline Environment Settings: & $\begin{array}{l}\text { Tools }>\text { Options }> \\
\text { Geoprocessing }> \\
\text { Environments Button }\end{array}$ & $\begin{array}{l}\text { General Settings: Set the Current Workspace to } \\
\text { the designated project folder or geodatabase. } \\
\text { Scratch Workspace: Set to Temp folder }\end{array}$ \\
\hline \multirow[t]{2}{*}{ File Settings: } & $\begin{array}{l}\text { Tools }>\text { Options }>\text { File } \\
\text { Types }>\text { New Type }\end{array}$ & $\begin{array}{l}\text { Set File extension: .afe } \\
\text { Set description type: Automated Feature } \\
\text { Extraction }\end{array}$ \\
\hline & & $\begin{array}{l}\text { An Automated Feature Extraction (AFE) file is } \\
\text { the product of a FA process. The AFE file } \\
\text { contains the processes run to produce that file } \\
\text { similar to the ArcMap ModelBuilder (Visual } \\
\text { Learning Systems, Inc., 2008) }\end{array}$ \\
\hline
\end{tabular}

Figure 5-2 represents a simplified workflow for the steps that were taken grouped by ArcCatalog, ArcMap, and Feature Analyst. The ArcCatalog window displays the 
steps taken to create a new geodatabase, load data, and define or project the data and images being analyzed. The ArcMap window encompasses the steps required to work within the .MXD, create and buffer feature points, and perform image clips to the buffered data. Additionally, within the ArcMap process window the images are registered, clipped, converted to relative reflectance, and transformed into PCA and SAVI raster datasets. The Feature Analyst process window displays the steps required to extract social trails from imagery. The steps included training file creation and training sample processing which resulted in a polygon feature class from the raster data. The following steps included removing anomalies via feature selection, removing outliers via pixel size aggregation, and converting the polygons to line features.

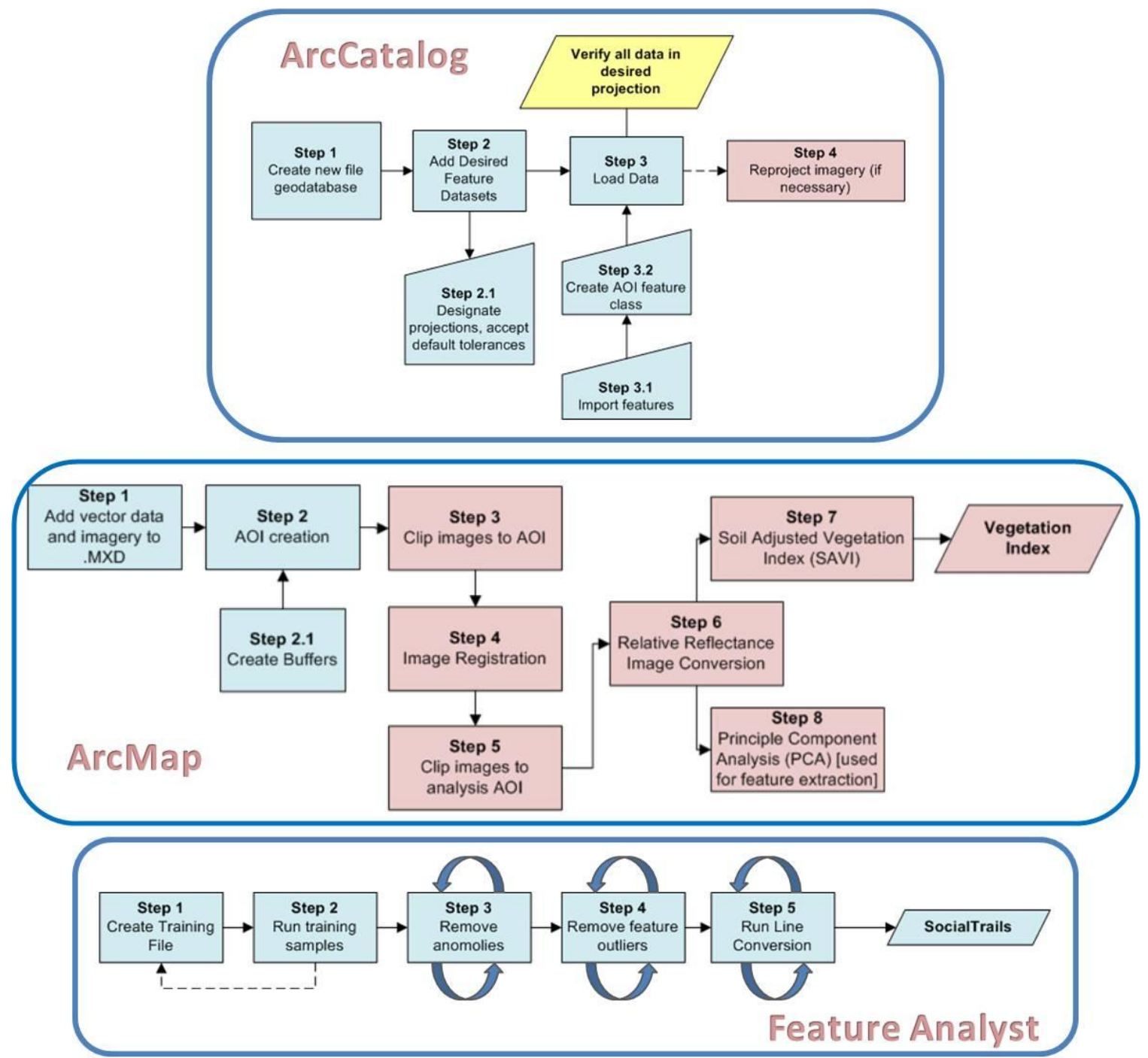

Figure 5-2: Process Workflow 


\subsection{Geodatabase Development}

The file geodatabase was created using the tools within ArcCatalog. Chapter 4 discussed the conceptual and logical models in detail, as well as specific changes made to the tables. The following steps were used to create and load the file geodatabase using ArcCatalog (see Figure 5-3):

1. Right click $>$ New File geodatabase (named appropriately)

a. Select the new geodatabase $>$ right click $>$ import $>$ XML Workspace

Document (select Schema only or Data from an existing dataset)

2. Open the geodatabase $>$ right click $>$ New Feature dataset

a. Complete the wizard

3. Right click $>$ New Feature class

a. Complete the wizard: Import the table settings from the source dataset

4. Loading Data: Can be performed multiple ways.

a. Select the new geodatabase $>$ right click $>$ import $>$ XML Workspace Document (select Data)

b. Select the new geodatabase $>$ select appropriate feature dataset $>$ import multiple (or single) features

***Note: Verify all feature classes / shapefiles are in desired projection prior to loading.

5. Create a new point feature class called AOI. This AOI feature class was created to designate the specific areas of interest that will be evaluated for social trail networks.

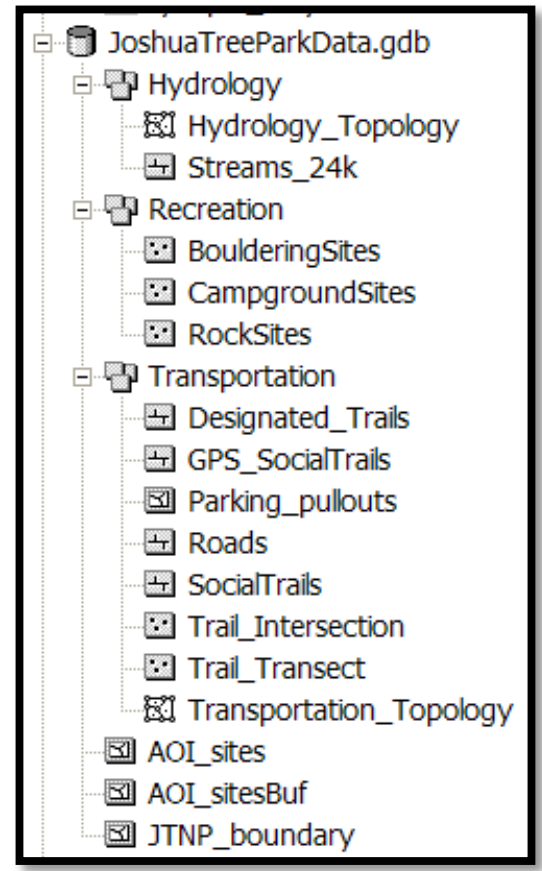

Figure 5-3: Final Geodatabase 


\subsection{Social Trail Extraction}

The methods used for the social trail extraction can be followed in Figure 5-2, including Step 4 in the ArcCatalog diagram and all steps in the ArcMap and Feature Analyst diagrams. Step 7 within ArcMap is discussed in more detail in section 5.4.

\subsubsection{Image and Vector Data Setup}

All QuickBird imagery to be processed needed to be in the same projection as the source image, which was the 2005 NAIP imagery. As noted in the methods section, this transformation was performed to meet future temporal requirements for the client. A more appropriate methodology would not re-project the imagery, but re-project and register the vector data to the image data. By manipulating the vector data rather than the raster data the user minimizes the amount of error introduced into the dataset.

In this case, the projection was NAD 1983 UTM Zone 11N. The imagery was projected using the <Project Raster> tool from ArcToolbox (Data Management Tools > Projections and Transformations $>$ Raster). It is important to note in Figure 5-4 that the output filename does not end with .IMG, and that a geographic transformation was applied, as well. The resulting image was in GRID format; therefore the name could not exceed thirteen characters. The transformation selected for this project was NAD_1983_To_WGS_1984_5. This datum transformation was selected based on the "United States CORS ITRF96" area coverage (ESRI, n.d.). The resampling technique should be set to bilinear, rather than the default (nearest neighbor). Nearest neighbor is more appropriate for discrete data, but since this is the default value it is often unknowingly used. Depending on the size of the image being processed, this operation may take more than an hour to complete. 


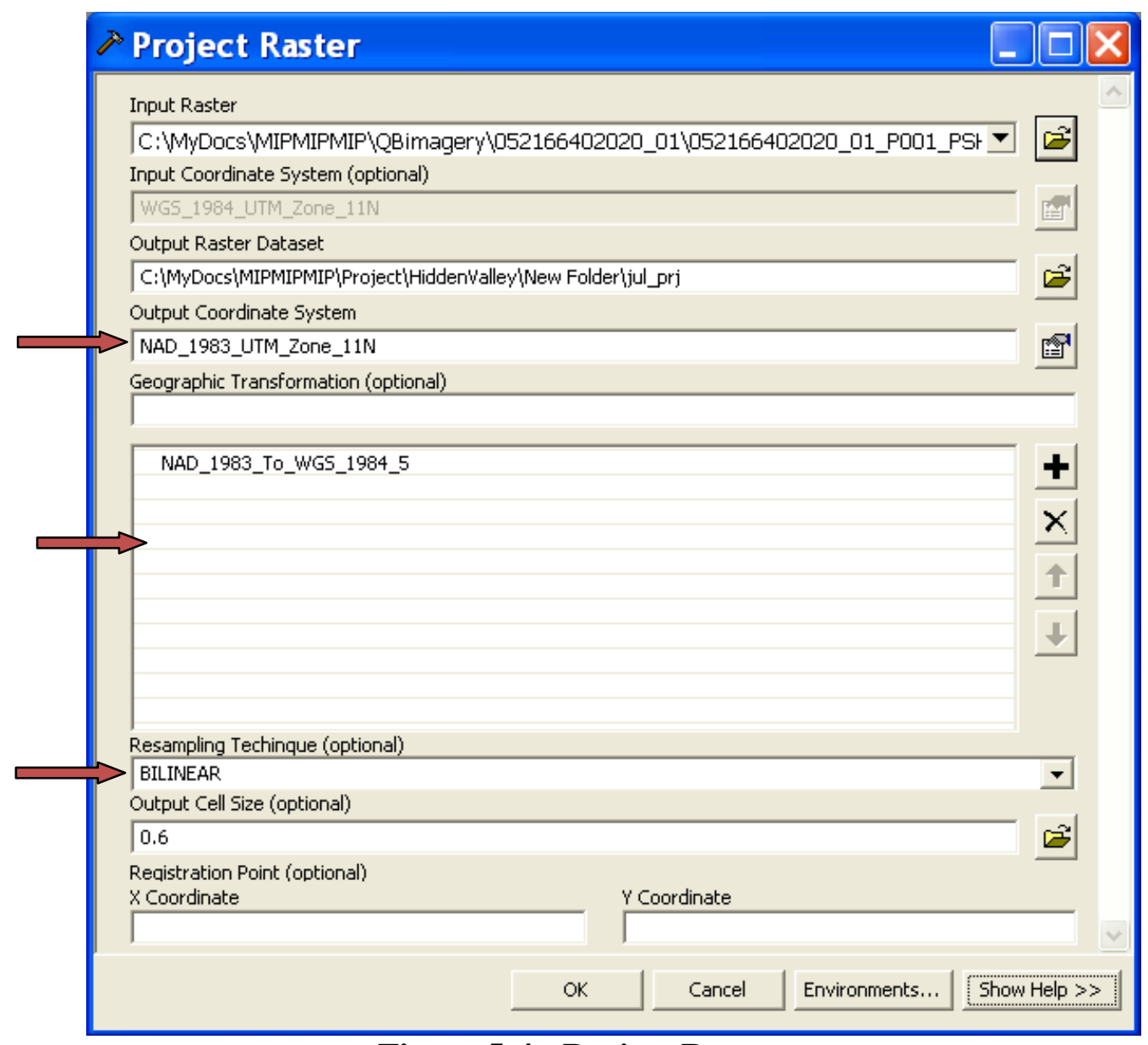

Figure 5-4: Project Raster

The next step was to open the ArcMap MIP.mxt document, add the projected imagery, and the desired vector layers. It was normal for the vectors not to line up with the imagery, because the imagery needed to be registered to the source image (see Figure 5-5). In this case the source image was a 2005 NAIP image provided by the client. 


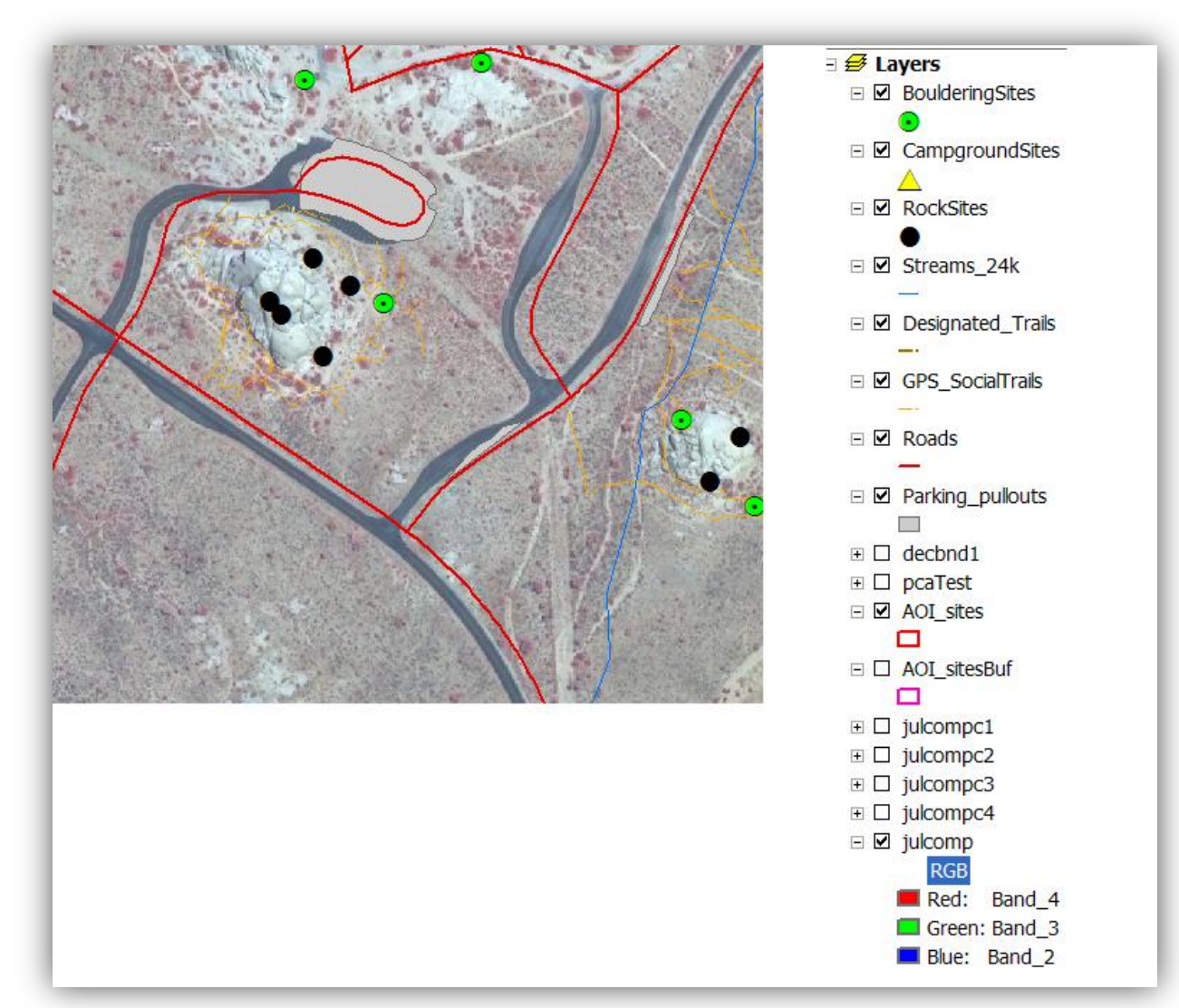

Figure 5-5: Vector Data Screenshot

Once the data was loaded into the ArcMap document, the empty point feature class AOI, which was created in geodatabase development, was modified through the following steps:

1. Populated the empty AOI feature class with points of interest by manual dropping of points or selecting features and copying them into the AOI feature class. These points indicated the location of areas of interest and the extent of the areas of interest were defined by the buffers around these points.

2. Created a one kilometer buffer around the specified targets in the AOI feature class called AOI_sites using the Buffer Wizard. In addition, a 1.1 kilometer buffer called AOI_sitesBuf, was also created on the AOI feature class (see Figure 5-6), because when image registration occurs the image edits often resulted in shapes that no longer fit the original buffer boundary. Any image overshoots or undershoots were avoided by adding this 1.1 kilometer buffer. 


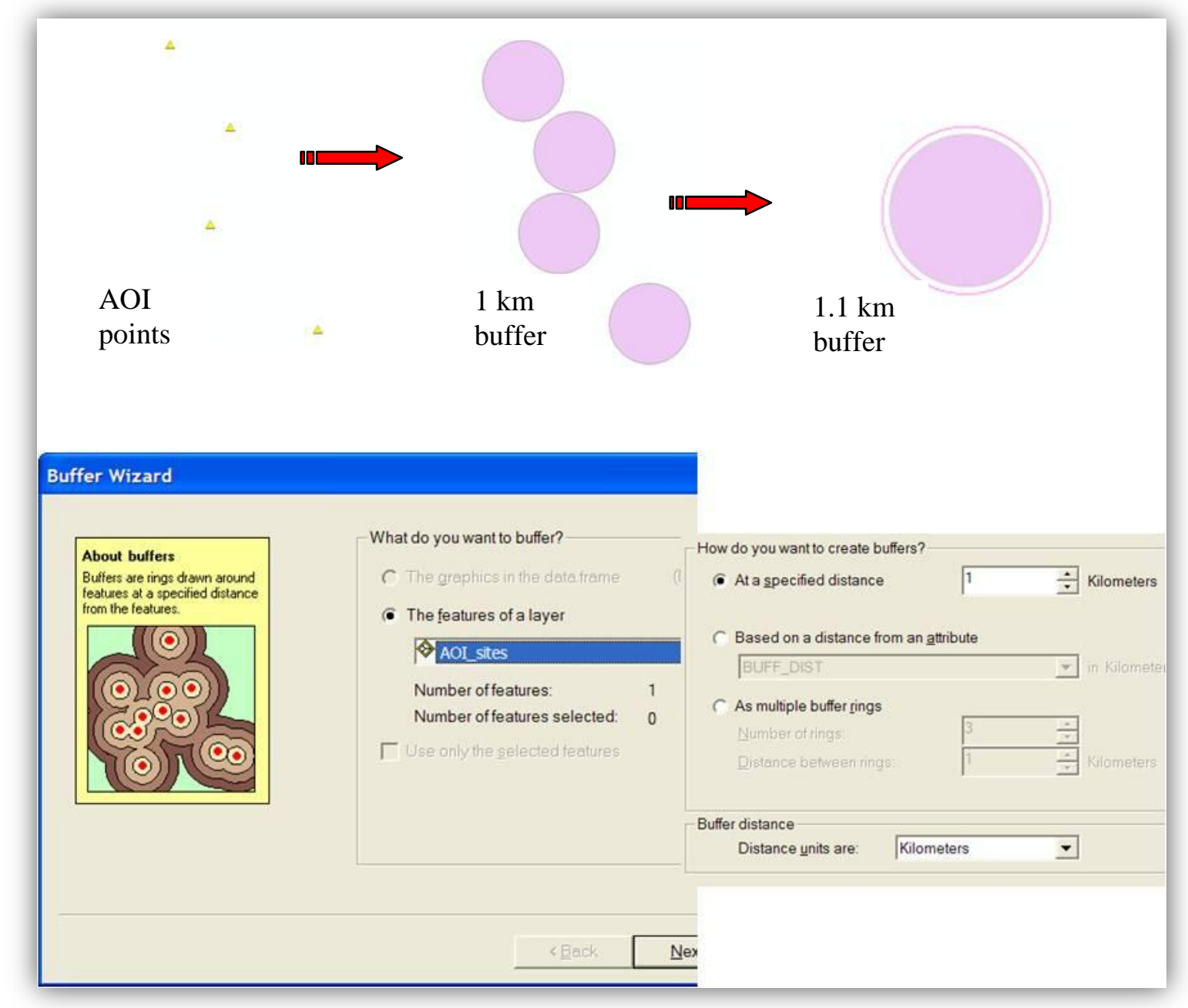

Figure 5-6: Buffer Wizard

3. The multi-band images were clipped to the AOI_sitesBuf layer (see Figure 5-7). ArcMap also has a batch function that can be used if the parameters are set correctly. The Use input features for Clipping Geometry box must also be checked to minimize data processing. The image data for the selected AOI's was then ready for the next processing step. 


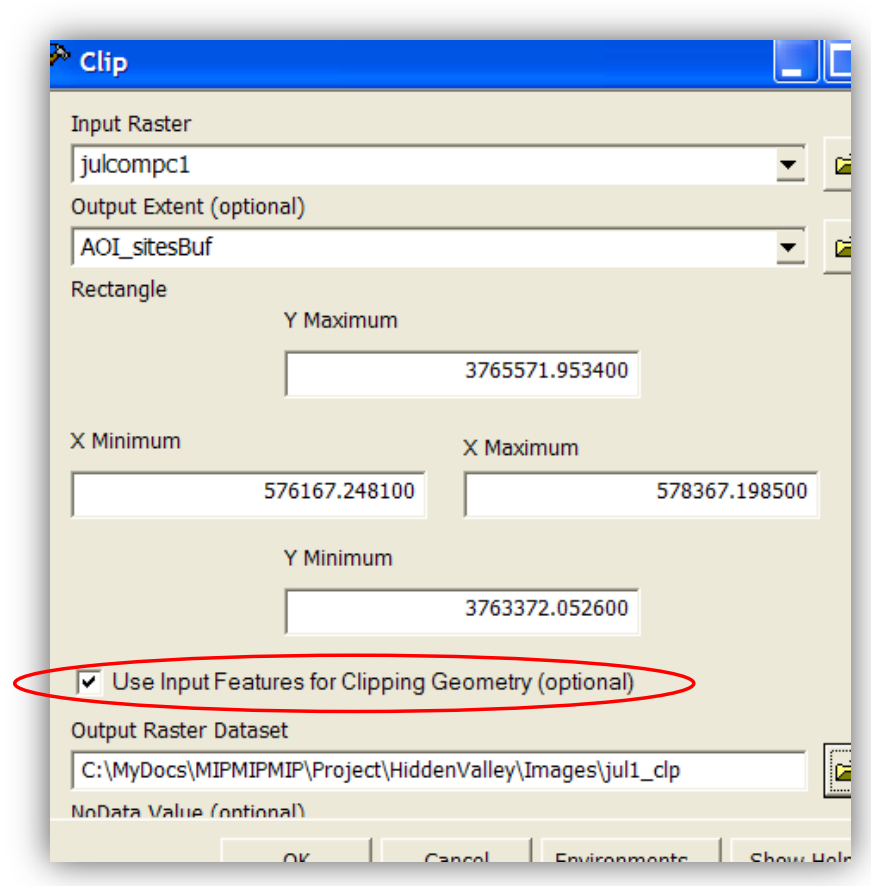

Figure 5-7: Image Clip

\subsubsection{Image Registration}

The clipped QuickBird images were georeferenced to the 2005 NAIP image. The steps taken to georeference the images were as follows using the Georeferencing toolbar (see Figure 5-8):

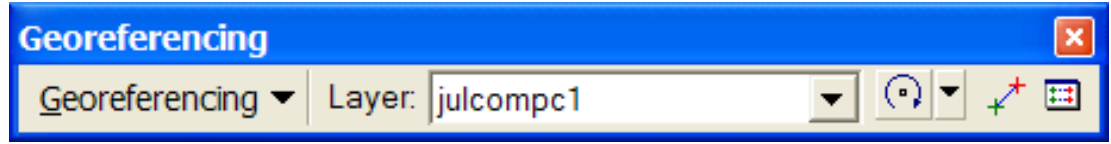

Figure 5-8: Georeferencing Toolbar

1. Selected $\AA^{+}$(Add Control Points)

2. Verified the image being referenced

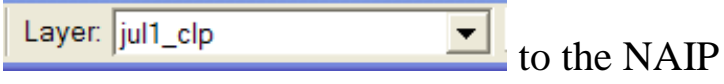
image was selected from the drop-down menu.

3. For the purpose of this project, a $1^{\text {st }}$ Order Polynomial (affine) transformation was used. The affine transformation adjusts the scaling, rotation, and shearing of the image through rectification of the ground coordinates to the image coordinates (Petrie, 2005). The type of transformation determines the number of control points, so a minimum of four links, or control points, were required by selecting a known feature (e.g., a street corner) from the QuickBird image and selecting the same feature on the source map or image (see Figure 5-9). 


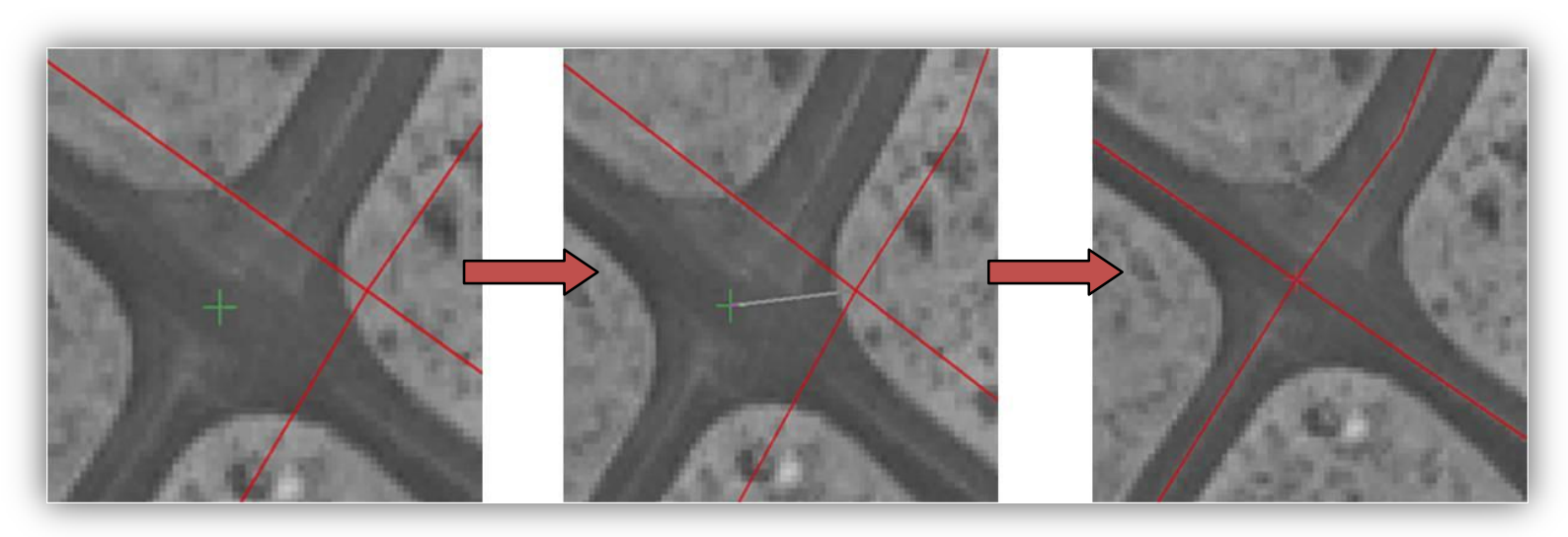

Figure 5-9: Control Point Registration

The first link was added in the center of the image followed by adding links to the corners and periphery areas. It was important to link permanent features, such as hard paved roads, as they were less likely to change over time. A minimum of three links are required to estimate the transformation, while the fourth link allows a statistical method to be applied (Bolstad, 2008b).

4. In addition to creating control points, it was important to pay attention to the root mean square error (RMSE) value in the Link Table (see Figure 5-10). The RMSE was calculated after three control points were dropped and the residual value was recalculated after each additional point. The residual values represent the distance between the original X, Y coordinates, and the output image coordinates. It was important to get the lowest RMSE value possible, because the lower value indicates higher transformation accuracy. To keep the RMSE low, residual outliers from the rest of the values were evaluated visually to determine the cause, and either modified or kept. The value could also be removed by

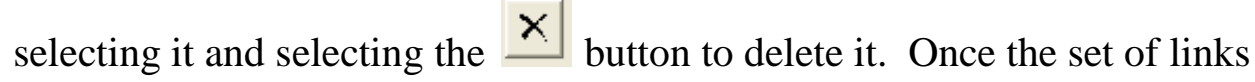
reached a RMSE value below 3 meters (chosen arbitrarily based on image resolution), it was saved as a .TXT file to use on the other bands of the image in a later step.

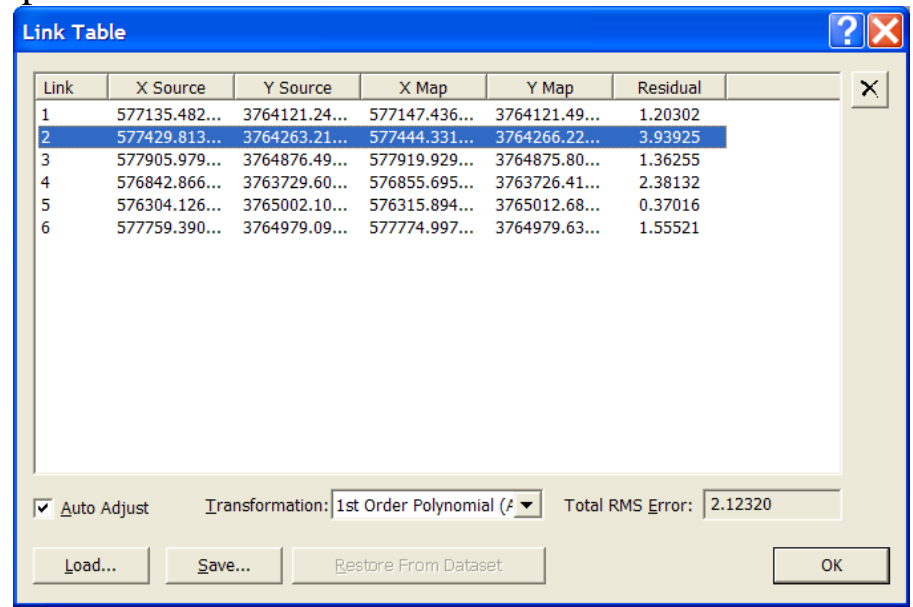

Figure 5-10: Link Table 
5. Re-sampled the image by selecting Rectify... from the Georeferencing dropdown menu. GRID image file was selected and the image resampling type selected was bilinear interpolation. The default resampling type, nearest neighbor was used for the image processing for JTNP, however it has been determined that bilinear interpolation should be used in the future. Bilinear interpolation uses a distance-based averaging method of the four closest cells to calculate the pixel value in the output image. Once the resampling process was completed the control points were deleted by selecting Delete Control Points the Georeferencing drop-down menu (see Figure 5-11).

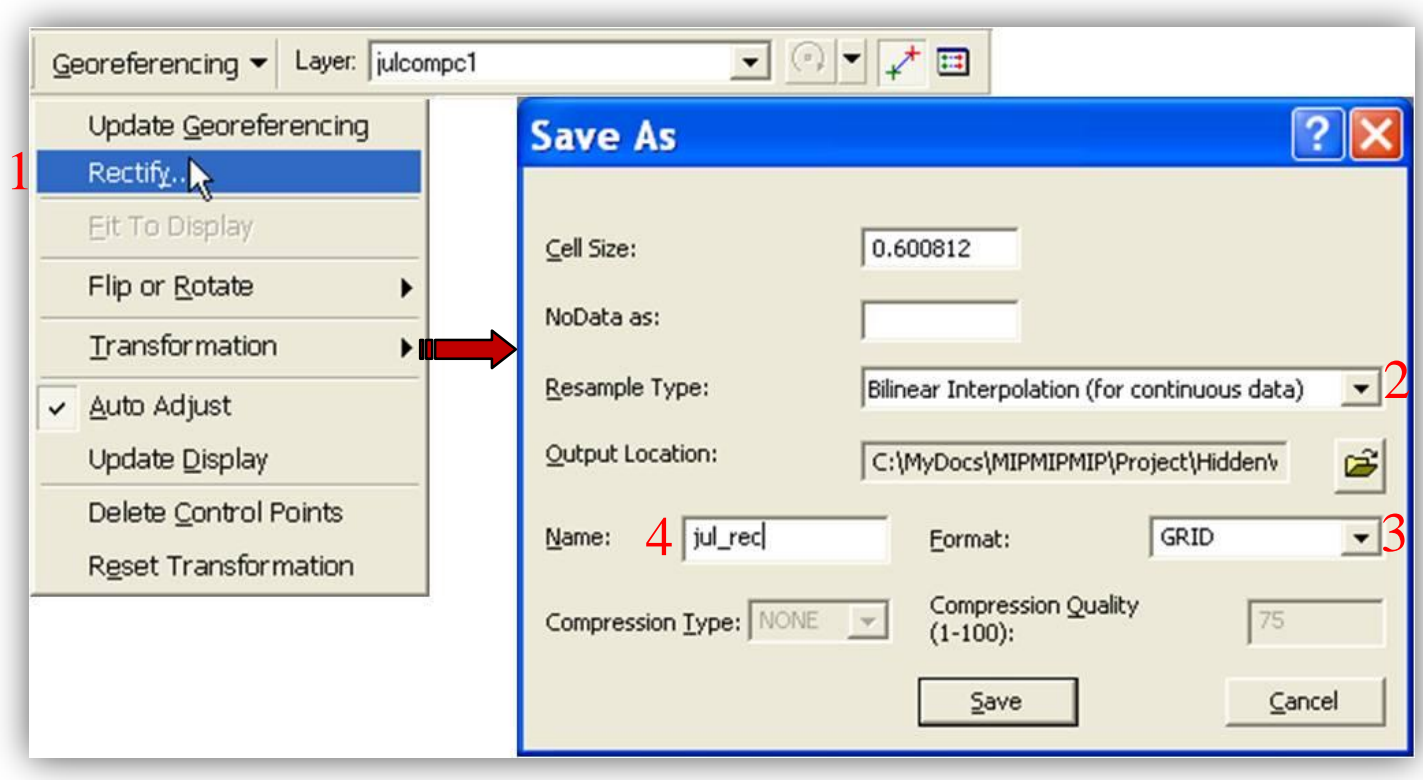

Figure 5-11: Re-sampling Image

6. The next image band was selected from the Georeferencing toolbar drop-down menu. The LinkTable.txt file saved from step 4 was loaded and used to repeat step 5. This was done for the remaining image bands. This replicated the image registration process for the other band layers.

7. The rectified images (bands 1,2,3,4, and composite) were now clipped to the AOI_sites layer as represented in Figure 5-7. This step clipped the registered images to the original one kilometer buffer.

\subsubsection{Relative Reflectance Conversion}

The imagery was converted from the current representation of radiance values to relative reflectance values. The necessity for relative reflectance values was based on the requirements for the vegetation indices and principal component image transformations. The Mean Calculation Model was used to calculate the mean pixel value within each image band (see Figure 5-12). 


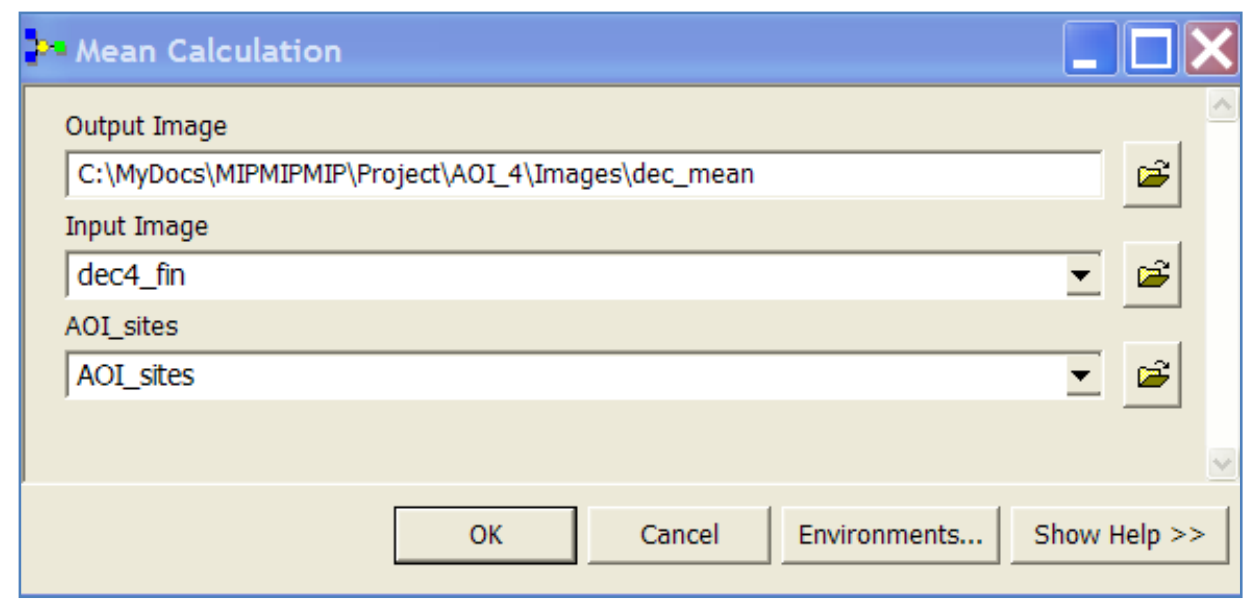

Figure 5-12: Mean Calculation Model

A map algebra equation was then used to calculate the relative reflectance of the images.

1. The first step was to select the Mean Calculation Model from the MIP Toolbox. The AOI_sites data was the buffered AOI site because that is the only region the tool should perform the calculations on. Leave the zone field to default values. The input value raster should be one of the image bands. The model preset the following parameters: the statistics type selected was Mean and the ignore NoData in calculations check-box was checked. If an error occurs while running this model, it may be necessary to enter each input value by using the browse buttons, rather than the drop-down menus.

2. Using the mean radiance value from Step1 a single output map algebra function was performed using the following equation: [The raster calculator tool (Spatial Analyst) provides a selection menu of all the raster's in the TOC, which makes creating the equation very simple. The user can then copy that equation into the map algebra tool.]

Relative Reflectance $=$ Float $([$ source image $]) /[$ Mean Calculation output $]$

\subsubsection{Principle Component Analysis (PCA)}

The principal component transform was used to highlight linear features and aid the extraction process (Cao, Stow, Kaiser, \& Coulter, 2007). The PCA was performed using the Principal Components tool in ArcToolbox (see Figure 5-13). This tool requires the Spatial Analyst extension to be activated. As displayed in Figure 5-13, the images were loaded, the output raster was named appropriately, and the number of principal components was set to 2 . 


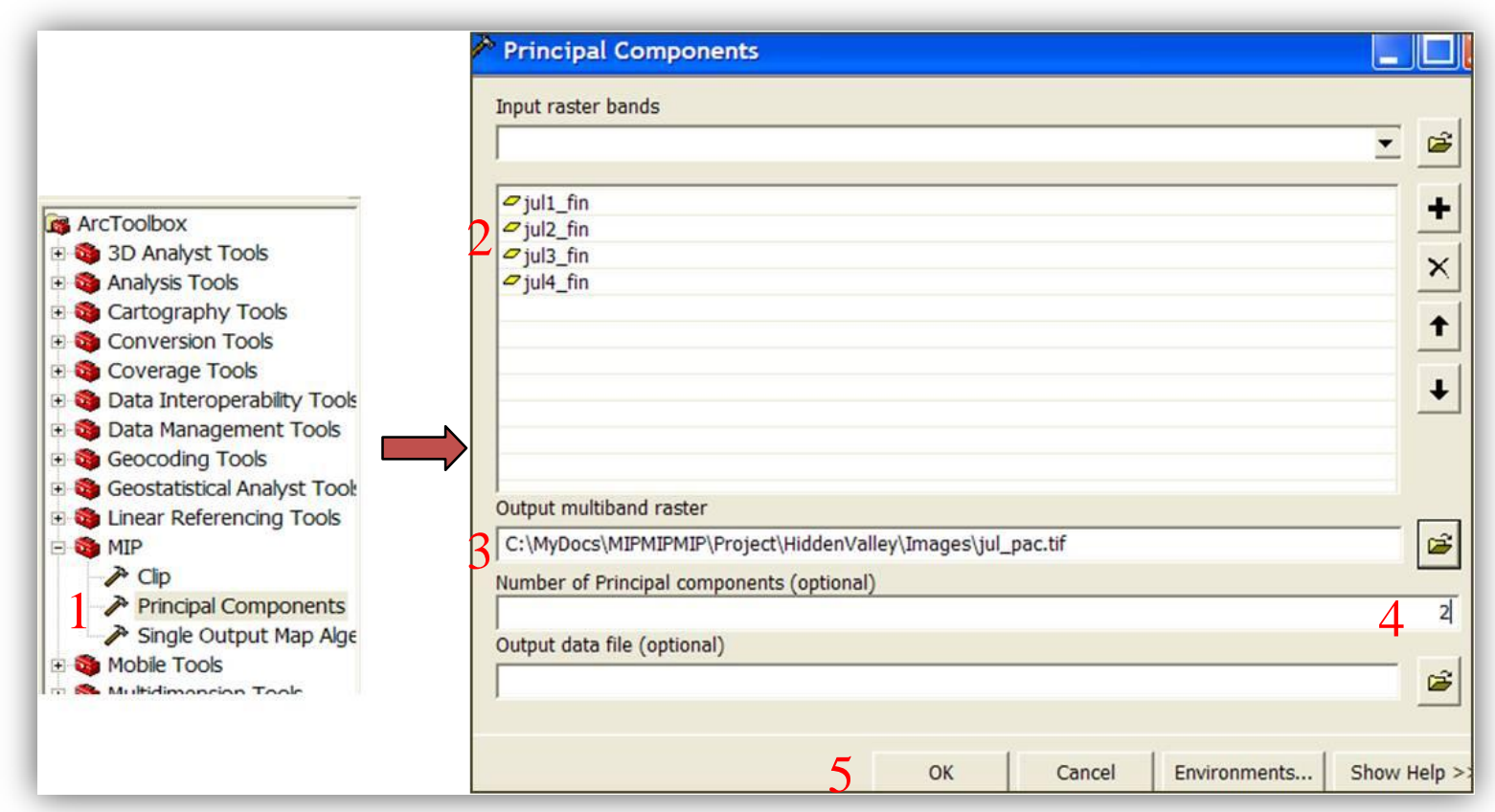

Figure 5-13: PCA Steps

The final step in creating the PCA raster's was to export the files from GRID format to TIFF format. The image type was changed because FA requires uncompressed images. The Raster to other Format Script was selected from the MIP Toolbox and the rectified and clipped images were loaded into the tool. The output location was set and the format selected was TIFF (see Figure 5-14). The PCA.tif images were then added to ArcMap.

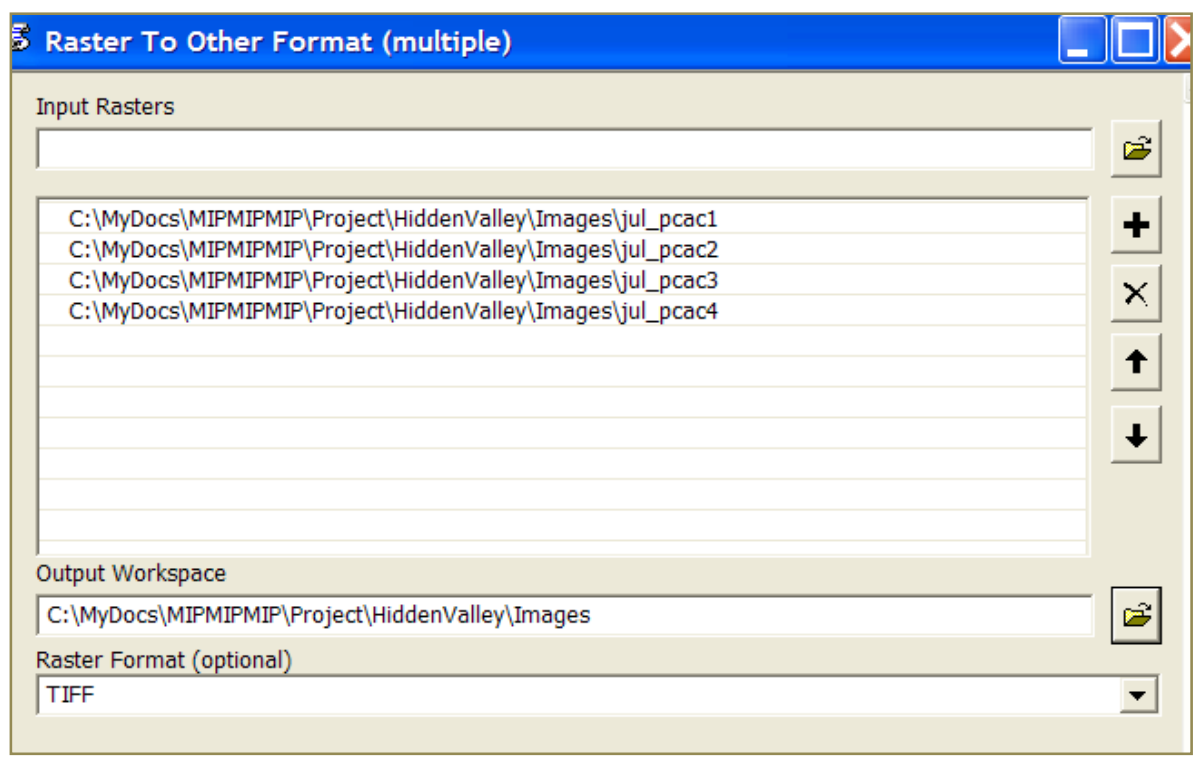

Figure 5-14: Raster to Other Format Tool 


\subsubsection{Feature Analyst}

The FA extension and toolset were used to extract social trails from the QuickBird imagery. FA was chosen for this project because it uses a simple process that includes digitizing a sample dataset, image classification based on the sample dataset, and reinforced learning through further refinement of the extraction models (Visual Learning Systems, Inc., 2008).

To use FA effectively it was important to know the source image size, pixel depth, and resolution. These values were found by opening the ArcMap Properties window and selecting the Source tab of the image to be used (see Figure 5-15).

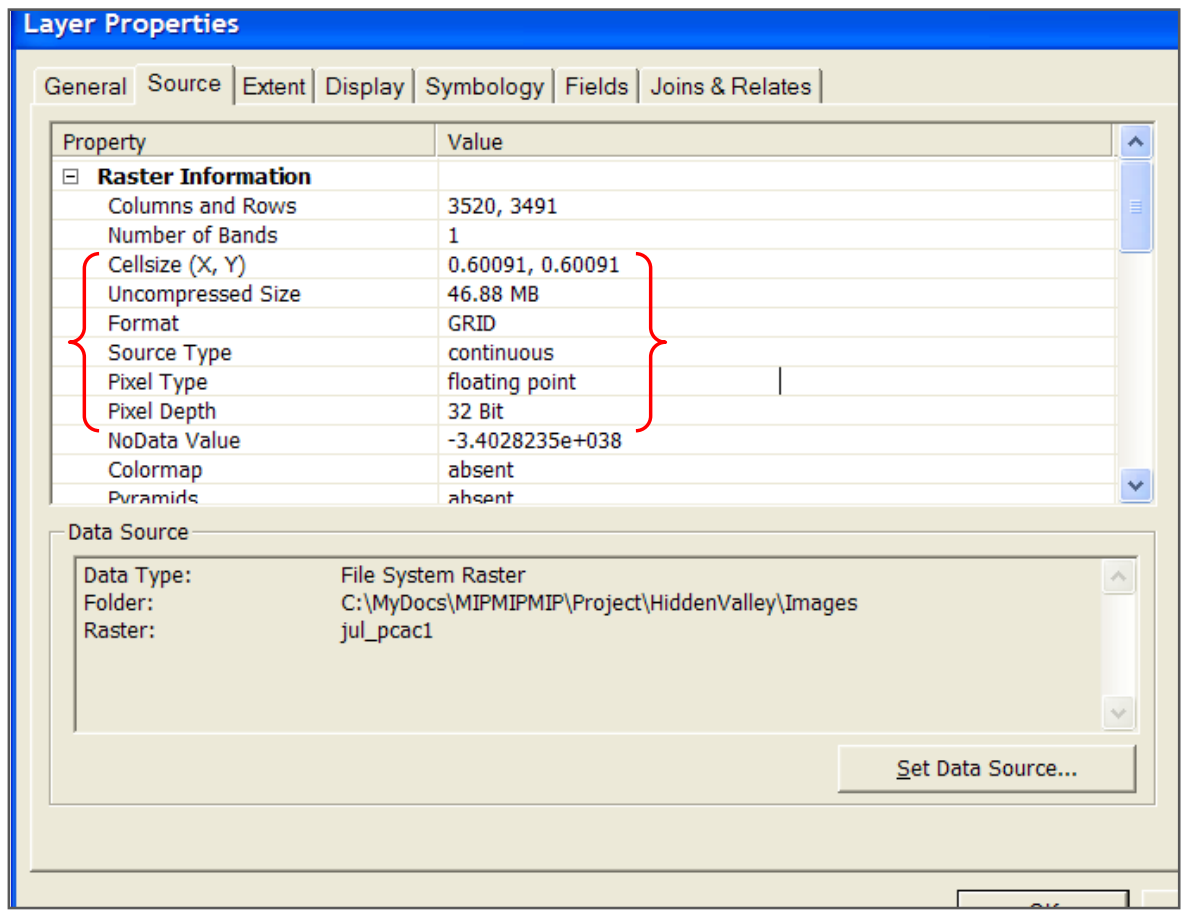

Figure 5-15: Image Information

The resolution was determined by the Cellsize value and the Pixel Depth value was used to determine the type of image stretch to apply during processing. For this project, the pixel depth was 32-bit, so FA applied a 2-Standard Deviation stretch to the image. Pixel depth indicates the range of values represented by each pixel, so the larger the bit value the larger the file size. According to the FA Reference Manual, images larger than 11-bit would have the 2-Standard Deviation stretch applied, while images smaller than 11-bit would have the histogram equalize stretch applied. The 2-Standard Deviation stretch was selected to eliminate outlier values by only displaying 95 percent of the histogram. When loading images into ArcMap the 2-Standard-Deviation stretch is the default. Within the ArcMap session it was useful to apply the same image stretch as what FA used. The purpose for applying the stretch in the ArcMap session was for visualization purposes only, because FA applies its own stretch within the algorithms used. An image stretch 
can be useful for enhancing the features the user will digitize as training data by stretching the digital values to display the entire spectrum of brightness values.

1. A feature class was created by selecting the Create New Feature Class tool on the FA 4.2 Toolbar (see Figure 5-16).

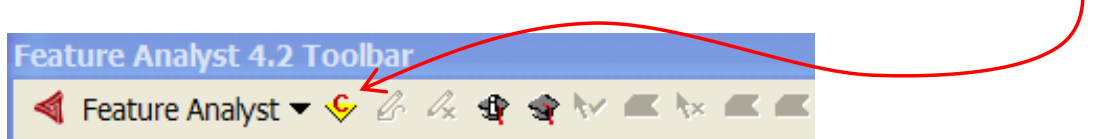

Figure 5-16: Feature Analyst 4.2 Toolbar

The feature-type line was then selected (see Figure 5-17).

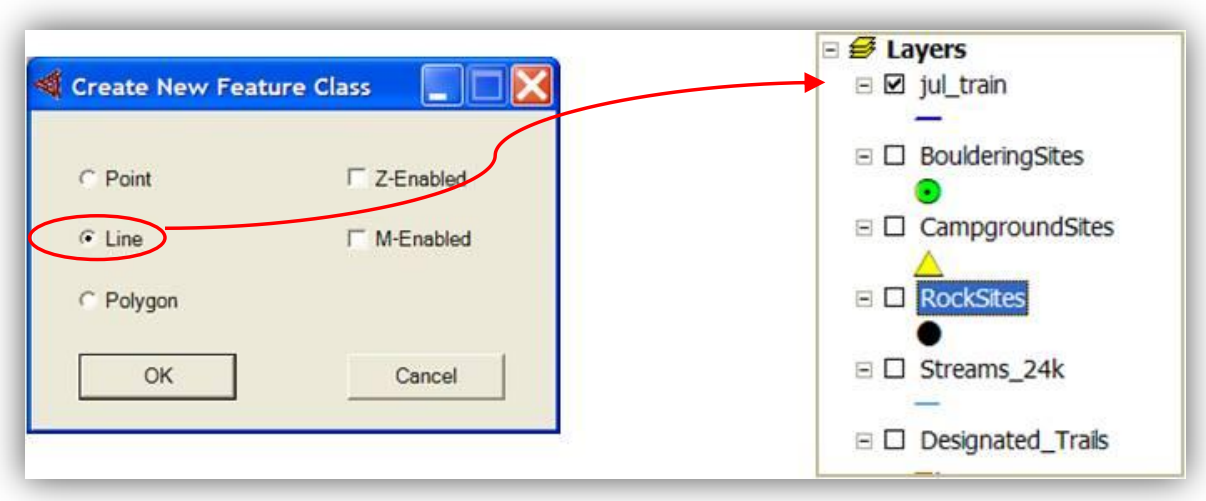

Figure 5-17: Create New Feature Class

This feature class was saved as a shapefile in the temp folder and named in a recognizable manner. The feature class gets automatically loaded into ArcMap upon saving. FA also displays a progress window that shows which step the program is on (see Figure 5-18).

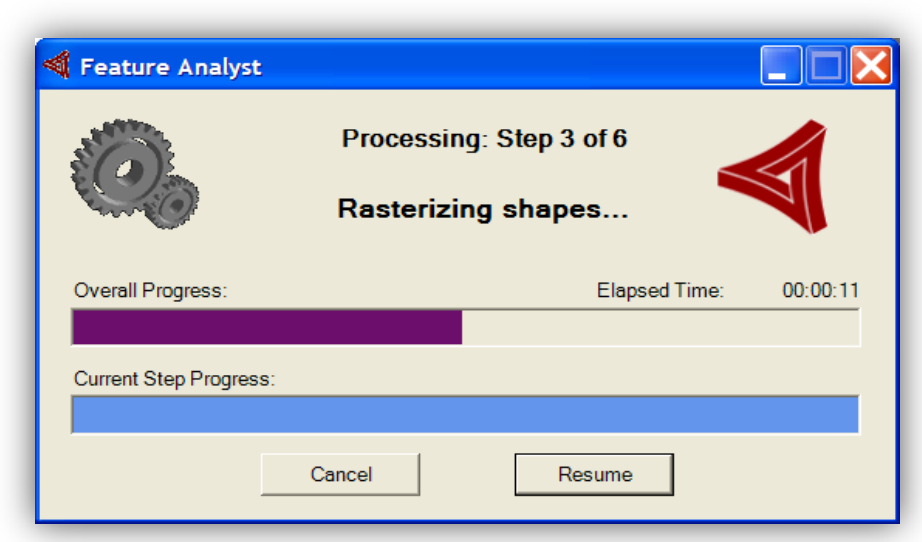

Figure 5-18: Feature Analyst Progress Window

2. An edit session was then started (for the shapefile created in the previous step) and training vectors were collected following the sequence highlighted in Figure 5-19. It is important to note that the feature being edited also needed to be highlighted in the TOC. 


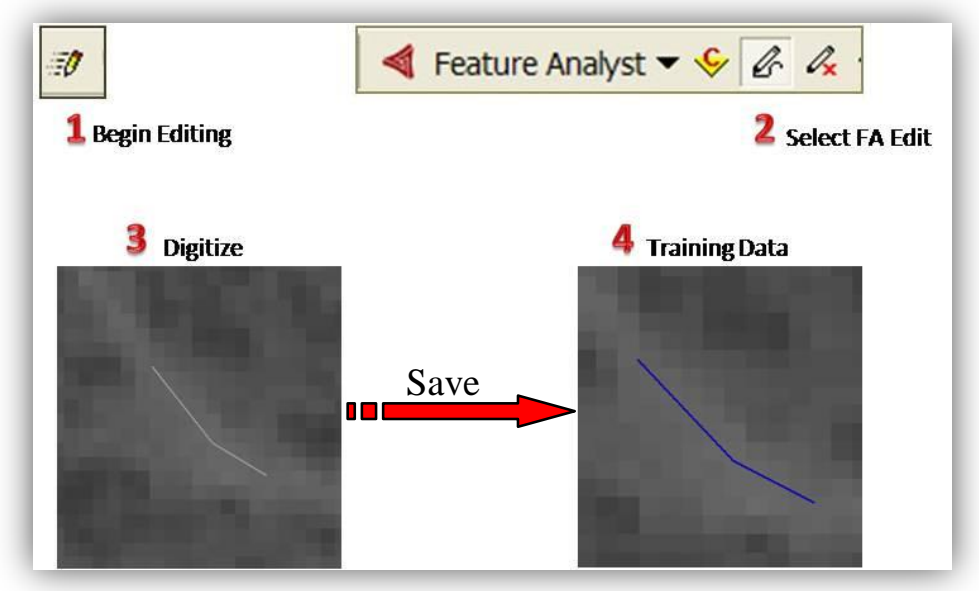

Figure 5-19: Training Sample Extraction

3. For this project, the training dataset included multiple (at least five) digitized segments of social trails. It was necessary to zoom in close enough to discern the different pixel shades when digitizing the features (see Figure 5-19). It is very important to digitize the features accurately to the pixel level, because the FA algorithms operate by analyzing the shapes and pixel values to extract features (see Figure 5-20). This task may require multiple attempts depending on digitizer experience.

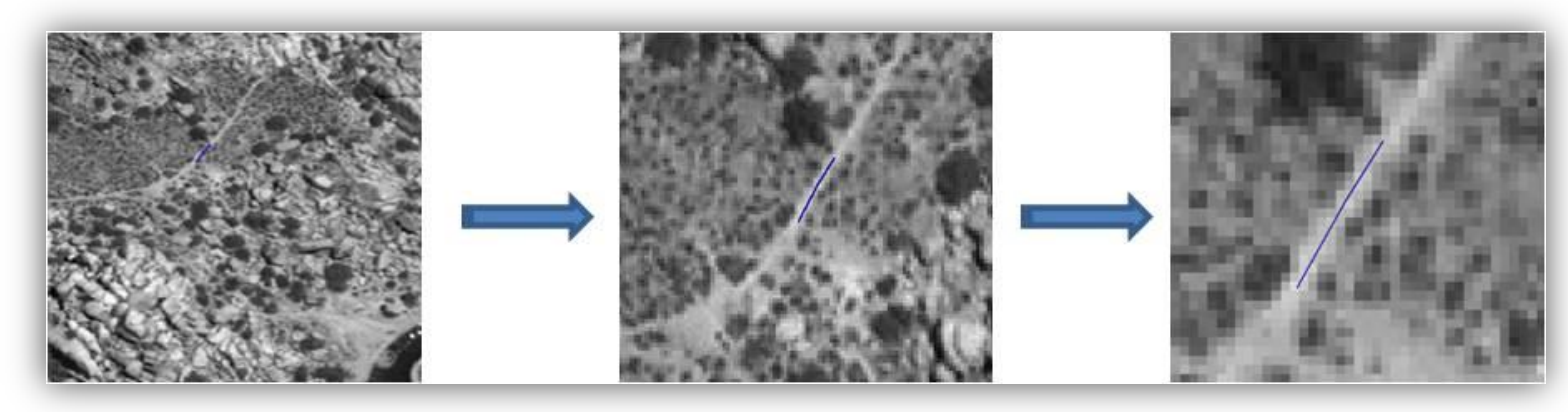

Figure 5-20: Zoom Level Examples

4. After sufficient training segments were taken (no more than 10) the edits were saved and editing stopped. It is very important to remember that all processes require the source feature class, in this case the training data, to be selected in the TOC. The Set Up Learning Tool was selected and a large window opened with multiple feature selections. For this project, the Narrow Linear Feature radio button was selected and the image resolution was set to 0.5 meter. FA automatically assigns the image resolution value based on the detected resolution (Visual Learning Systems, Inc., 2008). Although the actual resolution was 0.6 meters, FA assigned the most appropriate resolution value available. The Advanced button was selected to expand the window to display four data tabs. 
a) The Input Bands tab allows the user to select specific images to be used in the analysis. For this project the first band of the PCA image output was used (see Figure 5-21).

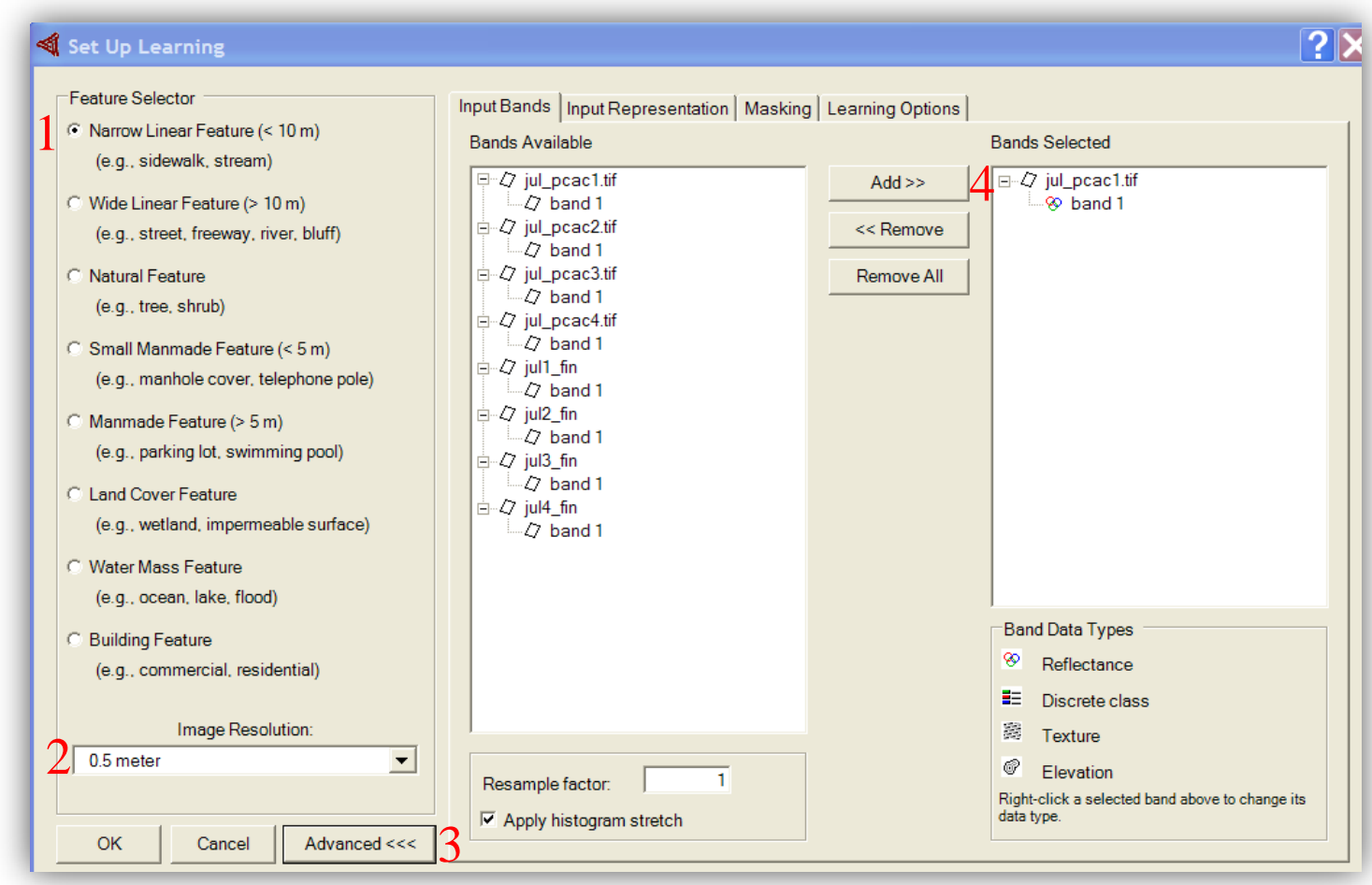

Figure 5-21: Learning: Input Bands 
b) The Input Representation tab contains drop-down menus for pattern choice and pattern width. Bull's Eye 4 was found to be the best model to use for extracting trails. The pattern width selected $(31-61)$ is a variable width that was selected based on model results (see Figure 5-22). The FA reference manual suggests for narrow linear features to select Bull's Eye 1 with a pattern width of 5. There are likely other combinations of pattern width and model representation (e.g. Bull's Eye) that can produce similar results.

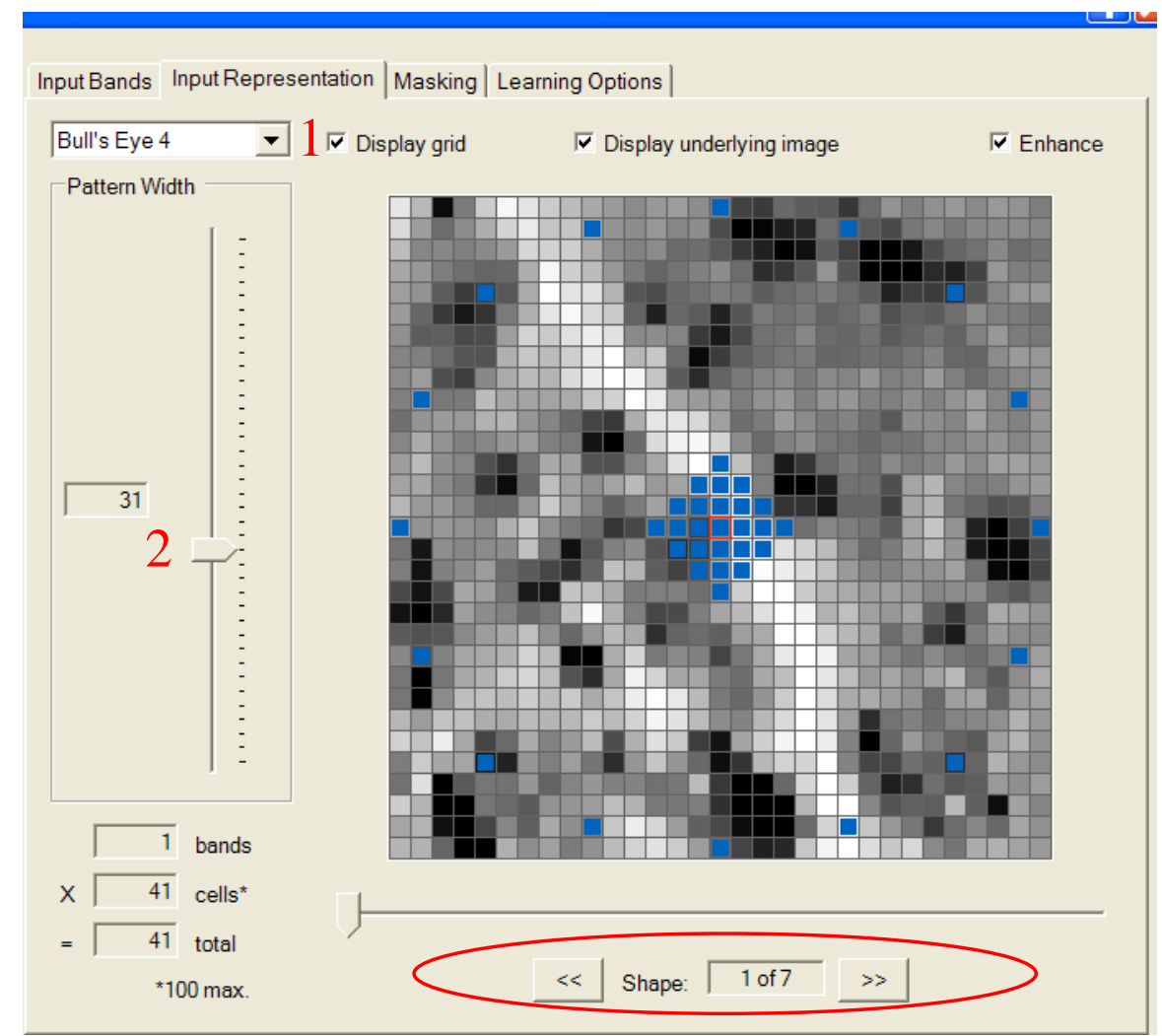

Figure 5-22: Learning: Input Representation

A pattern width of 61 tended to provide the best results, however 31 also gave decent results. The image display in Figure 5-22 can also be used as a reference to visually check the accuracy of the training data by using the arrow buttons to navigate.

c) The last tab includes the learning options. For this project, the Aggregate areas box was unchecked and all other selections were left to the default settings (see Figure 5-23). 


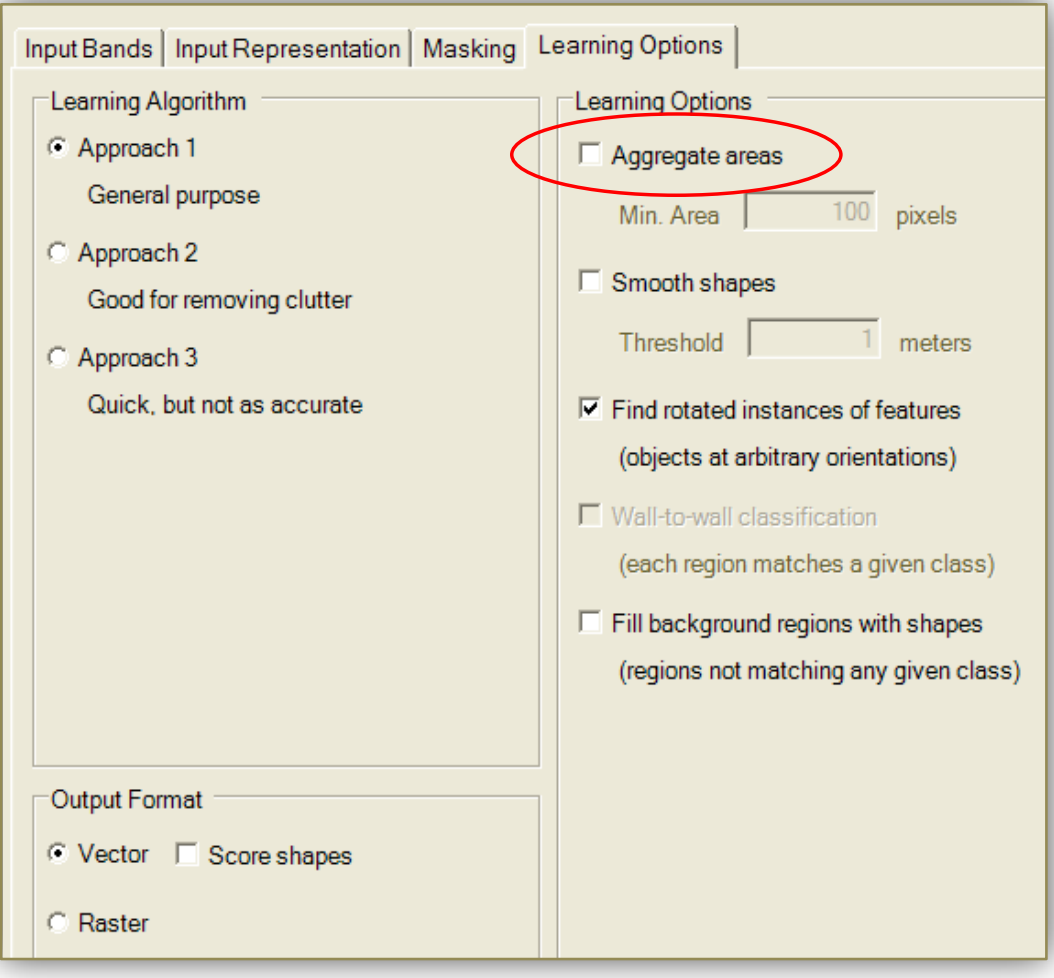

Figure 5-23: Learning Options

d) Once the Set Up Learning menu had been completely reviewed, the next step was to name the new training feature class in the One Step Learning

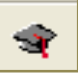
window. This was an iterative process that could take several attempts before results were considered satisfactory. Suggestions for improving results include adding more sample features, deleting some of the disqualified sample features, or editing specific samples that were not digitized accurately.

5. Anomalous features were removed using the Remove Clutter Tool (see Figure 24).

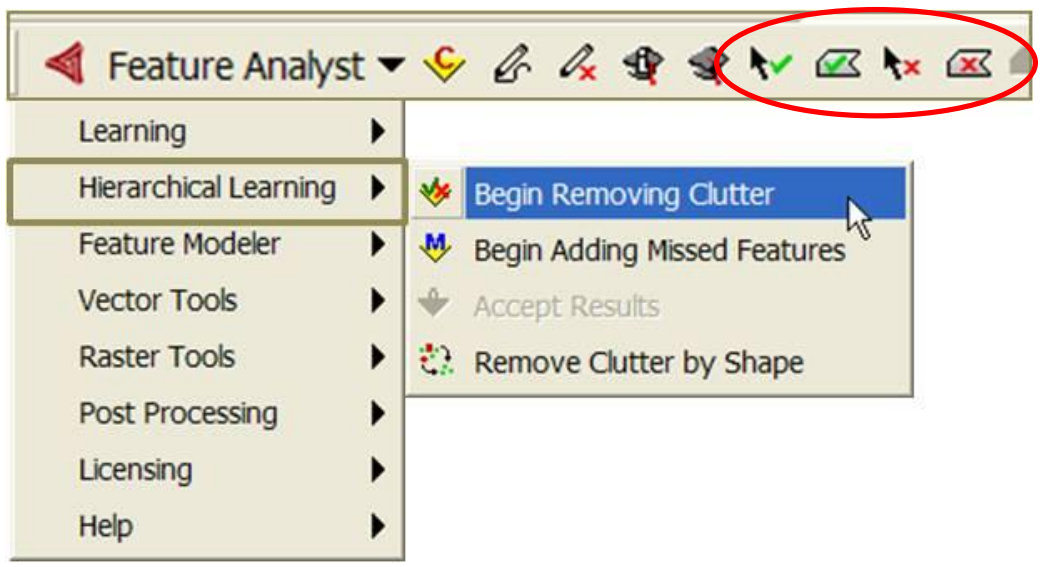

Figure 5-24: FA Remove Clutter Tools 
Select the FA dropdown toolbar, select hierarchical learning, and select Begin Removing Clutter. A new feature class was created with _Rmv at the end of the name indicating the role for that feature class.

a) Once the editing session started with the _Rmv feature class selected several tools became active in Figure 5-24.

b) The Remove Clutter tools can select entire features to keep or delete, or the user can digitize around features that should be kept or deleted (see circled features in Figure 5-24). Using the tools described, appropriate features were selected to delete or keep. It is important to not select too many features to delete, otherwise the resulting feature class will be missing features that were originally correct. The main features needed to delete include rock and boulder areas and the open areas away from any known trails (see Figure 525).

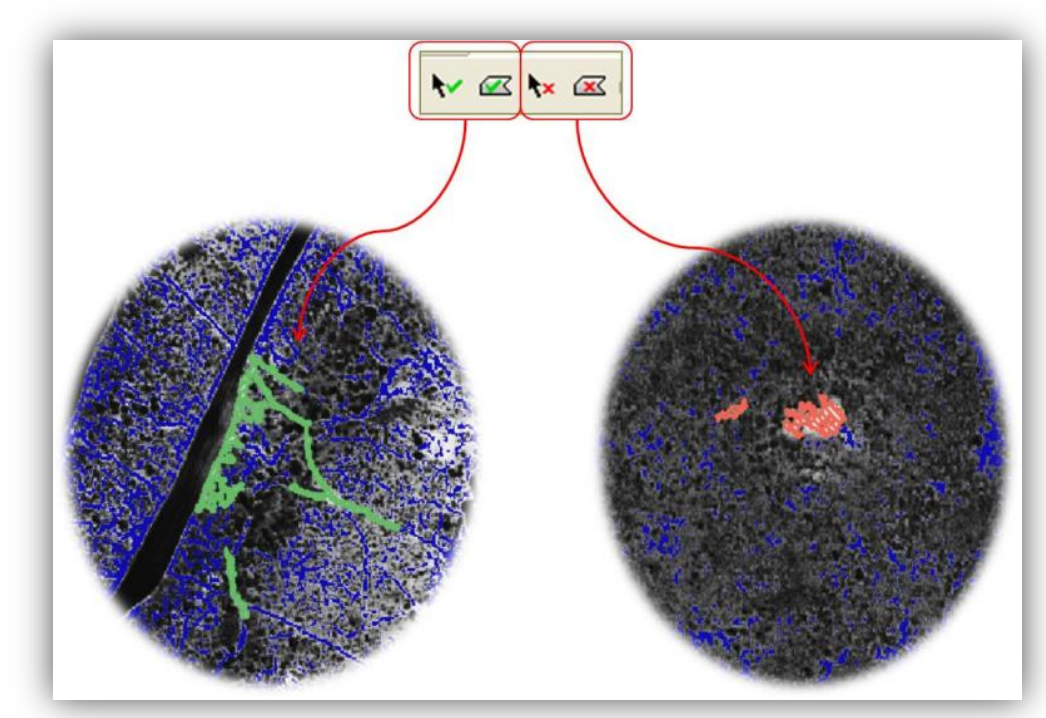

Figure 5-25: Remove Clutter Selection Examples

In general, the focus should be on which features to keep, rather than delete, but FA requires one feature for each (keep - delete). The user will need to turn off the old training/learning layers as new ones get added to avoid confusion.

c) Once a selection of features was selected for retention or deletion, the edits needed to be saved and editing session stopped. The One Stop Learning Tool

$\$$ would complete this step by creating a new feature dataset. This was an iterative process and was repeated until satisfactory results were reached. The user may want to run this step several times and then continue, because the following aggregation step weeds out many of the unwanted 'speckle' features. The user can also skip the Remove Clutter step if the current results are acceptable.

6. The resulting dataset from the previous step was edited using the Aggregation Tool to further remove outliers. This tool removes features or holes that are smaller than a size designated by the user. The tool was accessed by selecting the 
FA drop-down menu, selecting Post Processing, and selecting Aggregate Features (see Figure 5-26). If the user was still in an edit session the program would request the user save and stop editing.

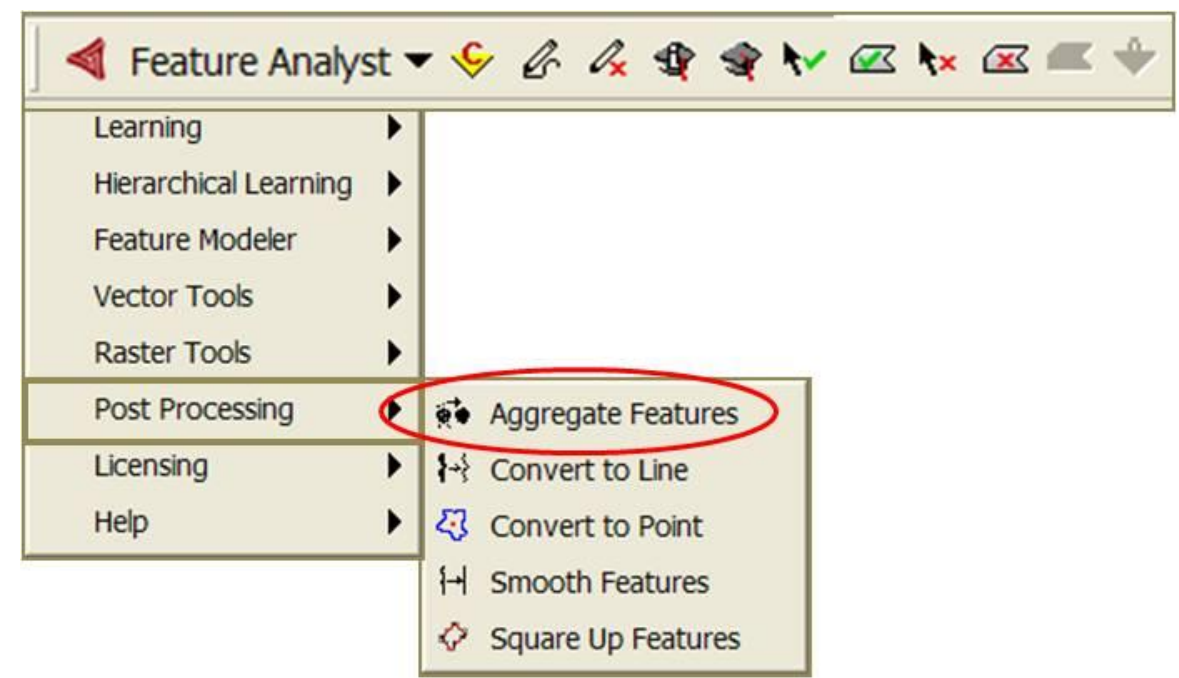

Figure 5-26: Aggregate Features

a) The range of values used for this project was between 5 and 15 . Generally, running several values was useful in determining which value produced the best results (see Figure 5-27).

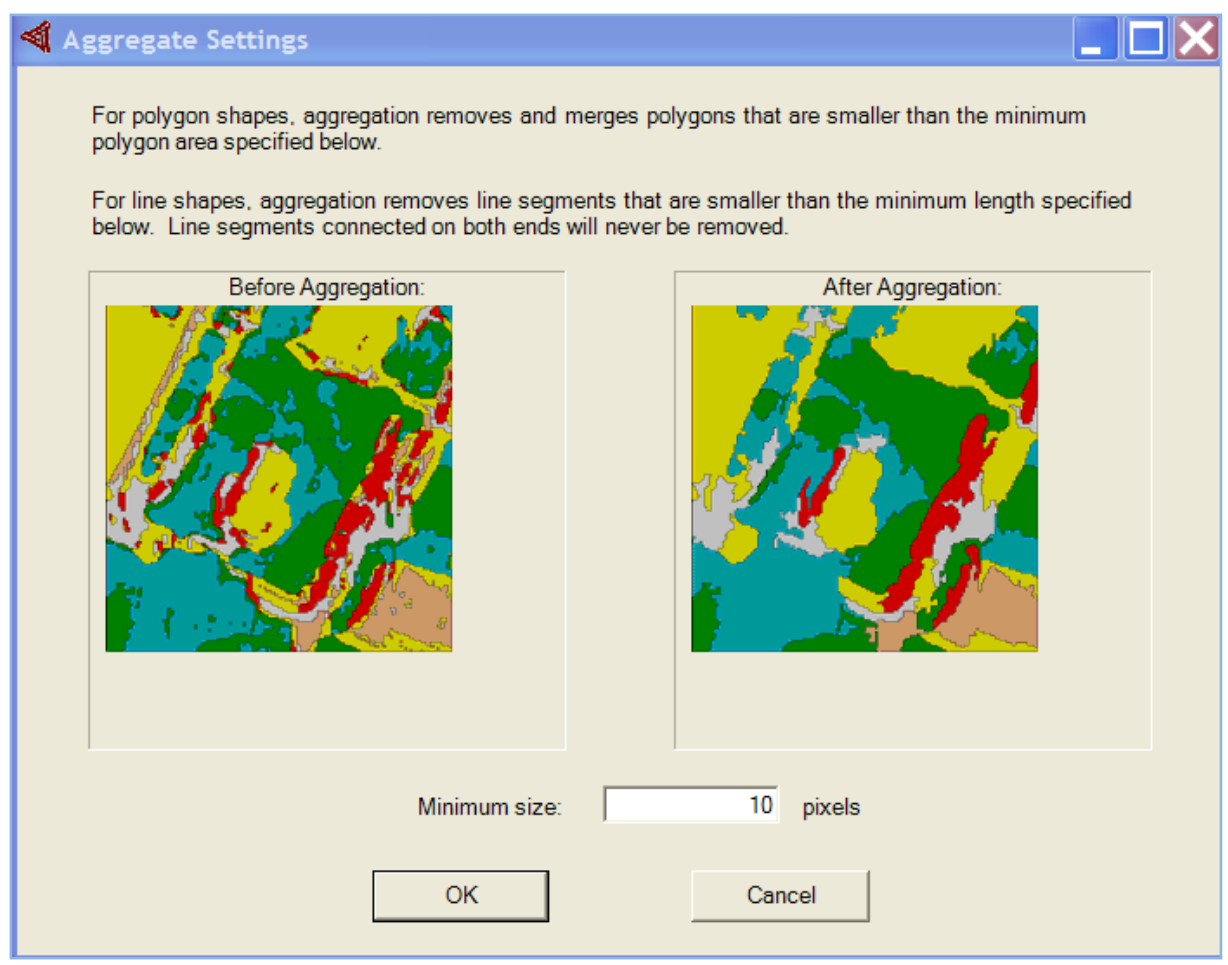

Figure 5-27: Aggregate Settings Window 
Again, the feature class that this aggregation was being conducted on needed to be selected first. The naming convention used to keep track of which aggregation values were used was: jul_train_Lrn5_Rmv_Lrn_Agg_10.shp.

7. The next step was to convert the polygon file to polyline feature class. The tool was accessed by selecting the FA drop-down menu, selecting Post Processing, and selecting the Convert to Line Tool (see Figure 5-28).

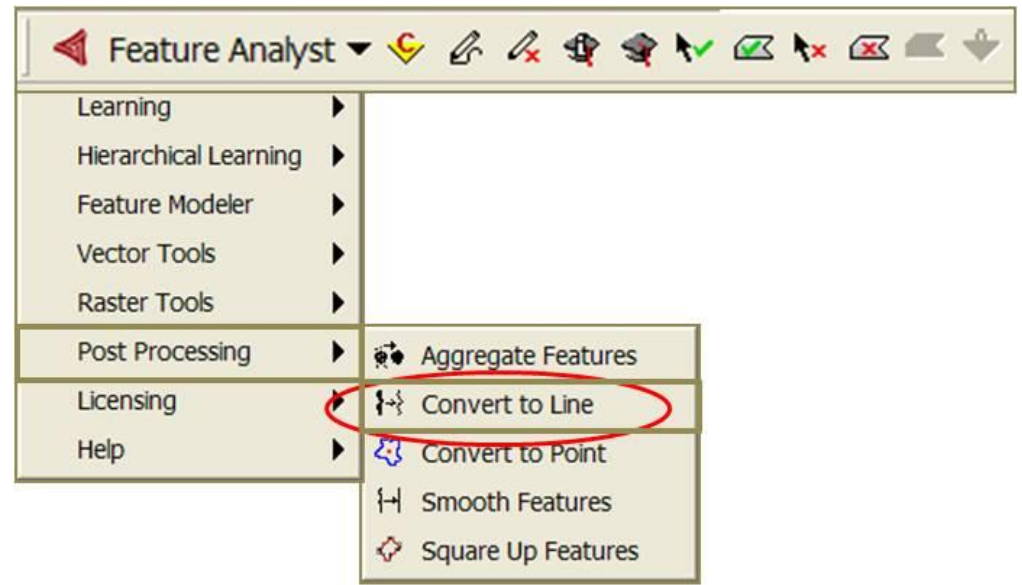

Figure 5-28: Convert to Line Tool

a) Several changes needed to be made within the Convert to Line menu. First, the polygons represent road networks and smooth resulting lines check-boxes should be un-checked. Second, the Gap jumping distance was set to 6 pixels (3.6 meters). Third, the Removes dangles with length less than $X$ pixels was set to at least 7 (4.2 meters), but no more than 10 (6 meters). Finally, the $R e$ work intersection segments with length less than $X$ pixels was set to 2 (1.2 meters) or 3 (1.8 meters). These value combinations were found to work well for this project, however other combinations might yield even better results (see Figure 5-29). Figure 5-29 also had check-boxes to allow FA to automatically determine the appropriate settings. The FA default values were set to 0 pixels for all three of the distance, dangle, and length settings. No information in the reference manual was provided to explain how FA determines appropriate lengths or distances if the user allows the software to make those determinations. 


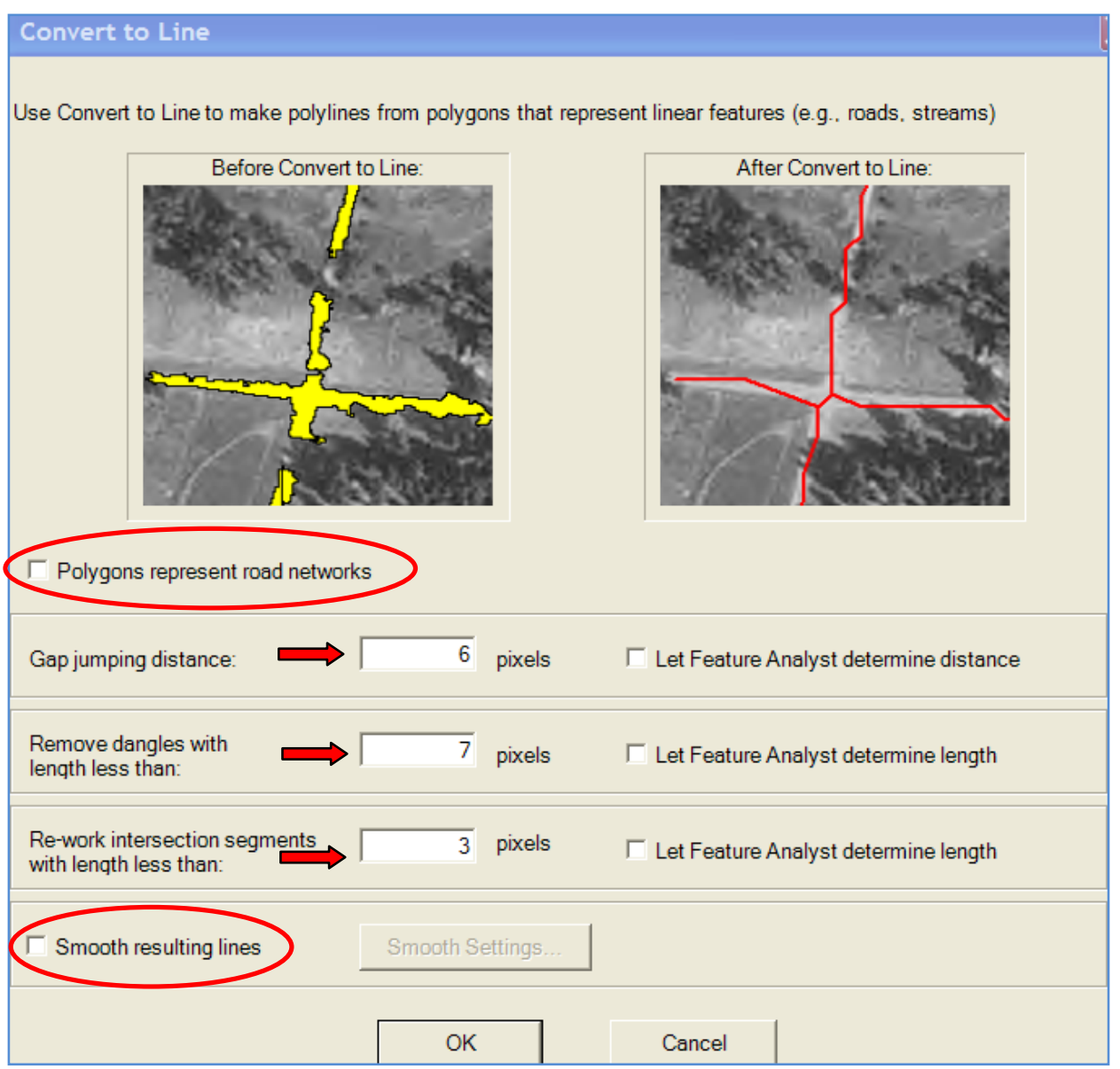

Figure 5-29: Convert to Line Window

b) The next window required the source image to be selected (see Figure 5-30). 


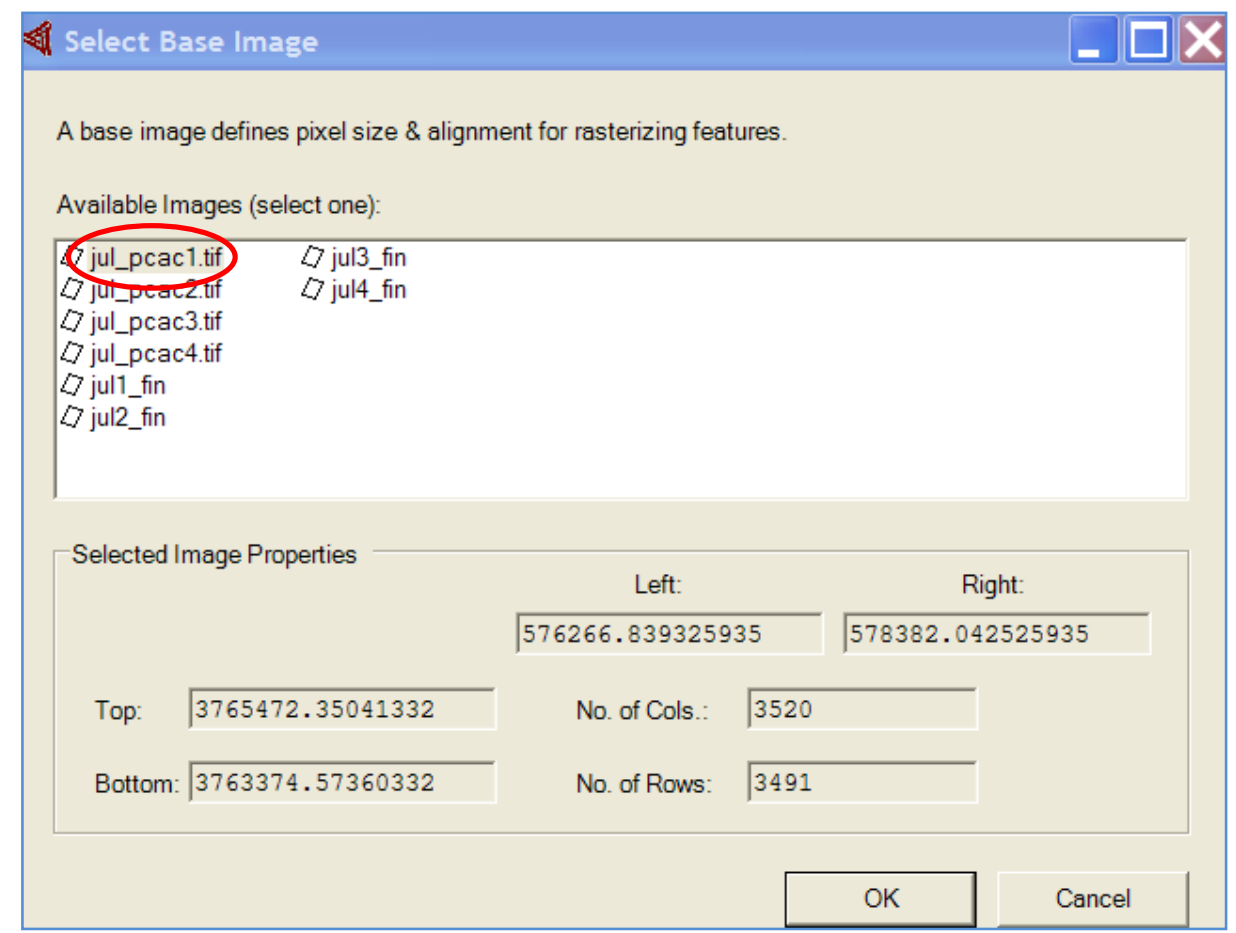

Figure 5-30: Select Base Image

The user could choose to save the line file directly to the SocialTrails feature class within the geodatabase or save it as a shapefile to verify the quality before loading it into the geodatabase.

8. The final step was to clean-up the vector line dataset by dissolving the line features, calculating the segment lengths, and deleting all lengths less than 5 meters (see Figure 5-31). Please note this step was used instead of adjusting the Remove Dangles setting in FA based on inconsistent results from FA (for that setting only). 


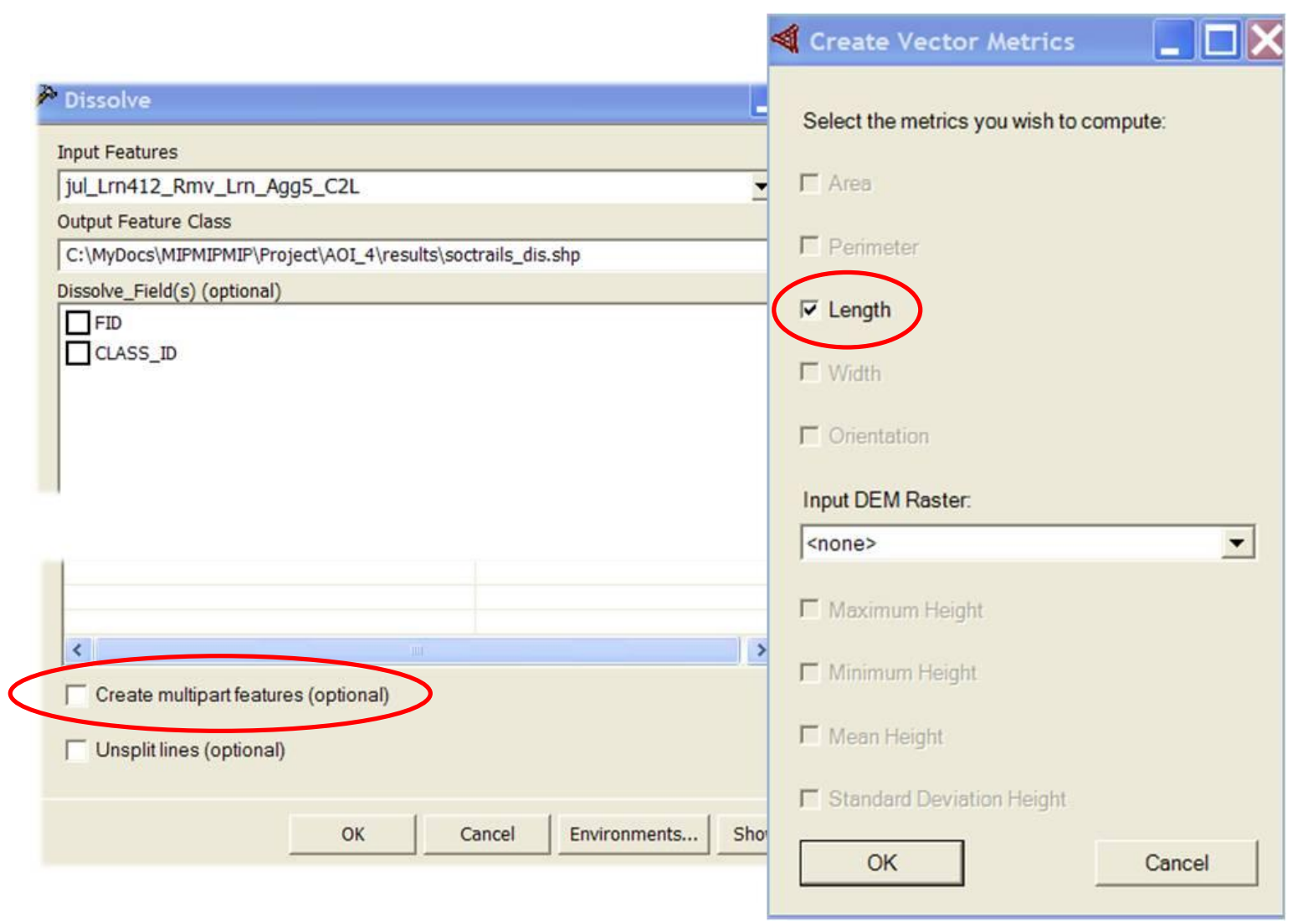

Figure 5-31: Polyline Clean-up

The dissolve process merges individual line segments that are connected into one feature so only outlier features are removed in the following steps. The Create Vector Metrics tool on the FA toolbar was used to add a length field and calculate the length of all the segments in the feature class. The final step was to use the Select by Attributes tool to select all segments with a length < five meters in length and delete those features. Deleting the shorter lengths was necessary to eliminate miscellaneous segments that were not true trail segments. The final feature class should contain only social trails with a length greater than five meters.

\subsection{Vegetation Index Creation}

A vegetation index was produced for this project to assist with future vegetation monitoring efforts. A Soil Adjusted Vegetation Index (SAVI) was used to minimize reflected soil brightness that would otherwise mask-out actual vegetation reflectance associated with the arid desert environment (Gilabert, Gonzalez-Piqueras, Garcia-Haro, \& Melia, 2002; Gong, Pu, Biging, \& Larrieu, 2003). The SAVI equation used for this project was: $(1+L) *(\mathrm{NIR})-(\mathrm{Red}) /(\mathrm{NIR})+(\mathrm{Red})+L($ Jensen, 2005$)$. The $L$ value was an adjustment value that ranged from zero for high vegetative cover to one for low vegetative cover (Gong, Pu, Biging, \& Larrieu, 2003; Jackson \& Huerte, 1991). The red and NIR bands were converted from radiance values to relative reflectance values prior to calculating the SAVI. 
Map algebra was used to formulate the equation in ArcMap. As noted in Figure 5-32, the map algebra equation used the image band layers separately to produce the desired result. As mentioned in sub-section 5.3.3, the raster calculator tool was very useful for formulating the equations.

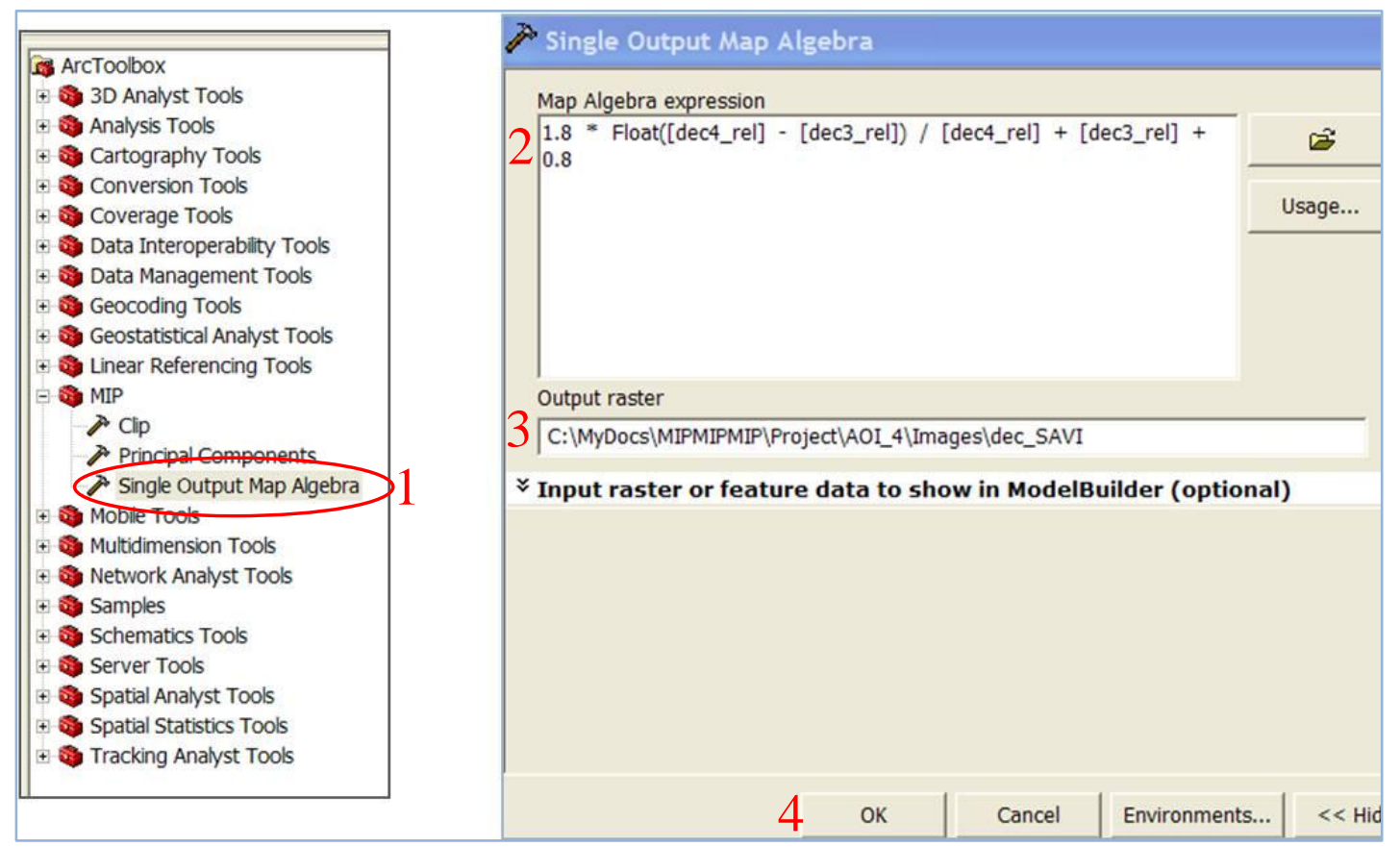

Figure 5-32: SAVI Process

The output value for SAVI ranges from -1 to 1, much like NDVI, with larger values indicating vegetation. In general, anything greater than zero could be considered vegetation.

\subsection{Summary}

This chapter discussed the methods and tools used to create a file geodatabase, a vegetation index, and a new feature class containing the social trails within that AOI. Directory structure and general environment settings were reviewed in detail. Figure 5-2 displayed a generic process workflow that was used as a guide for the rest of the chapter. Each step within the process workflow figure was explained in detail with visual aids provided to supplement the textual explanation. The subsections within Chapter 5 broke down the workflow processes into geodatabase development, social trail extraction, and vegetation index creation. Each subsection described in detail how each phase of the project was implemented. Further discussion on process results and refinements will be reviewed in chapter 6 . 


\section{Chapter 6 - Results and Analysis}

The first five chapters discussed system design and the procedures that were used to accomplish the three main tasks requested by the client. This chapter will focus on results obtained and the analyses on the resulting trail feature classes. Section 6.1 discusses the vegetation index results and possible alternatives for use or collection. Section 6.2 describes the methods applied to ascertain the quality and validity of the social trails dataset. Section 6.3 discusses the social trails extraction results, method adjustments, and analyzes the quality and utility of the social trails data.

\subsection{Vegetation Index Results}

The original project plan selected the normalized difference vegetation index (NDVI) as the vegetation index deliverable, but after further research and discussion with the client the index was changed to a soil adjusted vegetation index (SAVI). The SAVI was used because it enhances vegetative reflectance values while minimizing all other values, therefore reducing the soil reflectance problem. The equation used to calculate the SAVI value was: $1.8 *(\mathrm{NIR}-\mathrm{Red}) /(\mathrm{NIR}+\mathrm{Red}+0.8)$. For this project, the 0.8 represented the $L$ variable chosen to offset the soil reflectance in lieu of the default 0.5 value that was often represented in texts and journal articles (Gilabert, Gonzalez-Piqueras, Garcia-Haro, \& Melia, 2002; Jackson \& Huerte, 1991). This $L$ value was chosen to represent the lower than average levels of vegetative cover.

Index results were classified using the Natural Breaks (Jenks) classification and displayed using a green to red color ramp. The Jenks classification is the most suitable classification to use for this type of data, because it adds class breaks that emphasize groupings within a dataset. In this case, seven breaks were used for each site. Typically, SAVI results are represented by a reflectance range from zero to one. However, because of the relative reflectance conversions the SAVI results had slightly different ranges. The vegetation indices produced noticeably different results depending on the image date. Based on these differences, it is imperative to maintain an imaging schedule for areas of concern, rather than using random available imagery. The problem that is very noticeable in the SAVI screenshots is that each site displayed different results, and there did not seem to be any pattern between the dates (see Figures 6-1 through 6-3). It also appears that sun angle or time of day had a significant effect on the index results, because of the large shadows.

The AOI 4 site seemed to be an enigma for the vegetation indices (see Figure 6-1). The SAVI value range is significantly larger than the other two sites and there seem to be significant differences between the two dates for AOI 4. Shadows are apparent around the larger rocks on the December image, but the rocks do not seem to even be present in the July image. A possible explanation for these differences could be a small rain storm passed over this area without affecting the other sites causing a sudden bloom of vegetation in that one region. 

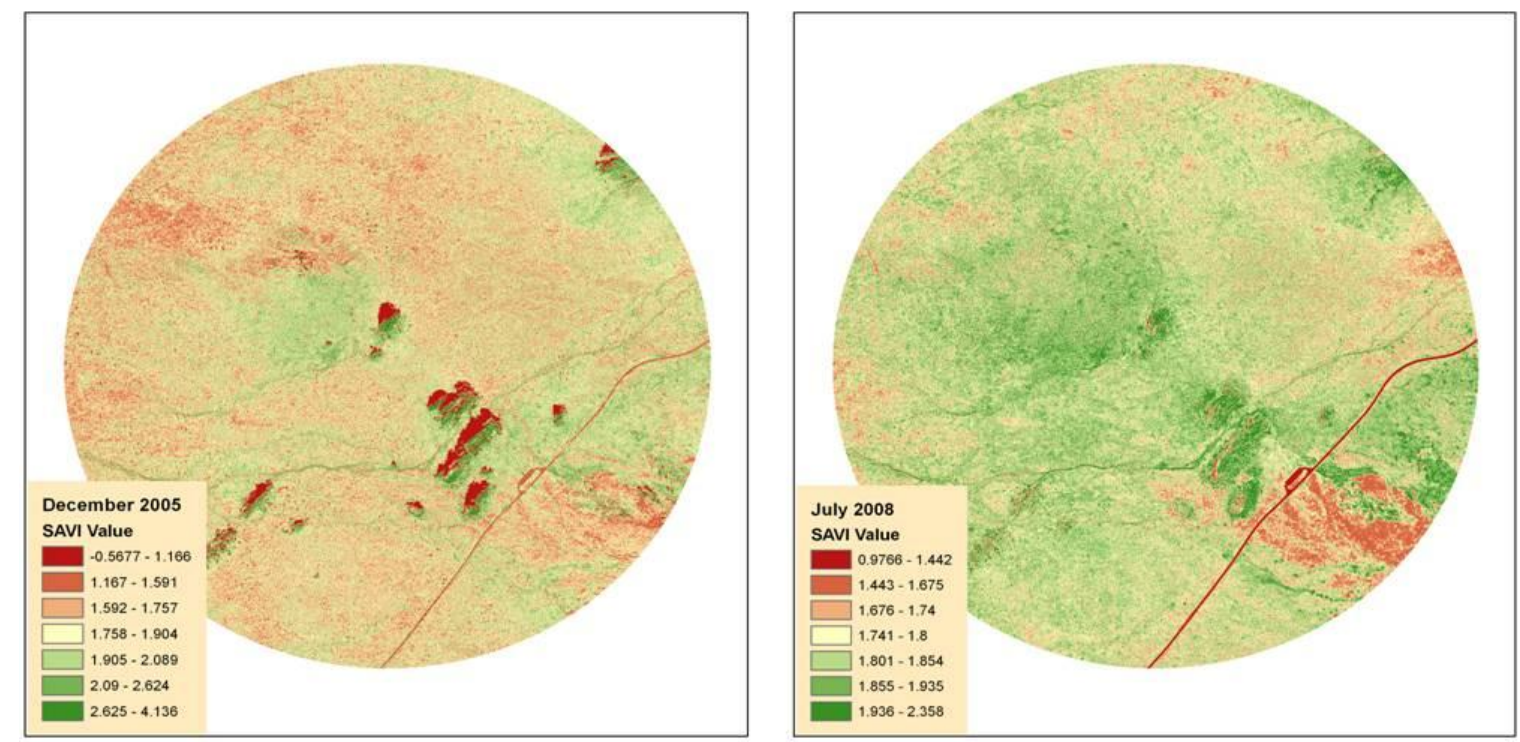

Figure 6-1: AOI 4 SAVI Result

The Jenks classification with 7 breaks was used to highlight the vegetation within each site. Specifically, the Ryan and Hidden Valley sites were representative of the expected 0 to 1 reflectance range (see Figures 6-2 and 6-3). The change from the reddish-orange to yellow-green indicates a gradual increase toward vegetation.
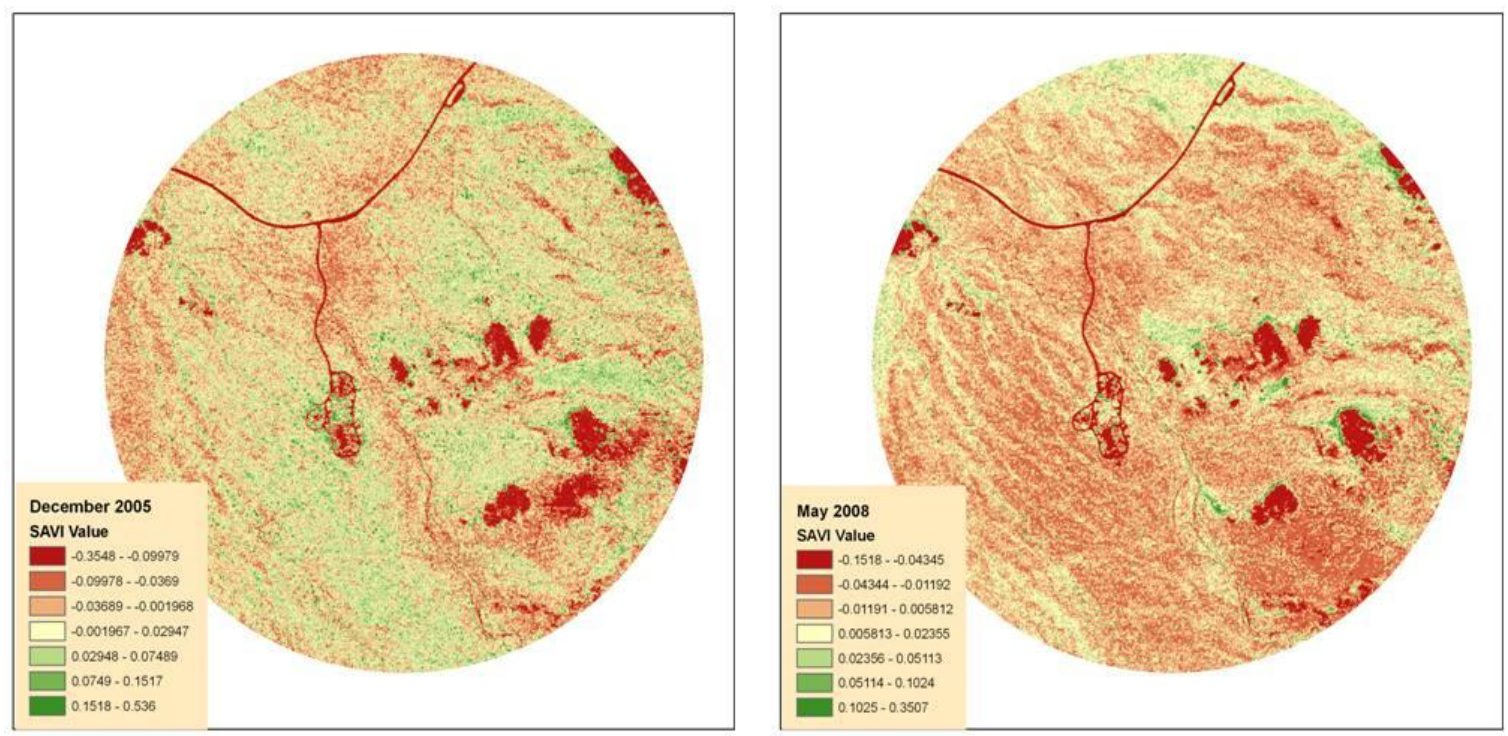

Figure 6-2: Ryan SAVI Results 

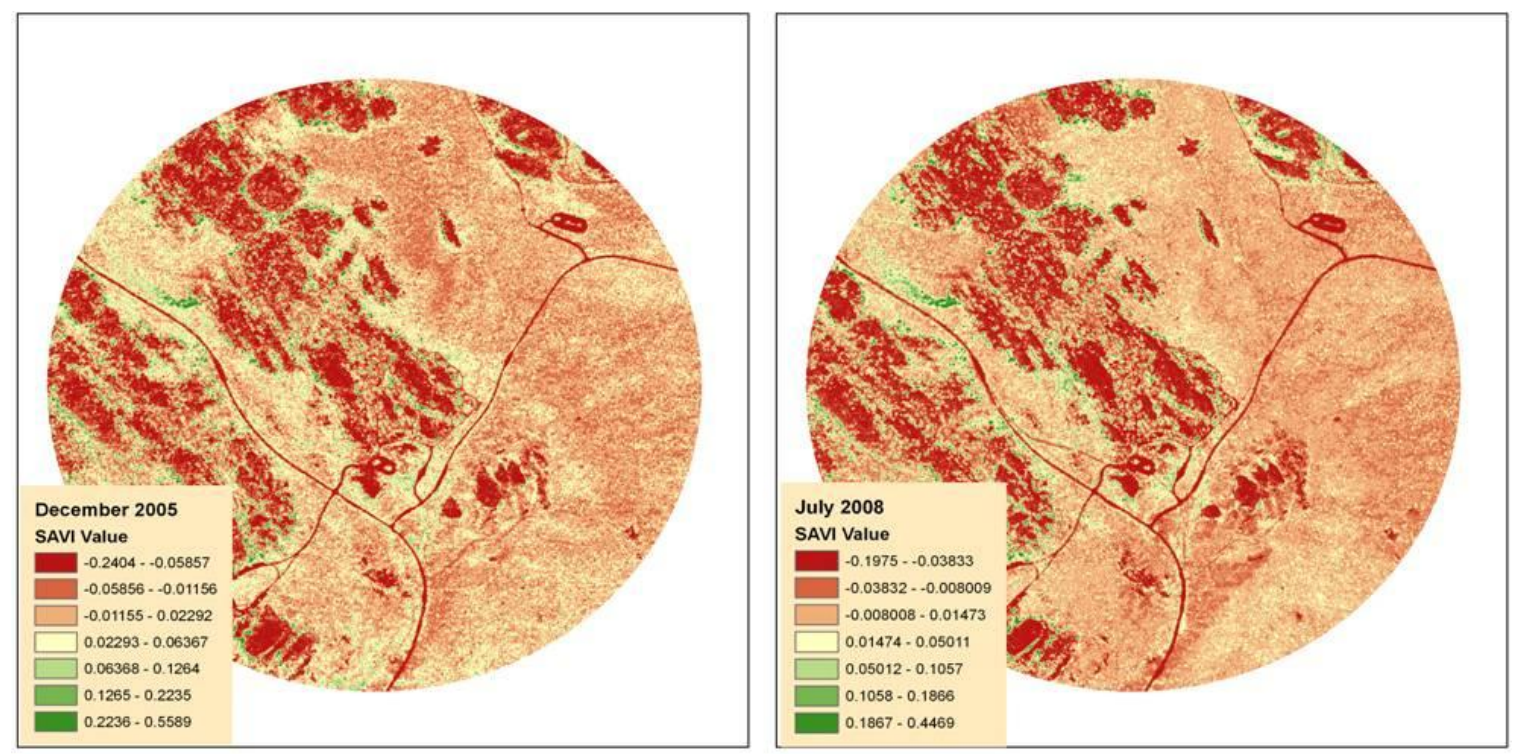

Figure 6-3: Hidden Valley SAVI

For the purpose of monitoring social trail disturbance effects on surrounding vegetation, sufficient data could be attained from peak growing season images. It is assumed that during peak growing season any disturbance effects could be easily identified. Discussion with vegetation scientists at JTNP may provide further insight into these results. The client was notified of these discrepancies, but at the completion of the project no answer or solution had been provided.

\subsection{Social Trails Quality Control (QC) Methods}

The extracted social trails were validated for quality using several different methods. First, throughout each FA process the results were visually reviewed and deemed either acceptable or unacceptable. If the results were unacceptable the process was re-run until acceptable results were achieved. This visual QC method was used to monitor the feature extraction progress of each AOI site, therefore eliminating lengthy edits to the final product. The value of reviewing the results from each FA process could mean saving several hours of re-processing after the final results are reviewed and found unacceptable.

Second, to remove as many of these inaccuracies as possible, a dissolve operation was performed on the dataset to merge the connecting segments into single linear features. Due to the nature of using a hierarchical learning process (Feature Analyst) to extract social trails, a certain amount of miscellaneous segments were expected to be extracted as trails. The miscellaneous segments generally were rocks or random soil patches that were prone to be mistakenly extracted as trails. Although every precaution was taken to clean the dataset prior to converting to lines, the miscellaneous segments were unavoidable. The dissolve function was also an attempt at weeding out the shorter non-trail segments, since it was assumed the longer segments were legitimate trails. The segment lengths were calculated and all segments below five meters were deleted. The decision to use five meters was somewhat arbitrary, but was an intermediate value below which shorter segments were not actual trails. 
The final QC method used for this project included using the GPS_SocialTrails feature class that was collected by JTNP. This dataset was used as a ground truthing mechanism; however, it was acknowledged by the client that there may have been some missed social trails in their GPS collection. This stage in the QC process was more of a validation of the overall quality of the social trails data, rather than an actual ranking of the accuracy or quality. This type of feature extraction data is extremely difficult to definitively rank or grade, therefore an overall review of the results was performed.

\subsection{Social Trails Results and Analysis}

The feature extraction portion of the project involved several iterative steps using the FA extension. As each step progressed, the extracted features became more trail-like and less random in nature (see Figures 6-4 and 6-5).

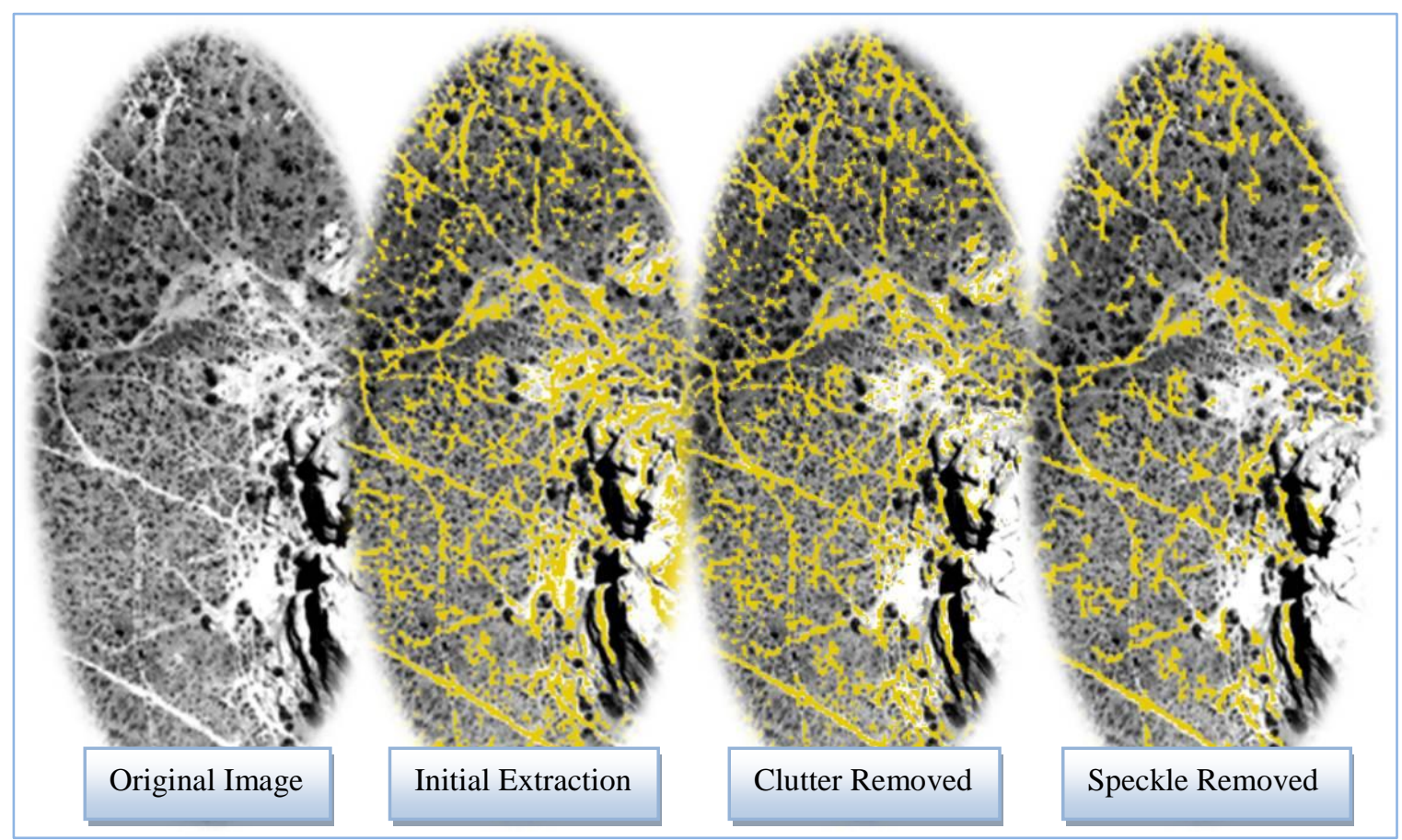

Figure 6-4: Social Trails Results 1 


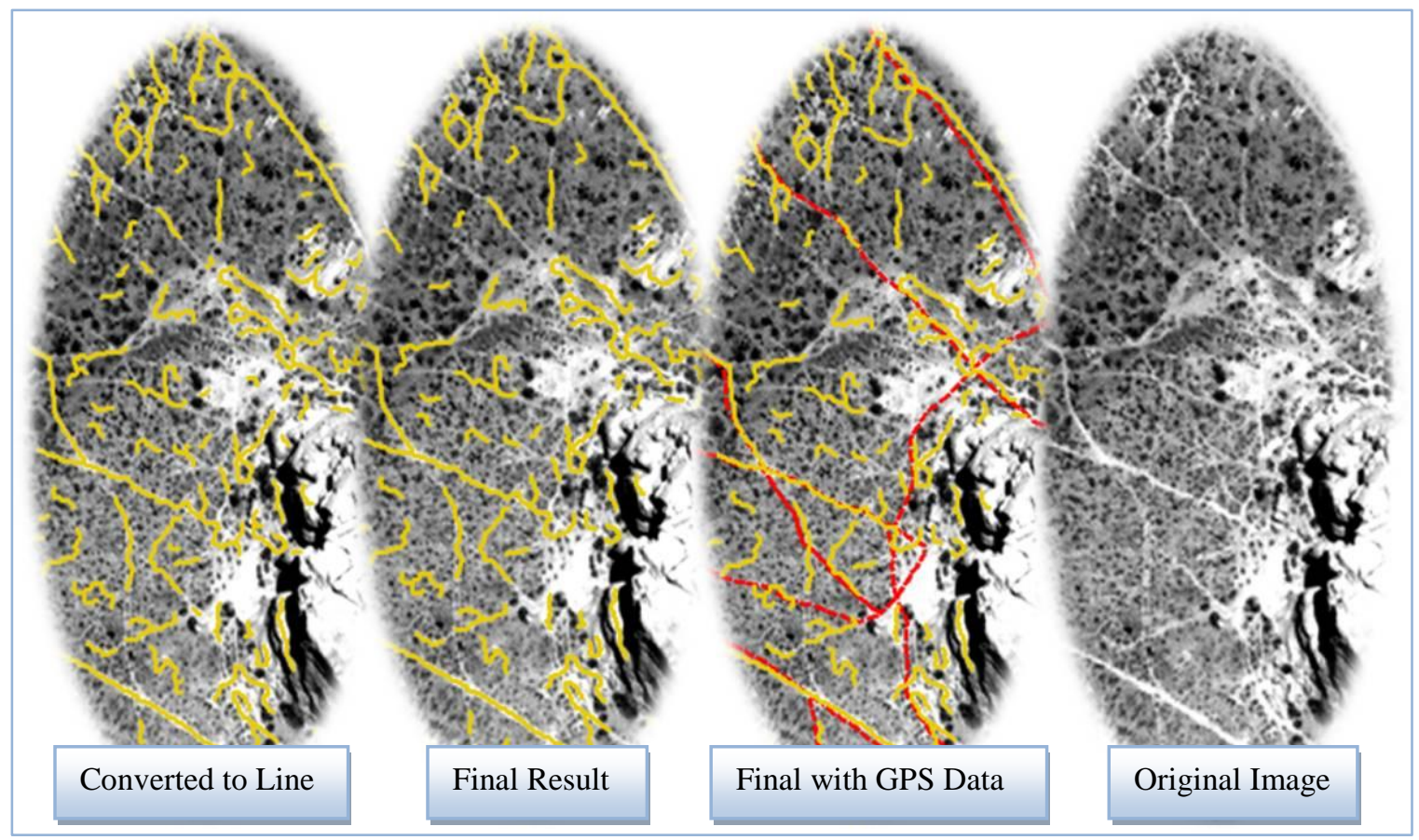

Figure 6-5: Social Trails Results 2

\subsubsection{Initial Extraction}

The initial extraction result, as seen in Figure 6-4, included a significant number of features that were not trails. Specifically, rocks and large soil covered areas were a continual issue when trying to extract out trails. Other areas that always caused problems were more sparsely vegetated locations that had natural bare soil areas. There also seemed to be a trend toward the more disturbed areas presenting better results than less disturbed areas.

The limitations of this process could be minimized by cropping out only the specific regions of interest, thereby not including the large rocks and boulders or vast regions that are not disturbed. Although initial results may appear too cluttered and include undesired features, this step is iterative and can be repeated for better results. It is important to note that the initial extraction is often excessively cluttered, but after the steps taken in sub-section 6.3.2 the trail features become more apparent.

\subsubsection{Clutter and Speckle Removal}

The remove clutter and remove speckle (aggregation) steps in Figure 6-4 resulted in a significant reduction of non-trail features. Specifically, the remove clutter tool allows the user to select features that are correctly extracted and features that are not correctly extracted. Essentially, the user is providing greater detail to the FA algorithm to correctly extract only trails. The speckle or aggregation tool removes features that don't meet a minimum pixel size, which is very useful in removing miscellaneous features.

A limitation of these two processes was that occasionally the algorithm would remove far more than was intended, or not remove enough. This dilemma was probably a result of the region of this study, which was dry, arid, sparsely vegetated, and very 
rocky. The spectral signatures between rocks, over-used trails, and streambeds were very similar, which in turn resulted in all of those features being identified as trails.

\subsubsection{Line Conversion and Final Result}

The final steps in the extraction process included converting the polygon features to linear features. The line conversion image in Figure 6-5 shows all the linear features extracted. As mentioned in Section 6.3.2, there were still short segments of remaining speckle features that did not get deleted. Using the Create Vector Metrics tool from FA, after the dissolve operation, every segment was measured and all features below five meters were deleted. Getting rid of the features below five meters in length greatly reduced the number of stray segments in the final dataset.

The final result with the GPS data in Figure 6-6, shows how the accuracy of the extracted trails has been significantly improved by refining the procedures. Although there are obviously some inaccurate segments extracted as trails in the image (highlighted in blue), there are also legitimate trails that the GPS data did not capture, as highlighted in green. This process attempted to semi-automate feature extraction with mixed results. The most important lesson learned from this project was that technology cannot eliminate the need for human review. This fact was demonstrated by both the FA results as well as the GPS data.

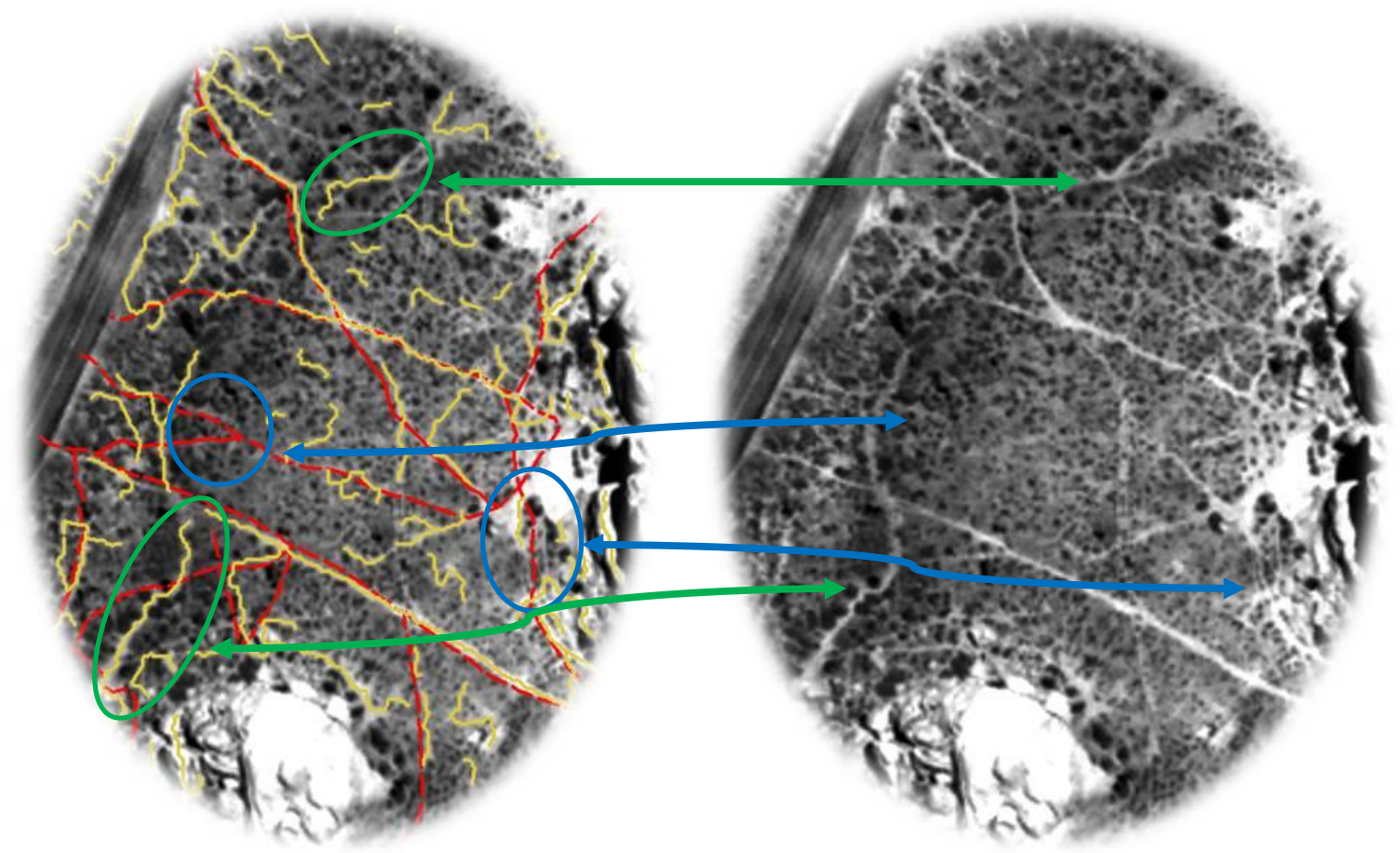

Figure 6-6: Hidden Valley Results

In general, training the algorithm to correctly extract the desired features was a difficult and frustrating task, but the end results were acceptable. The most difficult issue with this process was that the output from FA included numerous erroneous segments, as demonstrated in Figure 6-6. Less disturbed areas, like AOI 4 in Figure 6-7, produced more erroneous results which were most likely a result of scattered vegetation. The 
actual trail features are continuous segments, but FA does not have the capability to "learn" which segments should be connected. The FA toolbar has a Connect Lines tool that should connect features that are within a designated distance, but through this project it was discovered this tool does not work. A ticket was logged with the IT staff at VLS, Inc. to remediate this bug, but until they fix this tool there is no simple way to connect the random segments.

A possible work-around until the Connect Lines feature works consistently would be to load the dissolved social trails feature class into a geodatabase and create topology rules for pseudo nodes, overlaps, and intersects. Rerunning the FA length calculator should also provide more accurate data.

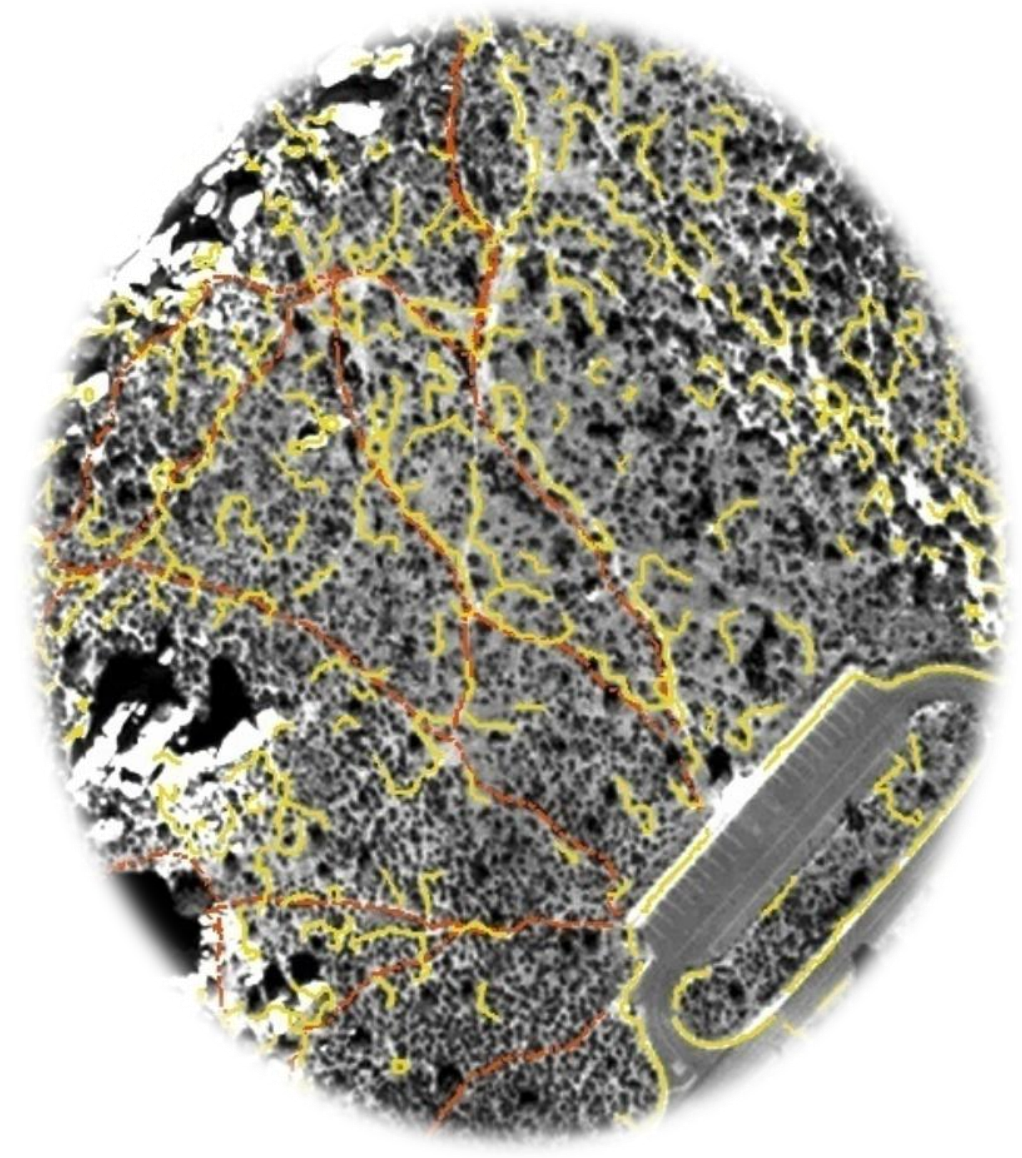

Figure 6-7: AOI 4 Miscellaneous Segments

\subsection{Summary}

This project set out to develop a vegetation index for disturbance monitoring, a master geodatabase of the park, and a set of tools and methods to extract social trail networks from imagery. Each of these objectives was met. A soil adjusted vegetation index was used to emphasize the small amounts of vegetation in the arid desert environment over the soil reflectance values. A baseline file geodatabase was developed to contain all the social trails data extracted from the imagery, in addition to other related feature datasets.

Finally, a set of tools and methods was developed that allows a user to extract social trail networks from imagery, rather than requiring GPS fieldwork. All tools and 
methods were created using ERSI software, which was originally a concern due to the intense image processing requirements of this project. The resulting feature datasets often met or exceeded expectations by correctly extracting trails where GPS trails data had been collected and occasionally extracting trails missed by the GPS trails data. The main problems with the FA trail extraction methods were, 1) the inability to connect line segments in an automated fashion, and 2) misrepresenting random soil patches as social trails. 


\section{Chapter 7 - Conclusions and Future Work}

The primary goal for this project was to develop a set of tools and methods that could assist JTNP staff with their recreation and vegetation monitoring programs. Specifically, the client was looking for a way to more efficiently and economically monitor social trail development and its effects on the surrounding vegetation using GIS and remote sensing techniques. With this in mind, the project was developed using imagery as the main component for feature extraction from an ESRI system with the Feature Analyst (FA) and Spatial Analyst extensions. The implemented tools and methods in the project enabled the client to monitor large regions of the park with less effort than field data collection.

\subsection{Project Results}

This project successfully met the goal of monitoring large regions of the park without expending large amounts of time or money. Contributions included a methodology to create a Soil Adjusted Vegetation Index (SAVI), a park-wide geodatabase, and a set of tools and methods to extract trails from remotely sensed data using ESRI software. The following subsections discuss the main results of the project.

\subsubsection{Vegetation Index}

The development of a vegetation index for this project was done in response to requests from the client. Originally, a normalized difference vegetation index (NDVI) was going to be used for this project, but after further research it was determined that a soil adjusted vegetation index (SAVI) would be more appropriate for an arid environment. When comparing the two indices, SAVI more accurately represented the vegetation reflectance values by minimizing the non-vegetation reflectance values. This was significant because in arid environments like JTNP the vegetation reflectance is often overpowered by the more prevalent soil reflectance.

Based on the SAVI results for each AOI (Section 6.1), further research was suggested to determine the best season or date for these analyses to avoid inconsistencies between sites and dates. Interpretation of the SAVI data was also a concern, due to the lack of supporting data such as species composition and morphology. Useful datasets for analyzing the SAVI results include California Gap Analysis data and soil layer data from JTNP. However, if the user views SAVI and trails data at similar scales, it is possible that disturbance trends will become identifiable.

In general, past literature indicates that very little is known about arid reflectance characteristics or other spectral values when being analyzed for social trails. However, at completion, a new respect for spectral and vegetation scientists and their knowledge was certainly earned. The nature of vegetation reflectance and how sensitive desert plants can be to temperature and moisture create a challenge for scientists to identify specific trends rather than random weather events. The SAVI process developed can be replicated and used for future analysis, which fulfills the functional requirements for a vegetation index. 


\subsubsection{Social Trail Extraction}

A set of tools and methods was developed to perform social trail extraction from QuickBird imagery. This task was accomplished using a combination of the Spatial Analyst extension and the Feature Analyst (FA) extension from Visual Learning Systems, Inc., as well as out-of-the-box functionality from ArcMap. The FA extension uses hierarchical learning algorithms to delineate features based on spectral and geometric signatures obtained from training data.

The FA tools were initially used to pull out broad samples of features that were similar in spectral or geometric value to the training data. The FA toolset was then used to gradually eliminate incorrect features until the final result was a line feature class. An important note to consider was that this process was iterative, and could be edited numerous times, with each time leading to slightly different results. With respect to the efficiency of this task, it will depend on user skill and experience.

Past studies showed that trail extraction would require either heads-up digitizing or walking the trails with GPS units. However, this project was conducted without using GPS units or digitization from imagery to extract the trails. The GPS social trails data provided by the client was used solely for verification purposes. Therefore, this project demonstrated that social trails can be extracted effectively from imagery without the need to walk every social trail.

Although the results in Section 6.3 show that not every social trail was detected exactly as it is on the ground, the final result was still acceptable, and therefore, the method was feasible. An important point to note is that the trails extracted will only be as good as the training data provided for the processing. Therefore, precise training data is the key to getting satisfactory results within one or two attempts. Another difficulty with feature extraction was that other ground features were extracted as trails because they had similar reflectance values as the training data. For example, naturally occurring dirt areas surrounding shrubs or rocks were often extracted as trails.

The decision to use ESRI with FA over other products such as ENVI, ERDAS Imagine, or Definiens resulted from the client already owning ESRI software, and its ease of use for non-GIS/remote sensing users. The FA software and maintenance costs average $\$ 6,600$ - $\$ 13,200$ per year, which may or may not be financially feasible, however the benefits over time could outweigh the cost. The FA tasks also require very little image processing knowledge. Attempting to identify and extract social trails in an environment consisting mostly of soil and rock was a daunting task, specifically when coupling it with automation capabilities, but it was possible. Although the results were not always perfect, they were acceptable, and were useful for helping park staff quickly examine social trail changes for large regions with moderate accuracy.

\subsubsection{Master Geodatabase}

The third main deliverable for this project was a master file geodatabase. Creation and loading of the master file geodatabase was completed with very few problems.

Topologies were created to clean up any miscellaneous errors with the vector data, and metadata were loaded directly from the associated text files. The conceptual model behind the geodatabase was functional in nature. There were three feature datasets in the geodatabase: Transportation, Recreation, and Hydrology. Each dataset was developed 
and populated based on functional relationship. For example, roads, trails, and other movement or traversing-related features were placed in the transportation dataset. This functional concept led to a very simple but data heavy geodatabase.

\subsection{Future Work}

This project has provided JTNP with a set of tools and methods to extract social trails from QuickBird imagery. However, there are many opportunities for future work. As can be seen from the results in Chapter Six, there is room for improvement. In addition to benefiting JTNP, the methods used and future work suggestions can apply to any natural space, not just JTNP. Below are four suggestions for future work.

First, the analysis and methods were tested on only one 28 square kilometer region within the park. Testing these methods against different terrain elevations, uselevels, and ecoregions within the park would more adequately evaluate the utility of this type of product. The iterativeness of this process, specifically with FA, makes it necessary to run the processes multiple times to find optimal settings for regions that have different physical characteristics. The optimal settings can be used as a reference for other similar studies.

Second, further research into remote sensing techniques of arid environments, specifically for trail feature extraction, could lead to improved extraction results. Suggestions include testing different image transforms other than PCA with the FA process, fusing PCA results with other image transform data to enhance trail features, or improving on the SAVI equation used. Investigating alternative vegetation indices may also provide better results.

Third, this project was conducted using ArcGIS 9.3.1. Future versions of ArcMap have already indicated increased image processing capability, which could be very useful to this type of project. Several techniques to improve results were not used for this project because of image processing limitations with ArcMap. Suggested enhancement techniques include performing spectral tasseled cap analysis and/or applying edge enhancement or high pass spatial filters. Witztum and Stow (2004) recognized the usefulness of these techniques in their study of recreation impacts on coastal sage scrub habitat. The tasseled cap transform was referenced using QuickBird imagery by Witztum and Stow (2004), and Yarbrough et al. (2005).

Finally, the FA extension comes with the capability to create batch processes and record all processes and parameters to create models to be used for automation purposes. There are also capabilities within ArcMap using ModelBuilder or Python scripting to automate many of the steps used in this project. Although a specialized ArcToolbox and model were included with this project there are many more automation techniques that could be applied to speed up the data-prep and feature extraction processes. During feature extraction processing FA puts a tremendous load on the CPU and it became difficult to perform any other work on that computer until the processing was completed. With that in mind, another possible benefit to automating the feature extraction portion would be the ability to run the program over low use time periods (e.g. nights or weekends). 


\subsection{Summary}

Joshua Tree National Park was looking for an economical and efficient method to examine recreation disturbance effects on vegetation and trails. Using geographic information systems (GIS) and remote sensing techniques, a set of tools and methods were developed to aid in the monitoring and extraction of social trails within the park. These methods resulted in a baseline geodatabase, vegetation indices, and a toolset to extract trails from imagery, all of which enable the client to track vegetation and trail changes through time. This project successfully fulfilled the client's requirements and may be improved in the future. 


\section{Works Cited}

Aronoff, S. (2005a). Characteristics of remotely sensed imagery. In S. Aronoff, Remote Sensing for GIS Managers (pp. 69-110). Redlands: ESRI Press.

Aronoff, S. (2005b). Remote sensing basics. In S. Aronoff, Remote Sensing for GIS Managers (pp. 53-68). Redlands: ESRI Press.

Belnap, J. (1995). Surface disturbances: Their role in accelerating desertification.

Environmental Monitoring and Assessment, 37 (1-3), 39-57.

DOI:10.1007/BF00546879.

Bolstad, P. (2008a). Chapter 14: Data Standards and Data Quality. In P. Bolstad, GIS Fundamentals: A First Text on Geographic Information Systems, Third Edition (pp. 511-532). White Bear Lake: Eider Press.

Bolstad, P. (2008b). Chapter 4: Maps and Data Entry. In P. Bolstad, GIS Fundamentals A First Text on Geographic Information Systems Third Edition (pp. 123-169). White Bear Lake: Eider Press.

California Native Plant Society. (1999). Vertical Veg: A partnership project to address resources protection and quality visitor experience in rock climbing areas of Joshua Tree National Park. Retrieved October 18, 2008, from California Native Plant Society: http://www.cnps.org/cnps/conservation/pdf/Vertical.pdf

Cao, L., Stow, D., Kaiser, J., \& Coulter, L. (2007). Monitoring cross-border trails using airborne digital multispectral imagery and interactive image analysis techniques. Geocarto International, 22 (2), 107-125.

Cole, D. N. (1983, February). Assessing and monitoring back-country trail conditions. Retrieved October 17, 2008, from http://dtl.lib.umt.edu/cgibin/showfile.exe?CISOROOT=/forest $\&$ CISOPTR=12\& filename=13.pdf

DiBiase, D. (n.d.). Chapter 5: Land Surveying and GPS. Retrieved June 28, 2009, from Pennsylvania State College of Earth and Mineral Sciences: Nature of Geographic Information Web site: https://www.eeducation.psu.edu/natureofgeoinfo/c5_p4.html

DigitalGlobe. (2009). DigitalGlobe Standard Imagery. Retrieved June 27, 2009, from DigitalGlobe Web site:

http://www.digitalglobe.com/file.php/684/DG_Products_Standard_Imagery_web. pdf

ESRI. (n.d.). Geographic Transformations. ArcGIS v9.3 Documentation . Redlands, California, United States of America.

Gilabert, M., Gonzalez-Piqueras, J., Garcia-Haro, F., \& Melia, J. (2002). A generalized soil-adjusted vegetation index. Remote Sensing of Environment, 82, 303-310.

Gong, P., Pu, R., Biging, G., \& Larrieu, M. (2003). Estimation of Forest Leaf Area Index Using Vegetation Indices Derived From Hyperion Hyperspectral Data. IEEE Transactions on Geoscience and Remote Sensing, 41 (6), 1355-1362.

Jackson, R., \& Huerte, A. (1991). Interpreting vegetation indices. Preventive Veterinary Medicine, 11, 185-200.

Jensen, J. (2005). Image Enhancement. In J. Jensen, Introductory Digital Image Processing, Third Edition (pp. 255-329). Upper Saddle River: Pearson Prentice Hall. 
Jewell, M., \& Hammitt, W. (2000). Assessing Soil Erosion on Trails: A Comparison of Techniques. USDA Forest Service Proceedings, (pp. 133-140).

Joshua Tree National Park. (2003, 01 22). index_24k metadata. FGDC CSDGM Standard. USGS.

Kim, M. K., Ednie, A. J., \& Daigle, J. J. (2006). Detecting vegetation change using multtemporal aerial photographs at Cadillac Mountain in Acadia National Park, Maine. Proceedings of the 2006 Northeastern Recreation Research Symposium (pp. 300-306). Gen. Tech. Rep. NRS-P-14. Newtown Square, PA: U.S. Department of Agriculture, Forest Service: http://www.treesearch.fs.fed.us/pubs/12693.

Klang, D. (1998). Automatic Detection of Changes in Road Databases using Satellite Imagery [Electronic Version]. ISPRS Commission IV Symposium on GIS Between Visions and Applications, 32/4, pp. 293-298. Stuttgart, Germany.

Leung, Y., \& Marion, J. L. (1999). Assessing trail conditions in protected areas: application of a problem-assessment method in Great Smoky Mountains National Park, USA. Retrieved October 17, 2008, from Environmental Conservation: http://cat.inist.fr/?aModele=afficheN\&cpsidt=1256873

Leung, Y., \& Marion, J. L. (2000). Recreation Impacts and Management in Wilderness: A State-of-Knowledge Review. RMRS-P-15-VOL-5. 2000 . RMRS Online Publications.

Lindsey, G., Wilson, J., Rubchinskaya, E., Yang, J., \& Han, Y. (2007). Estimating urban trail traffic: Methods for existing and proposed trails [Electronic version]. Landscape and Urban Planning, 81 (4), 299-315.

Marion, J. L., Leung, Y., \& Nepal, S. K. (2006). Monitoring Trail Conditions: New Methodological Considerations. The George Wright Forum , 36-49.

Miller, A. (n.d.). Designate Access Trails and Restore Social Trails in fragile Desert Landscapes. NPS. PMIS \#146864.

Miller, A. (2008, October 1). MIP Client Meeting. (J. Lee, Interviewer)

Morris, S., \& Barnard, K. (2008). Finding Trails. Computer Vision and Pattern Recognition, 1-8.

Murdock, E. (2004). Understanding Recreation Flow to Protect Wilderness Resources at Joshua Tree National Park, California. Second International Conference on Monitoring and Management of Visitor Flows in Recreational and Protected Areas (pp. 120-126). Finnish Forest Research Institute.

National Park Service. (n.d.). Data and Information Data Clearinghouse. Retrieved June 27, 2009, from National Park Service (NPS), US Department of the Interior: http://www.nps.gov/gis/data_info/

Nepal, S. K., \& Nepal, S. A. (2004). Visitor Impacts on Trails in the Sagarmatha (Mt. Everest) National Park, Nepal. AMBIO: A Journal of the Human Environment, 33 (6), 334-340.

Nepal, S. K., \& Way, P. (2007). Characterizing and Comparing Backcountry Trail Conditions in Mount Robson Provincial Park, Canada. AMBIO: A Journal of the Human Environment, 36 (5), 394-400.

Nepal, S. (2003). Trail Impacts in Sagarmatha (Mt. Everest) National Park, Nepal: A Logistic Regression Analysis. Environmental Management, 32 (3), 312-321. 
NPS. (n.d.). Nature \& Science. Retrieved October 11, 2008, from nps.gov Joshua Tree National Park: http://www.nps.gov/jotr/naturescience/index.htm

NPS. (n.d.). Operating hours and Seasons. Retrieved May 26, 2009, from NPS Joshua Tree National Park: http://www.nps.gov/jotr/planyourvisit/hours.htm

Okin, W. J., Okin, G. S., Roberts, D. A., \& Murray, B. (1999). Multiple endmember spectral mixture analysis: Endmember choice in an arid shrubland. Retrieved October 19, 2008, from JPL Airborne Earth Science Workshop: ftp://popo.jpl.nasa.gov/pub/docs/workshops/99_docs/46.pdf

Petrie, G. (2005). Appendix A: Rectification and georeferencing of optical imagery. In S. Aronoff, Remote Sensing for GIS Managers (pp. 421-454). Redlands: ESRI Press.

Rahman, R., Park, D., \& La Doux, T. (2007). Effectiveness of social trail closure methods in Joshua Tree National Park, A Preliminary Study. Omaha: Midwest Regional Office.

Scott, R. L. (1998). Wilderness Management and Restoration in High Use Areas of Olympic National Park, Washington, U.S.A. Retrieved May 15, 2009, from USDA Forest Service Proceedings RMRS-P-4: http://www.fs.fed.us/rm/pubs/rmrs_p004/rmrs_p004_144_147.pdf

Stow, D., Hamada, Y., Coulter, L., \& Anguelova, Z. (2008). Monitoring shrubland habitat changes through object-based change identification with airborne multispectral imagery. Remote Sensing of Environment, 1051-1061. DOI:10.1016/j.rse.2007.07.011.

Tomlinson, R. (2007). Thinking about GIS: Geographic Information System Planning for Managers, Third Edition. Redlands: ESRI Press.

Visual Learning Systems, Inc. (2007). VLS Software: Feature Analyst. Retrieved June 20, 2009, from http://www.vls-inc.com/feature_analyst.htm

Visual Learning Systems, Inc. (2008). Feature Analyst 4.2 for ArcGIS. Reference Manual. Missoula: Visual Learning Systems, Inc.

Witztum, E., \& Stow, D. (2004). Analysing direct impacts of recreation activity on coastal sage scrub habitat with very high resolution multi-spectral imagery. International Journal of Remote Sensing, 25 (17), 3477-3496.

Yarbrough, L., Easson, G., \& Kuszmaul, J. (2005). QuickBird 2 Tasseled Cap Transform Coefficients: A Comparison of Derivation Methods. Pecora 16 "Global Priorities in Land Remote Sensing", (pp. October 23-27, 2005). Sioux Falls, South Dakota. 



\section{Appendix A: Vector Layer Requirements}

\begin{tabular}{|c|c|c|}
\hline Source data name & $\begin{array}{c}\text { Project name } \\
\text { designation }\end{array}$ & Layer Description \\
\hline trails.shp & Designated_Trails & $\begin{array}{l}\text { Feature class containing all designated trails } \\
\text { within JTNP, including: Length, Type, Name, } \\
\text { Name2, Name3, Nature_Tr, Handicap, Category, } \\
\text { Source, Shape_Length }\end{array}$ \\
\hline & & $\begin{array}{l}\text { Feature class containing GPS collected social } \\
\text { trails at various regions within the park, including: }\end{array}$ \\
\hline $\begin{array}{l}\text { trail (from } \\
\text { JOTR_SocialTrails08.mdb) }\end{array}$ & GPS_SocialTrails & $\begin{array}{l}\text { Use_Code, Comment, Date_Surv, BouldArea, } \\
\text { Observer, QC, Picture, Shape_Length }\end{array}$ \\
\hline Parking_pullouts.shp & Parking_pullouts & $\begin{array}{l}\text { Feature class containing a record of designated } \\
\text { parking pullouts within the park, including: Id, } \\
\text { Name, ParkingLot, Area, RoadText, Paved, } \\
\text { Shape_Length, Shape_Area }\end{array}$ \\
\hline rds_pub2.shp & Roads & $\begin{array}{l}\text { Feature class containing roads within and around } \\
\text { the park, including: length, Roads_Name, } \\
\text { Roads_Numb, Category, Roads_Nam2, } \\
\text { Length_Mil, Road_Type, Shape_Length }\end{array}$ \\
\hline $\begin{array}{l}\text { Trail_Intersection (from } \\
\text { JOTR_SocialTrails08.mdb) }\end{array}$ & Trail_Intersection & $\begin{array}{l}\text { Feature class containing intersection points of } \\
\text { trails, including: Comment, Date_Surv, } \\
\text { BouldArea, Observer, QC, Picture }\end{array}$ \\
\hline $\begin{array}{l}\text { Trail_Transect (from } \\
\text { JOTR_SocialTrails08.mdb) }\end{array}$ & Trail_Transect & $\begin{array}{l}\text { Feature class containing trail transect } \\
\text { measurements and observations, including: Width, } \\
\text { Depth, Comment, Date_Surv, BouldArea, } \\
\text { Observer, QC, Picture }\end{array}$ \\
\hline $\begin{array}{l}\text { hydro } 24 \mathrm{k} \text { (all shapefiles } \\
\text { within folder) }\end{array}$ & Streams_24k & $\begin{array}{l}\text { Feature class containing all hydro features } \\
\text { (streams) from the hydro24k folder, including: } \\
\text { Length, Minor2, Name, Shape_Length }\end{array}$ \\
\hline bouldering.shp & BoulderingSites & $\begin{array}{l}\text { Feature class containing known bouldering sites } \\
\text { within JTNP, including: Id, Name, Lat, Long, } \\
\text { Easting, Northing }\end{array}$ \\
\hline campg.shp & CampgroundSites & $\begin{array}{l}\text { Feature class containing all campsite areas, } \\
\text { including: Name, Type }\end{array}$ \\
\hline rocks.shp & RockSites & $\begin{array}{l}\text { Feature class containing known rock climbing } \\
\text { sites, including: Rocks_, Name, Easting, Northing, } \\
\text { In_Wild }\end{array}$ \\
\hline park.shp & JTNP_boundary & $\begin{array}{l}\text { Feature class containing a polygon of JTNP, } \\
\text { including: Area, Perimeter, Id, Name, Name2, } \\
\text { Shape_Length, Shape_Area }\end{array}$ \\
\hline
\end{tabular}




\section{Appendix B: Geodatabase Schema}

\begin{tabular}{|c|c|c|}
\hline \multicolumn{3}{|c|}{ Domains } \\
\hline $\begin{array}{l}\text { Domain Name } \\
\text { Road Type } \\
\text { Trail Type } \\
\text { Trail Use Class } \\
\text { Yes No }\end{array}$ & Owner & $\begin{array}{l}\text { Domain Type } \\
\text { Coded Value } \\
\text { Coded Value } \\
\text { Coded Value } \\
\text { Coded Value }\end{array}$ \\
\hline$\overline{\text { Road_Type }}$ & & \\
\hline $\begin{array}{l}\text { Owner } \\
\text { Description } \\
\text { Domain Type } \\
\text { Field Type } \\
\text { Merge Policy } \\
\text { Split Policy }\end{array}$ & $\begin{array}{l}\text { Road types } \\
\text { Coded Value } \\
\text { String } \\
\text { Default Value } \\
\text { Default Value }\end{array}$ & \\
\hline $\begin{array}{l}\text { Domain Members } \\
\text { Name } \\
\text { PAVED } \\
\text { DIRT } \\
\text { DIRT_4x4 }\end{array}$ & $\begin{array}{l}\text { Value } \\
\text { PAVED } \\
\text { DIRT } \\
\text { DIRT_4x4 }\end{array}$ & \\
\hline Trail_Type & & \\
\hline $\begin{array}{l}\text { Owner } \\
\text { Description } \\
\text { Domain Type } \\
\text { Field Type } \\
\text { Merge Policy } \\
\text { Split Policy }\end{array}$ & $\begin{array}{l}\text { Trail type } \\
\text { Coded Value } \\
\text { String } \\
\text { Default Value } \\
\text { Default Value }\end{array}$ & \\
\hline $\begin{array}{l}\text { Domain Members } \\
\text { Name } \\
\text { Foot } \\
\text { Corridor } \\
\text { Horse } \\
\text { Bike } \\
\text { Bike-Horse }\end{array}$ & $\begin{array}{l}\text { Value } \\
\text { Foot } \\
\text { Corridor } \\
\text { Horse } \\
\text { Bike } \\
\text { Bike-Horse }\end{array}$ & \\
\hline Trail_Use_Class & & \\
\hline $\begin{array}{l}\text { Owner } \\
\text { Description } \\
\text { Domain Type } \\
\text { Field Type } \\
\text { Merge Policy } \\
\text { Split Policy }\end{array}$ & $\begin{array}{l}\text { Trail use intensity classes } \\
\text { Coded Value } \\
\text { String } \\
\text { Default Value } \\
\text { Default Value }\end{array}$ & \\
\hline $\begin{array}{l}\text { Domain Members } \\
\text { Name } \\
\text { Class } 1 \\
\text { Class } 2 \\
\text { Class } 3\end{array}$ & $\begin{array}{l}\text { Value } \\
\text { Class } 1 \\
\text { Class } 2 \\
\text { Class } 3\end{array}$ & \\
\hline
\end{tabular}




$\begin{array}{ll}\begin{array}{l}\text { Restored } \\ \text { Yes_No }\end{array} & \text { Restored } \\ \text { Owner } & \\ \text { Description } & \\ \text { Domain Type } & \text { Yes or No } \\ \text { Field Type } & \text { Coded Value } \\ \text { Merge Policy } & \text { String } \\ \text { Split Policy } & \text { Default Value } \\ \text { Domain Members } & \text { Default Value } \\ \text { Name } & \text { Value } \\ \text { Yes } & \text { Y } \\ \text { No } & \mathrm{N}\end{array}$

ObjectClasses

\begin{tabular}{|l|}
\hline ObjectClass Name \\
\hline Hydrology
\end{tabular} |Type Geometry Subtype

\begin{tabular}{|l|l|l|l|}
\hline Streams 24k & Simple & Polyline & - \\
\hline Recreation & FeatureClass & SR \\
\hline
\end{tabular}

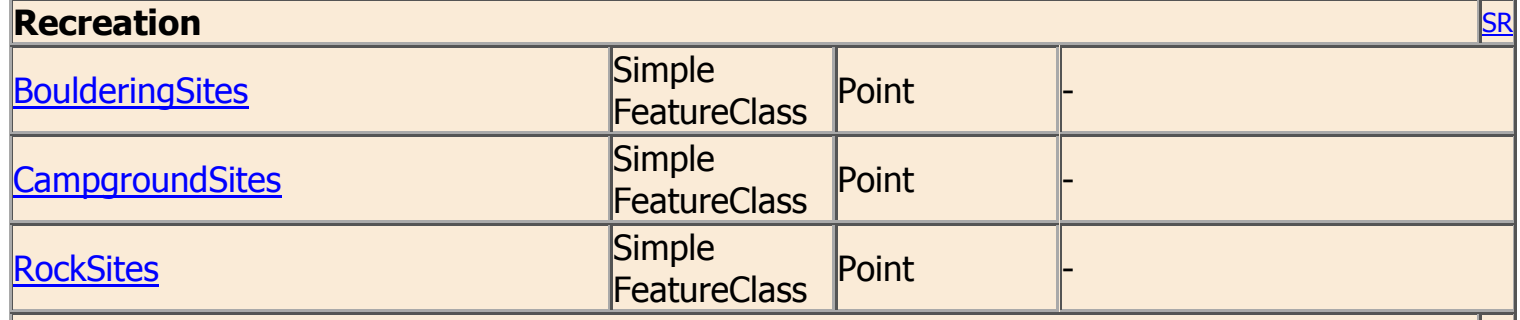

\begin{tabular}{|c|c|c|c|}
\hline \multicolumn{4}{|l|}{ Transportation } \\
\hline Designated Trails & \begin{tabular}{|l} 
Simple \\
FeatureClass
\end{tabular} & Polyline & \\
\hline GPS SocialTrails & $\begin{array}{l}\text { Simple } \\
\text { FeatureClass }\end{array}$ & Polyline & \\
\hline Parking pullouts & \begin{tabular}{|l} 
Simple \\
FeatureClass
\end{tabular} & Polygon & - \\
\hline Roads & $\begin{array}{l}\text { Simple } \\
\text { FeatureClass }\end{array}$ & Polyline & \\
\hline SocialTrails & $\begin{array}{l}\text { Simple } \\
\text { FeatureClass }\end{array}$ & Polyline & \\
\hline Trail Intersection & \begin{tabular}{|l} 
Simple \\
FeatureClass
\end{tabular} & Point & \\
\hline Trail Transect & $\begin{array}{l}\text { Simple } \\
\text { FeatureClass }\end{array}$ & Point & - \\
\hline \multicolumn{4}{|c|}{ Stand Alone ObjectClass(s) } \\
\hline AOI sites & \begin{tabular}{|l} 
Simple \\
FeatureClass
\end{tabular} & Polygon & SR \\
\hline AOI sitesBuf & $\begin{array}{l}\text { Simple } \\
\text { FeatureClass }\end{array}$ & Polygon & $S R$ \\
\hline JTNP boundary & \begin{tabular}{|l} 
Simple \\
FeatureClass
\end{tabular} & Polygon & SR \\
\hline
\end{tabular}

AOI_sites

Alias AOI_sites Geometry:Polygon 


\section{Dataset \\ Type \\ Field Name \\ OBJECTID \\ Shape \\ NAME \\ TYPE \\ BUFF_DIST \\ Shape_Length \\ Shape_Area \\ Subtype Name \\ Index Name \\ FDO_OBJECTID \\ FDO_Shape}

FeatureType Simple

\section{AOI_sitesBuf}

FeatureClass

Alias Name OBJECTID

Shape

Shape_Length Shape_Area Default Value Ascending Yes

No
Average Number of Points: 0

Has M:No

Has Z:No

Grid Size: 2000

Model Name Type Precn.ScaleLengthNull

OBJECTID OID

Shape

Geometry

String

String

Double

Shape_Length Double

Shape Area

Double

Unique

Domain

Yes $\quad$ OBJECTID

No Shape

\begin{tabular}{llll}
\multicolumn{4}{l}{ Precn.Scale LengthNull } \\
0 & 0 & 4 & No \\
0 & 0 & 0 & Yes \\
0 & 0 & 30 & Yes \\
0 & 0 & 20 & Yes \\
0 & 0 & 8 & Yes \\
0 & 0 & 8 & Yes \\
0 & 0 & 8 & Yes
\end{tabular}

Yes
Yes
Yes
Yes
Yes
Yes

Geometry:Polygon

Average Number of Points: 0

Has M:No

Has Z:No

Grid Size: 0

Alias Name

OBJECTID

Shape

Shape

NAME

TYPE

BUFF_DIST

Shape Length

Shape_Area

Subtype Name

Index Name

FDO_OBJECTID

FDO_Shape

BoulderingSites

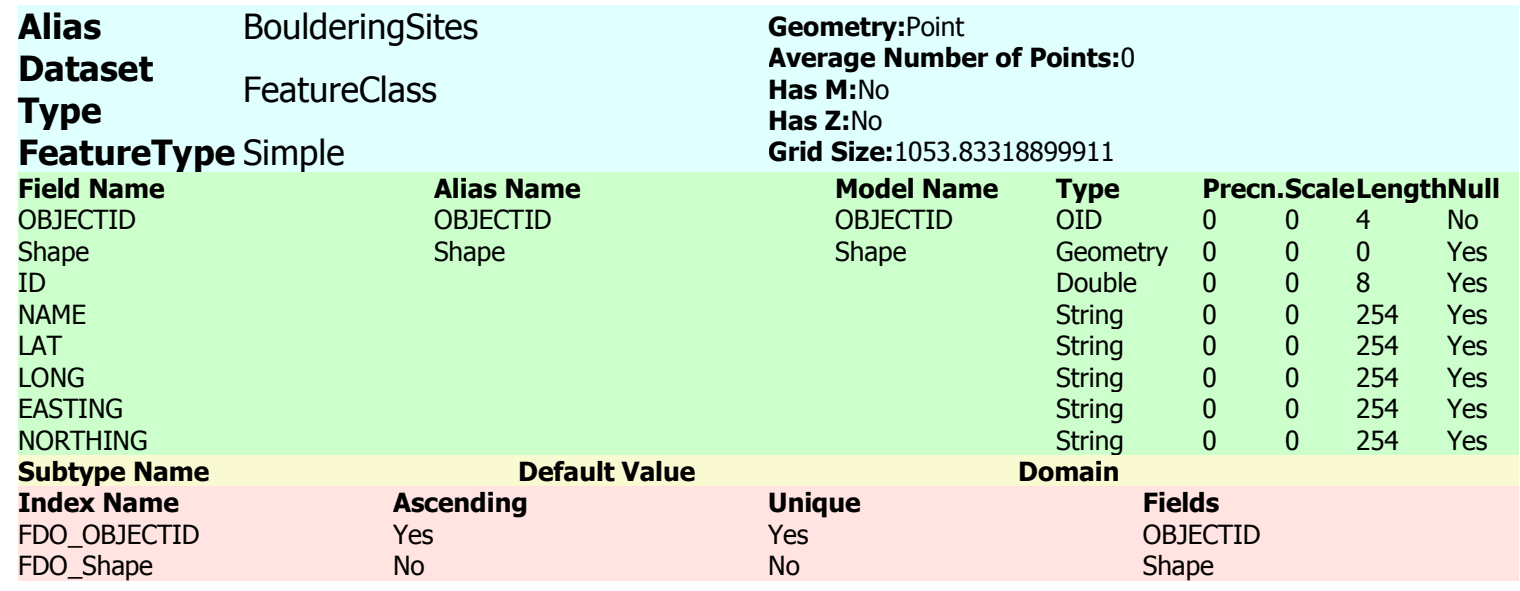

\section{CampgroundSites}

Shape Length

Shape_Area

Ascending

Yes

No

\begin{tabular}{llllll} 
Model Name & Type & \multicolumn{4}{c}{ Precn.Scale LengthNull } \\
OBJECTID & OID & 0 & 0 & 4 & No \\
Shape & Geometry & 0 & 0 & 0 & Yes \\
& String & 0 & 0 & 30 & Yes \\
& $\begin{array}{l}\text { String } \\
\text { Double }\end{array}$ & 0 & 0 & 20 & Yes \\
Shape_Length & $\begin{array}{c}\text { Double } \\
\text { Shape_Area }\end{array}$ & 0 & 0 & 8 & Yes \\
Double & 0 & 0 & 8 & Yes \\
Domain & & & & Yes \\
Dome & \multicolumn{3}{c}{ Fields } \\
OBJECTID \\
Shape
\end{tabular}

No

Shape 


\begin{tabular}{llll} 
Subtype Name & \multicolumn{2}{c}{ Default Value } & Domain \\
Index Name & Ascending & Unique & Fields \\
FDO_OBJECTID & Yes & Yes & OBJECTID \\
FDO_Shape & No & No & Shape
\end{tabular}

\section{Designated_Trails}

\begin{tabular}{|c|c|c|c|c|c|c|c|}
\hline $\begin{array}{l}\text { Alias } \\
\text { Dataset } \\
\text { Type } \\
\text { FeatureType }\end{array}$ & $\begin{array}{l}\text { Designated_Trails } \\
\text { FeatureClass } \\
\text { Simple }\end{array}$ & $\begin{array}{l}\text { Geometry:Polyline } \\
\text { Average Number c } \\
\text { Has M:No } \\
\text { Has Z:No } \\
\text { Grid Size: } 6300\end{array}$ & oints: 0 & & & & \\
\hline Field Name & Alias Name & Model Name & Type & Prec & $1.5 c$ & eLen & hNull \\
\hline OBJECTID & OBJECTID & OBJECTID & OID & 0 & 0 & 4 & No \\
\hline Shape & Shape & Shape & Geometry & 0 & 0 & 0 & Yes \\
\hline LENGTH & & & Double & 0 & 0 & 8 & Yes \\
\hline TYPE & TYPE & TYPE & String & 0 & 0 & 20 & Yes \\
\hline NAME & & & String & 0 & 0 & 48 & Yes \\
\hline NAME2 & & & String & 0 & 0 & 48 & Yes \\
\hline NAME3 & & & String & 0 & 0 & 48 & Yes \\
\hline NATURE_TR & & & String & 0 & 0 & 16 & Yes \\
\hline HANDICAP & & & String & 0 & 0 & 16 & Yes \\
\hline CATEGORY & & & Double & 0 & 0 & 8 & Yes \\
\hline SOURCE & & & String & 0 & 0 & 16 & Yes \\
\hline Shape_Length & Shape_Length & Shape_Length & Double & 0 & 0 & 8 & Yes \\
\hline $\begin{array}{l}\text { Subtype Name } \\
\text { ObjectClass } \\
\text { TYPE }\end{array}$ & Default Value & & $\begin{array}{l}\text { omain } \\
\text { ail Type }\end{array}$ & & & & \\
\hline $\begin{array}{l}\text { Index Name } \\
\text { FDO_OBJECTID } \\
\text { FDO_Shape }\end{array}$ & $\begin{array}{l}\text { Ascending } \\
\text { Yes } \\
\text { No }\end{array}$ & $\begin{array}{l}\text { Unique } \\
\text { Yes } \\
\text { No }\end{array}$ & $\begin{array}{l}\text { OB } \\
\text { She }\end{array}$ & $\begin{array}{l}\text { ds } \\
\text { ECTID } \\
\text { ge }\end{array}$ & & & \\
\hline
\end{tabular}

\section{GPS_SocialTrails}

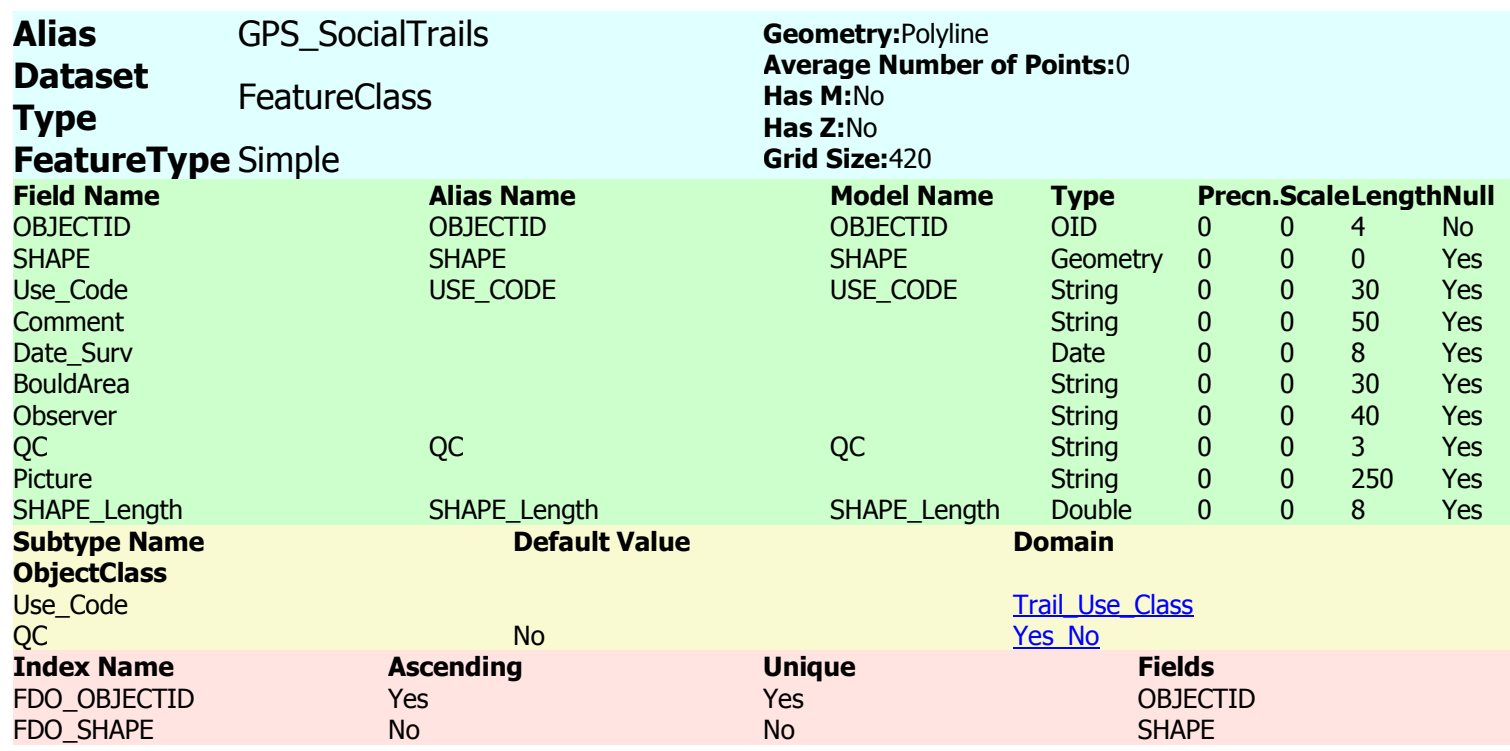

\section{JTNP_boundary}

\section{Alias JTNP_boundary \\ Dataset \\ Type \\ FeatureType Simple}

Field Name

OBJECTID

Shape

AREA

PERIMETER
Alias Name

OBJECTID

Shape
Geometry:Polygon

Average Number of Points: 0

Has M:No

Has Z:No

Grid Size: 120000

\begin{tabular}{llllll} 
Model Name & Type & \multicolumn{3}{c}{ Precn.ScaleLengthNull } \\
OBJECTID & OID & 0 & 0 & 4 & No \\
Shape & Geometry & 0 & 0 & 0 & Yes \\
& Double & 0 & 0 & 8 & Yes \\
& Double & 0 & 0 & 8 & Yes
\end{tabular}




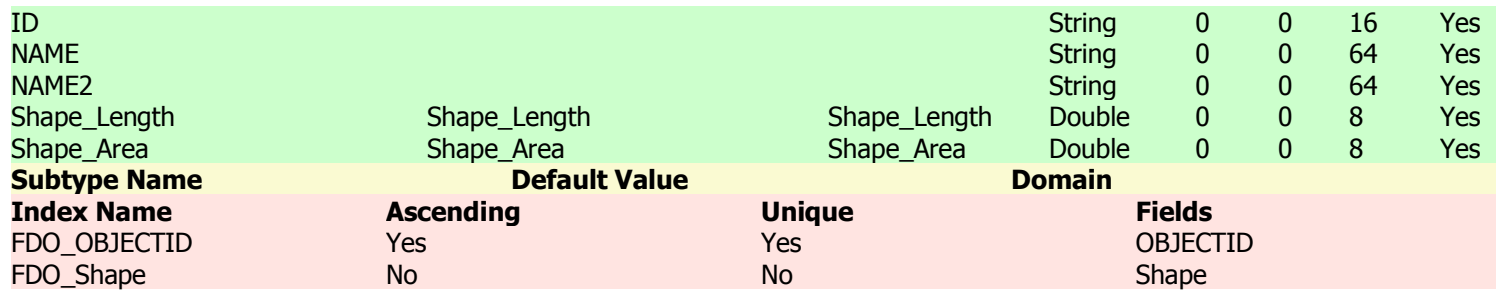

\section{Parking_pullouts}

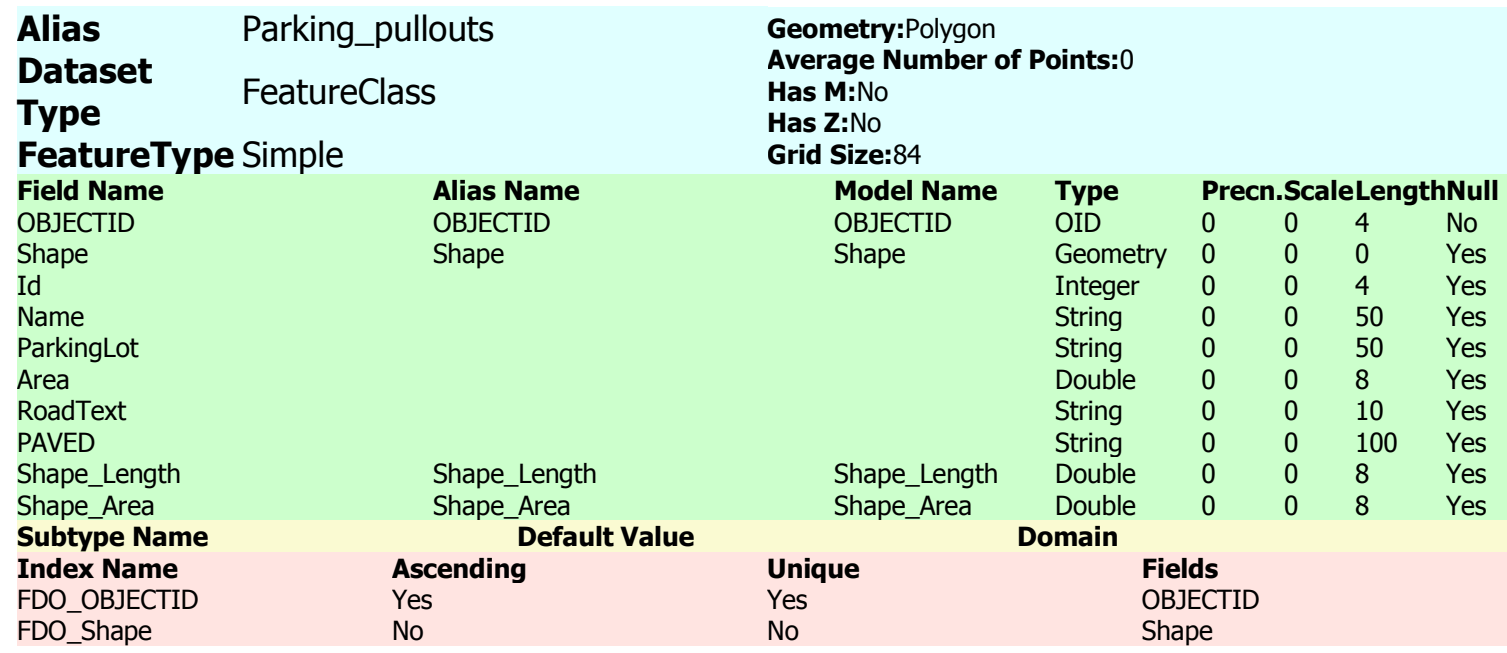

Roads

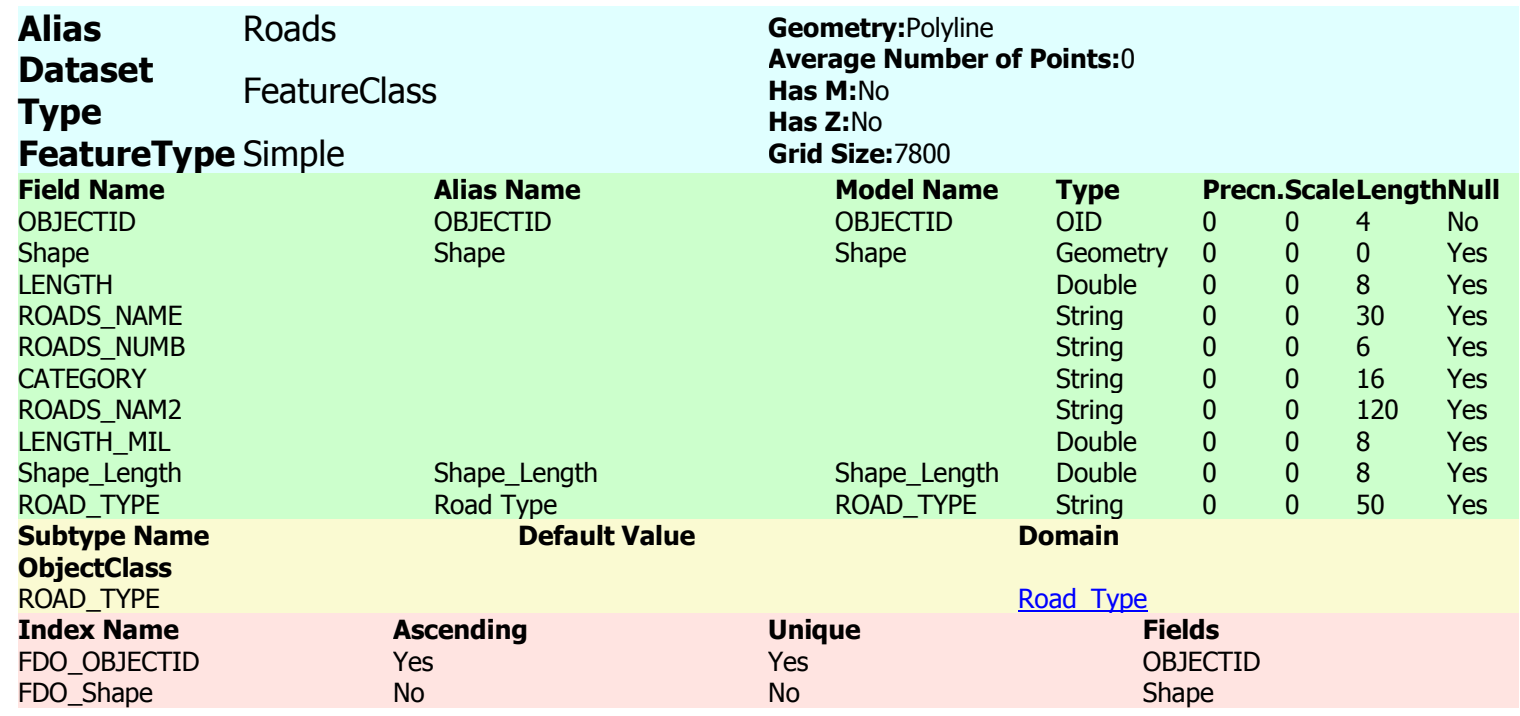

\section{RockSites}

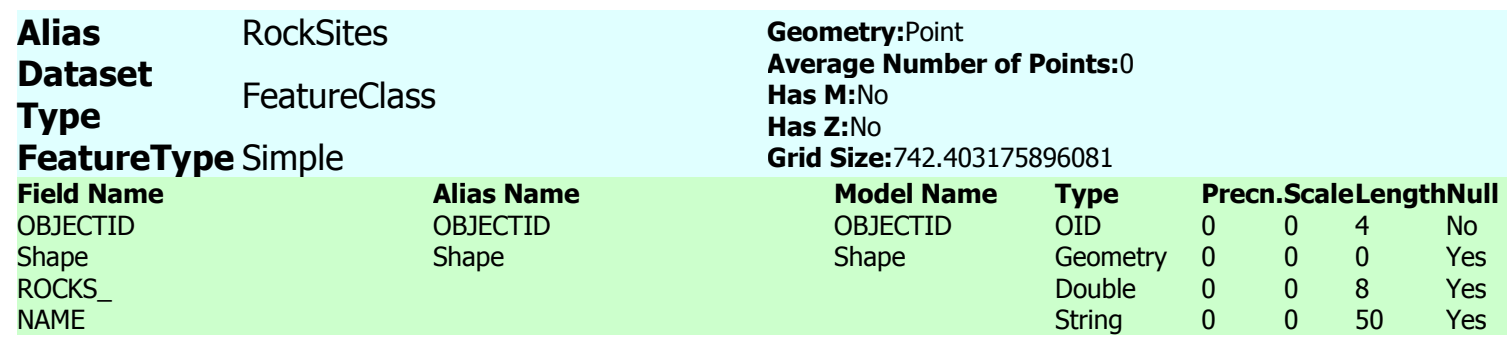




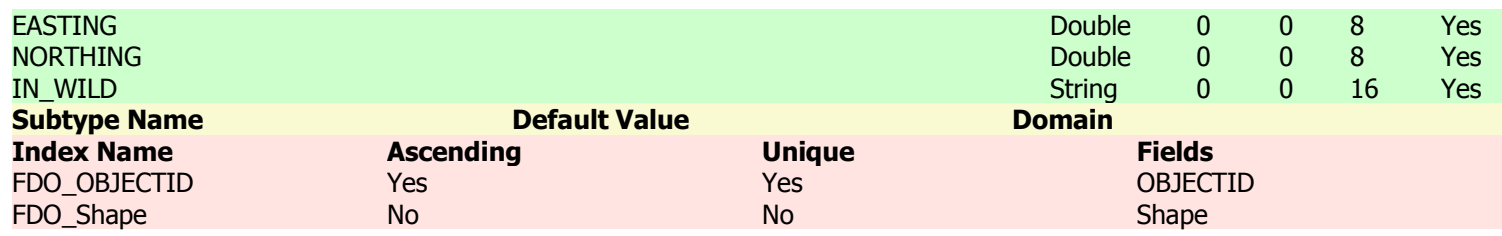

SocialTrails

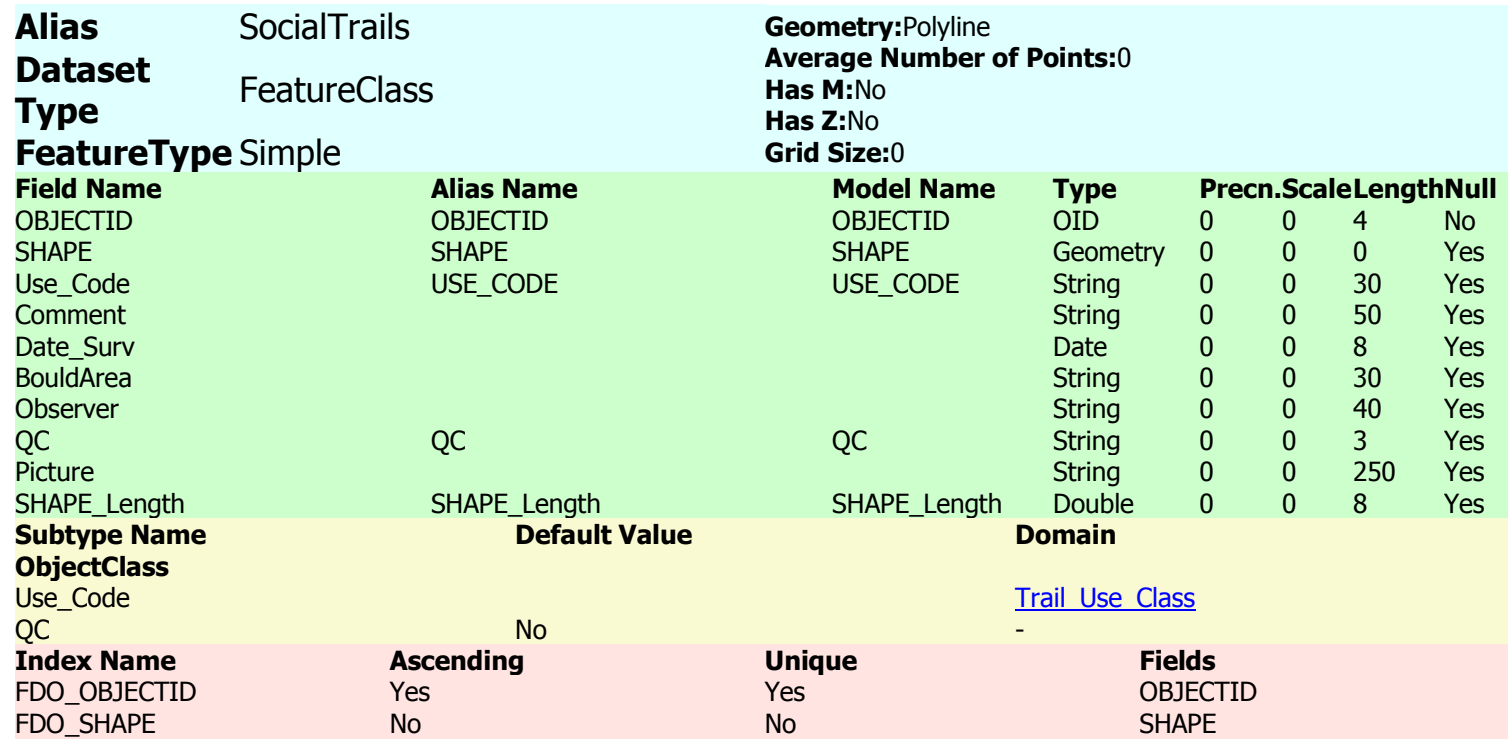

Streams_24k

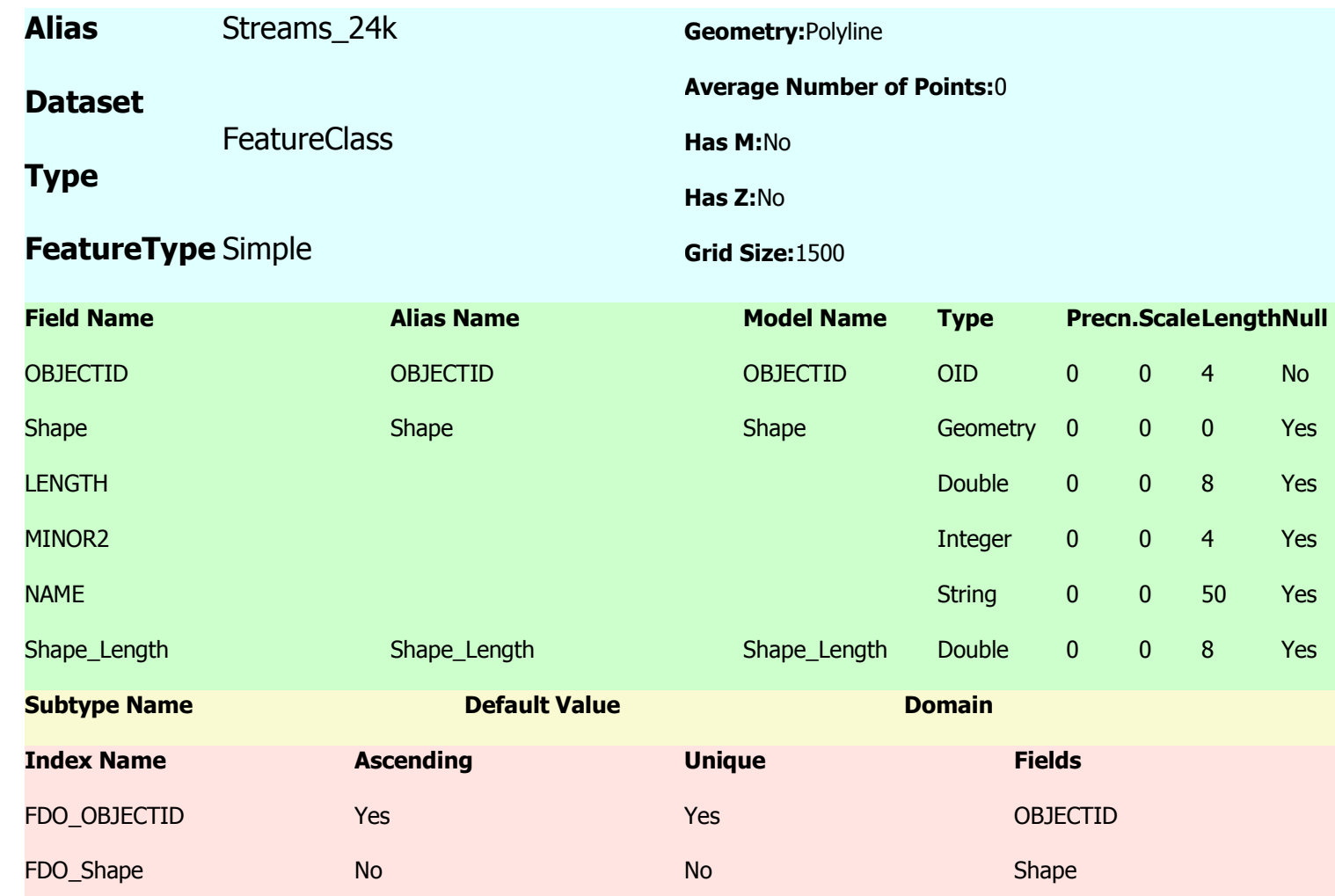

\section{Trail_Intersection}




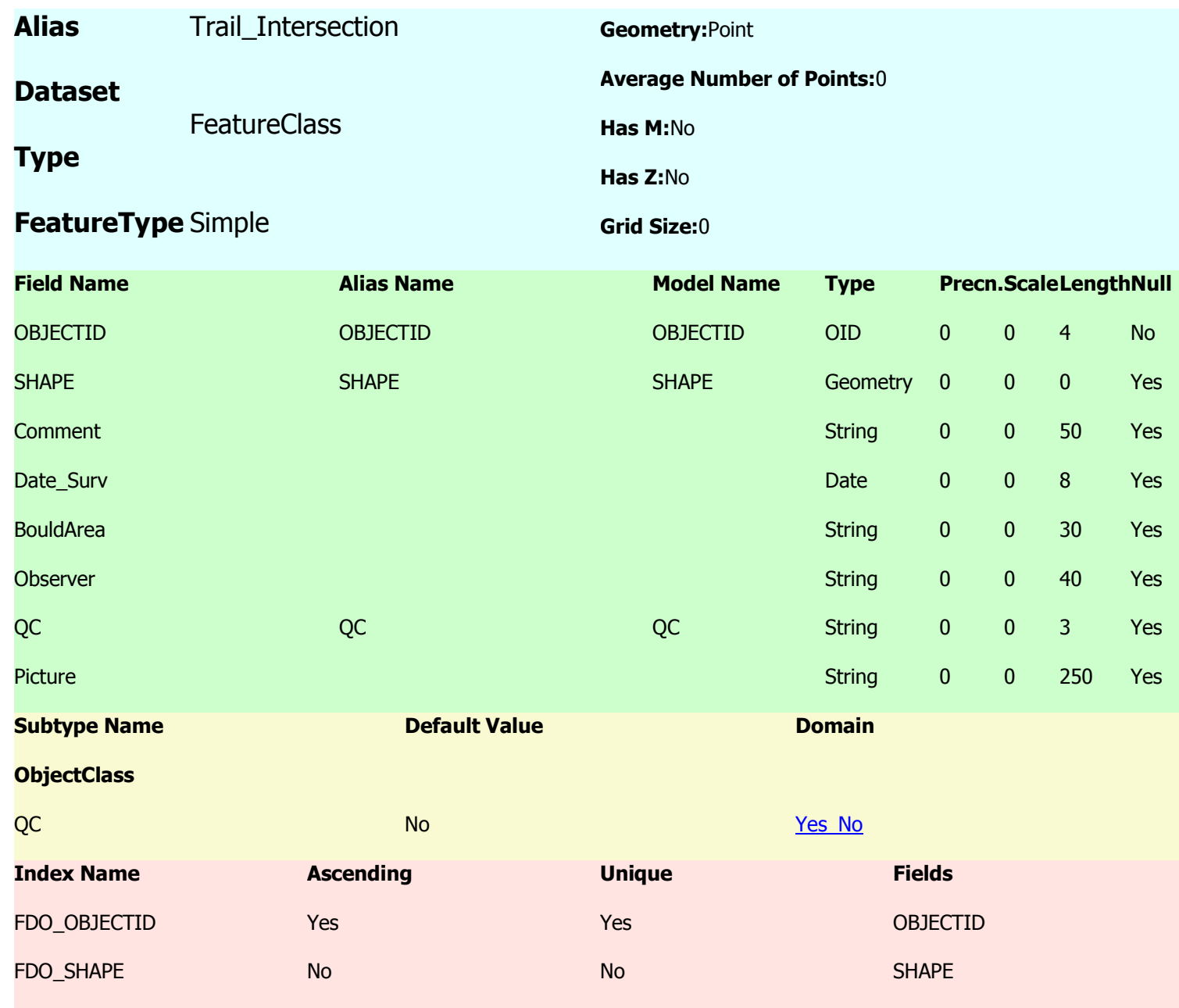

\section{Trail_Transect}

\begin{tabular}{|c|c|c|c|c|c|c|c|}
\hline Alias & ect & Geometry:Point & & & & & \\
\hline Dataset & & Average Number 0 & oints:0 & & & & \\
\hline Type & & $\begin{array}{l}\text { Has M:No } \\
\text { Has Z:No }\end{array}$ & & & & & \\
\hline FeatureT & & Grid Size:32.084243 & 57622 & & & & \\
\hline Field Name & Alias Name & Model Name & Type & & $1.5 c$ & eLen & hNull \\
\hline OBJECTID & OBJECTID & OBJECTID & OID & 0 & 0 & 4 & No \\
\hline SHAPE & SHAPE & SHAPE & Geometry & 0 & 0 & 0 & Yes \\
\hline Width & & & Single & 0 & 0 & 4 & Yes \\
\hline Depth & & & Single & 0 & 0 & 4 & Yes \\
\hline Comment & & & String & 0 & 0 & 50 & Yes \\
\hline Date_Surv & & & Date & 0 & 0 & 8 & Yes \\
\hline BouldArea & & & String & 0 & 0 & 30 & Yes \\
\hline
\end{tabular}


Observer

QC

Picture

Subtype Name

ObjectClass

QC

Index Name

FDO_OBJECTID

FDO_SHAPE
QC

Default Value

No

$\begin{array}{lllll}\text { String } & 0 & 0 & 40 & \text { Yes } \\ \text { String } & 0 & 0 & 3 & \text { Yes } \\ \text { String } & 0 & 0 & 250 & \text { Yes }\end{array}$

Domain

Yes No
Unique

Yes

No
Fields

OBJECTID

SHAPE

\section{Spatial References}

\begin{tabular}{|c|c|c|}
\hline $\begin{array}{l}\text { Dimensi } \\
\text { on }\end{array}$ & Minimum & Precision \\
\hline \multicolumn{3}{|c|}{ AOI_sites } \\
\hline $\mathbf{X}$ & \begin{tabular}{|l}
-5120900 \\
-9998100
\end{tabular} & 10000 \\
\hline $\mathbf{M}$ & - & - \\
\hline $\mathbf{Z}$ & - & - \\
\hline \multicolumn{3}{|c|}{$\begin{array}{l}\text { PROJCS["NAD_1983_UTM_Zone_11N",GEOGCS["GCS_North_American_1983",DATUM["D_North_American_1983",SPHEROID["GR } \\
\text { S_1980",6378137.0,298.257222101]],PRIMEM["Greenwich",0.0],UNIT["Degree",0.0174532925199433]],PROJECTION["Transvers } \\
\text { e_Mercator"],PARAMETER["False_Easting",500000.0],PARAMETER["False_Northing",0.0],PARAMETER["Central_Meridian",- } \\
\text { 117.0],PARAMETER["Scale_Factor",0.9996],PARAMETER["Latitude_Of_Origin",0.0],UNIT["Meter",1.0],AUTHORITY["EPSG",26911] } \\
\text { ] }\end{array}$} \\
\hline \multicolumn{3}{|c|}{ AOI_sitesBuf } \\
\hline $\mathbf{x}$ & \begin{tabular}{|l|}
-5120900 \\
-9998100
\end{tabular} & 10000 \\
\hline$M$ & - & - \\
\hline
\end{tabular}




\begin{tabular}{|c|c|c|}
\hline $\mathbf{Z}$ & - & - \\
\hline \multicolumn{3}{|c|}{ Coordinate System Description } \\
\hline \multirow{5}{*}{\multicolumn{3}{|c|}{$\begin{array}{l}\text { PROJCS["NAD_1983_UTM_Zone_11N",GEOGCS["GCS_North_American_1983",DATUM["D_North_American_1983",SPHEROID["GR } \\
\text { S_1980",6378137.0,298.257222101]],PRIMEM["Greenwich",0.0],UNIT["Degree",0.0174532925199433]],PROJECTION["Transvers } \\
\text { e_Mercator"],PARAMETER["False_Easting",500000.0],PARAMETER["False_Northing",0.0],PARAMETER["Central_Meridian",-- } \\
\text { 117.0],PARAMETER["Scale_Factor",0.9996],PARAMETER["Latitude_Of_Origin",0.0],UNIT["Meter",1.0],AUTHORITY["EPSG",26911] } \\
\text { ] }\end{array}$}} \\
\hline & & \\
\hline & & \\
\hline & & \\
\hline & & \\
\hline \multicolumn{3}{|c|}{ Hydrology } \\
\hline $\mathbf{x}$ & -5120900 & \multirow{3}{*}{10000} \\
\hline & & \\
\hline $\mathbf{Y}$ & -9998100 & \\
\hline $\mathbf{M}$ & -100000 & 10000 \\
\hline $\mathbf{Z}$ & -100000 & 10000 \\
\hline \multicolumn{3}{|c|}{ Coordinate System Description } \\
\hline \multirow{5}{*}{\multicolumn{3}{|c|}{$\begin{array}{l}\text { PROJCS["NAD_1983_UTM_Zone_11N",GEOGCS["GCS_North_American_1983",DATUM["D_North_American_1983",SPHEROID["GR } \\
\text { S_1980",6378137.0,298.257222101]],PRIMEM["Greenwich",0.0],UNIT["Degree",0.0174532925199433]],PROJECTION["Transvers } \\
\text { e_Mercator"],PARAMETER["False_Easting",500000.0],PARAMETER["False_Northing",0.0],PARAMETER["Central_Meridian",- } \\
\text { 117.0],PARAMETER["Scale_Factor",0.9996],PARAMETER["Latitude_Of_Origin",0.0],UNIT["Meter",1.0],AUTHORITY["EPSG",26911] } \\
\text { ] }\end{array}$}} \\
\hline & & \\
\hline & & \\
\hline & & \\
\hline & & \\
\hline \multicolumn{3}{|c|}{ JTNP_boundary } \\
\hline $\mathbf{X}$ & 522340.53125 & \multirow{3}{*}{10000} \\
\hline & & \\
\hline $\mathbf{Y}$ & 3668143.21875 & \\
\hline \multicolumn{3}{|c|}{$\mathbf{M}$} \\
\hline $\mathbf{Z}$ & - & - \\
\hline \multicolumn{3}{|c|}{ Coordinate System Description } \\
\hline \multicolumn{3}{|c|}{ PROJCS["NAD_1983_UTM_Zone_11N",GEOGCS["GCS_North_American_1983",DATUM["D_North_American_1983",SPHEROID["GR } \\
\hline \multicolumn{3}{|c|}{ S_1980",6378137.0,298.257222101]],PRIMEM["Greenwich",0.0],UNIT["Degree",0.0174532925199433]],PROJECTION["Transvers } \\
\hline \multicolumn{3}{|c|}{ e_Mercator"],PARAMETER["False_Easting",500000.0],PARAMETER["False_Northing",0.0],PARAMETER["Central_Meridian",- } \\
\hline \multicolumn{3}{|c|}{ 117.0],PARAMETER["Scale_Factor",0.9996],PARAMETER["Latitude_Of_Origin",0.0],UNIT["Meter",1.0],AUTHORITY["EPSG",26911] } \\
\hline ] & & \\
\hline
\end{tabular}




\begin{tabular}{|c|c|c|}
\hline \multicolumn{3}{|c|}{ Recreation } \\
\hline $\mathbf{X}$ & -5120900 & \multirow{2}{*}{10000} \\
\hline $\mathbf{Y}$ & -9998100 & \\
\hline $\mathbf{M}$ & -100000 & 10000 \\
\hline $\mathbf{Z}$ & -100000 & 10000 \\
\hline \multicolumn{3}{|c|}{ Coordinate System Description } \\
\hline \multirow{5}{*}{\multicolumn{3}{|c|}{$\begin{array}{l}\text { PROJCS["NAD_1983_UTM_Zone_11N",GEOGCS["GCS_North_American_1983",DATUM["D_North_American_1983",SPHEROID["GR } \\
\text { S_1980",6378137.0,298.257222101]],PRIMEM["Greenwich",0.0],UNIT["Degree",0.0174532925199433]],PROJECTION["Transvers } \\
\text { e_Mercator"],PARAMETER["False_Easting",500000.0],PARAMETER["False_Northing",0.0],PARAMETER["Central_Meridian",-- } \\
\text { 117.0],PARAMETER["Scale_Factor",0.9996],PARAMETER["Latitude_Of_Origin",0.0],UNIT["Meter",1.0],AUTHORITY["EPSG",26911] } \\
\text { ] }\end{array}$}} \\
\hline & & \\
\hline & & \\
\hline & & \\
\hline & & \\
\hline \multicolumn{3}{|c|}{ Transportation } \\
\hline $\mathbf{X}$ & -5120900 & \multirow{3}{*}{10000} \\
\hline & & \\
\hline $\mathbf{Y}$ & -9998100 & \\
\hline $\mathbf{M}$ & -100000 & 10000 \\
\hline $\mathbf{Z}$ & -100000 & 10000 \\
\hline \multicolumn{3}{|c|}{ Coordinate System Description } \\
\hline \multicolumn{3}{|c|}{ PROJCS["NAD_1983_UTM_Zone_11N",GEOGCS["GCS_North_American_1983",DATUM["D_North_American_1983",SPHEROID["GR } \\
\hline \multicolumn{3}{|c|}{ S_1980",6378137.0,298.257222101]],PRIMEM["Greenwich",0.0],UNIT["Degree",0.0174532925199433]],PROJECTION["Transvers } \\
\hline \multicolumn{3}{|c|}{ e_Mercator"],PARAMETER["False_Easting",500000.0],PARAMETER["False_Northing",0.0],PARAMETER["Central_Meridian",- } \\
\hline \multicolumn{3}{|c|}{ 117.0],PARAMETER["Scale_Factor",0.9996],PARAMETER["Latitude_Of_Origin",0.0],UNIT["Meter",1.0],AUTHORITY["EPSG",26911] } \\
\hline ] & & \\
\hline
\end{tabular}

the output generated by those commands are not to be used in a production environment. ESRI is not responsible for errors, omission or any damages resulting from the use of application and associated output. Use of this application is conditional on the acceptance of this statement. 


\section{Appendix C: MIDL}

\begin{tabular}{|c|c|c|}
\hline Component & Details & Notes \\
\hline \multirow[t]{4}{*}{$\begin{array}{l}\text { 1. Data } \\
\text { Identification }\end{array}$} & $\begin{array}{l}\text { Name: 05DEC12184712-S2AS- } \\
\text { 052166402010_01_P001 }\end{array}$ & QuickBird \\
\hline & Source Agency: DigitalGlobe & \\
\hline & Internet location: & www.emap int.com \\
\hline & Metadata: Full & \\
\hline \multirow[t]{5}{*}{$\begin{array}{l}\text { 2. Data volume } \\
\text { considerations }\end{array}$} & Digital data format: GeoTIF & \\
\hline & $\begin{array}{l}\text { Percentage available: Study } \\
\text { Extent Only }\end{array}$ & \\
\hline & Primary record type: GeoTIF & \\
\hline & Primary record volume: 1 & \\
\hline & $\begin{array}{l}\text { Total data volume: } 1.2 \mathrm{~GB} \\
\text { (uncompressed) }\end{array}$ & \\
\hline \multicolumn{3}{|l|}{$\begin{array}{l}\text { 3. Data } \\
\text { Characteristics }\end{array}$} \\
\hline \multirow[t]{8}{*}{ Image portion } & Size: 1.2 GB (uncompressed) & \\
\hline & Photo image: No & \\
\hline & $\begin{array}{l}\text { Projection/Datum: WGS } 84 \text { UTM } \\
\text { Zone } 11 \mathrm{~N}\end{array}$ & \\
\hline & Number of Bands: 4 & \\
\hline & Cellsize: $0.6,0.6$ & \\
\hline & Data Type: Unsigned 16-bit & \\
\hline & Source Type: continuous & \\
\hline & Columns and Rows: 9986, 16148 & \\
\hline \multirow[t]{4}{*}{$\begin{array}{l}\text { 4. Data } \\
\text { availability and } \\
\text { cost }\end{array}$} & $\begin{array}{l}\text { Percent coverage available now: } \\
100 \% \text { of study site }\end{array}$ & \\
\hline & Currency: Dec 2005 & \\
\hline & $\begin{array}{l}\text { Restrictions on use: Educational, } \\
\text { Copyright DigitalGlobe }\end{array}$ & $\begin{array}{l}\text { () COPYRIGHT } 2008 \\
\text { DigitalGlobe, Inc., Longmont CO } \\
\text { USA } 80503 \text {. DigitalGlobe and } \\
\text { the DigitalGlobe logos are } \\
\text { trademarks of DigitalGlobe, Inc. } \\
\text { The use and/or dissemination of } \\
\text { this data and/or of any product in } \\
\text { any way derived there from are } \\
\text { restricted. Unauthorized use } \\
\text { and/or dissemination is } \\
\text { prohibited." }\end{array}$ \\
\hline & $\begin{array}{l}\text { Cost of dataset acquisition: } \\
\$ 380.80\left(28 \mathrm{~km}^{2} \text { at } \$ 13.60 \text { per }\right. \\
\mathrm{km})\end{array}$ & $\begin{array}{l}\text { Purchased from eMap } \\
\text { International }\end{array}$ \\
\hline
\end{tabular}




\begin{tabular}{|c|c|c|}
\hline Component & Details & Notes \\
\hline \multirow[t]{4}{*}{$\begin{array}{l}\text { 1. Data } \\
\text { Identification }\end{array}$} & $\begin{array}{l}\text { Name: 08MAY10184800-S2AS- } \\
\text { 052166402020_01_P001 }\end{array}$ & QuickBird \\
\hline & Source Agency: DigitalGlobe & \\
\hline & Internet location: & www.emap int.com \\
\hline & Metadata: Full & \\
\hline \multirow[t]{5}{*}{$\begin{array}{l}\text { 2. Data volume } \\
\text { considerations }\end{array}$} & Digital data format: GeoTIF & \\
\hline & $\begin{array}{l}\text { Percentage available: Study } \\
\text { Extent Only }\end{array}$ & \\
\hline & Primary record type: GeoTIF & \\
\hline & Primary record volume: 1 & \\
\hline & $\begin{array}{l}\text { Total data volume: } 969 \mathrm{MB} \\
\text { (uncompressed) }\end{array}$ & \\
\hline \multicolumn{3}{|l|}{$\begin{array}{l}\text { 3. Data } \\
\text { Characteristics }\end{array}$} \\
\hline \multirow[t]{8}{*}{ Image portion } & Size: 969 MB (uncompressed) & \\
\hline & Photo image: No & \\
\hline & $\begin{array}{l}\text { Projection/Datum: WGS } 84 \text { UTM } \\
\text { Zone } 11 \mathrm{~N}\end{array}$ & \\
\hline & Number of Bands: 4 & \\
\hline & Cellsize: $0.6,0.6$ & \\
\hline & Data Type: Unsigned 16-bit & \\
\hline & Source Type: continuous & \\
\hline & Columns and Rows: 9986,16148 & \\
\hline \multirow[t]{4}{*}{$\begin{array}{l}\text { 4. Data } \\
\text { availability and } \\
\text { cost }\end{array}$} & $\begin{array}{l}\text { Percent coverage available now: } \\
50 \% \text { of study site }\end{array}$ & \\
\hline & Currency: May 2008 & \\
\hline & $\begin{array}{l}\text { Restrictions on use: Educational, } \\
\text { Copyright DigitalGlobe }\end{array}$ & $\begin{array}{l}\text { (C) COPYRIGHT } 2008 \\
\text { DigitalGlobe, Inc., Longmont CO } \\
\text { USA 80503. DigitalGlobe and } \\
\text { the DigitalGlobe logos are } \\
\text { trademarks of DigitalGlobe, Inc. } \\
\text { The use and/or dissemination of } \\
\text { this data and/or of any product in } \\
\text { any way derived there from are } \\
\text { restricted. Unauthorized use } \\
\text { and/or dissemination is } \\
\text { prohibited." }\end{array}$ \\
\hline & $\begin{array}{l}\text { Cost of dataset acquisition: } \\
\$ 380.80\left(28 \mathrm{~km}^{2} \text { at } \$ 13.60 \text { per }\right. \\
\mathrm{km})\end{array}$ & $\begin{array}{l}\text { Purchased from eMap } \\
\text { International }\end{array}$ \\
\hline
\end{tabular}




\begin{tabular}{|c|c|c|}
\hline Component & Details & Notes \\
\hline \multirow[t]{4}{*}{$\begin{array}{l}\text { 1. Data } \\
\text { Identification }\end{array}$} & $\begin{array}{l}\text { Name: 08JUL03184850-S2AS- } \\
\text { 052166402020_01_P002 }\end{array}$ & QuickBird \\
\hline & Source Agency: DigitalGlobe & \\
\hline & Internet location: & www.emap int.com \\
\hline & Metadata: Full & \\
\hline \multirow[t]{5}{*}{$\begin{array}{l}\text { 2. Data volume } \\
\text { considerations }\end{array}$} & Digital data format: GeoTIF & \\
\hline & $\begin{array}{l}\text { Percentage available: Study } \\
\text { Extent Only }\end{array}$ & \\
\hline & Primary record type: GeoTIF & \\
\hline & Primary record volume: 1 & \\
\hline & $\begin{array}{l}\text { Total data volume: } 513 \mathrm{MB} \\
\text { (uncompressed) }\end{array}$ & \\
\hline \multicolumn{3}{|l|}{$\begin{array}{l}\text { 3. Data } \\
\text { Characteristics }\end{array}$} \\
\hline \multirow[t]{8}{*}{ Image portion } & Size: 1.2 GB (uncompressed) & \\
\hline & Photo image: No & \\
\hline & $\begin{array}{l}\text { Projection/Datum: WGS } 84 \text { UTM } \\
\text { Zone } 11 \mathrm{~N}\end{array}$ & \\
\hline & Number of Bands: 4 & \\
\hline & Cellsize: $0.6,0.6$ & \\
\hline & Data Type: Unsigned 16-bit & \\
\hline & Source Type: continuous & \\
\hline & Columns and Rows: 7789,8584 & \\
\hline \multirow[t]{4}{*}{$\begin{array}{l}\text { 4. Data } \\
\text { availability and } \\
\text { cost }\end{array}$} & $\begin{array}{l}\text { Percent coverage available now: } \\
50 \% \text { of study site }\end{array}$ & \\
\hline & Currency: July 2008 & \\
\hline & $\begin{array}{l}\text { Restrictions on use: Educational, } \\
\text { Copyright DigitalGlobe }\end{array}$ & $\begin{array}{l}\text { ( ) COPYRIGHT } 2008 \\
\text { DigitalGlobe, Inc., Longmont CO } \\
\text { USA } 80503 \text {. DigitalGlobe and } \\
\text { the DigitalGlobe logos are } \\
\text { trademarks of DigitalGlobe, Inc. } \\
\text { The use and/or dissemination of } \\
\text { this data and/or of any product in } \\
\text { any way derived there from are } \\
\text { restricted. Unauthorized use } \\
\text { and/or dissemination is } \\
\text { prohibited." }\end{array}$ \\
\hline & $\begin{array}{l}\text { Cost of dataset acquisition: } \\
\$ 380.80\left(28 \mathrm{~km}^{2} \text { at } \$ 13.60 \text { per }\right. \\
\mathrm{km})\end{array}$ & $\begin{array}{l}\text { Purchased from eMap } \\
\text { International }\end{array}$ \\
\hline
\end{tabular}




\begin{tabular}{|c|c|c|}
\hline Component & Details & Notes \\
\hline \multirow[t]{4}{*}{$\begin{array}{l}\text { 1. Data } \\
\text { Identification }\end{array}$} & Name: Keysview_hydro.shp & $\begin{array}{l}\text { All shapefiles in the } \\
\text { Hydro_24k folder met the } \\
\text { same criteria; Streams_24k }\end{array}$ \\
\hline & Source Agency: NPS & \\
\hline & Internet location: & \\
\hline & Metadata: Partial & \\
\hline \multirow[t]{5}{*}{$\begin{array}{l}\text { 2. Data volume } \\
\text { considerations }\end{array}$} & Digital data format: Shapefile & \\
\hline & Percentage available: $100 \%$ & $\begin{array}{l}\text { Multiple shapefiles cover the } \\
\text { entire park boundary }\end{array}$ \\
\hline & Primary record type: digital & \\
\hline & $\begin{array}{l}\text { Primary record volume: } 1 \\
\text { shapefile }\end{array}$ & \\
\hline & Total data volume: $63.92 \mathrm{~KB}$ & $3.57 \mathrm{MB}$ (total) \\
\hline \multicolumn{3}{|l|}{$\begin{array}{l}\text { 3. Data } \\
\text { Characteristics }\end{array}$} \\
\hline \multirow[t]{3}{*}{ Digital portion } & Size: $63.92 \mathrm{~KB}$ & 3.57 MB (total) \\
\hline & Scale: $1: 24,000$ & \\
\hline & $\begin{array}{l}\text { Projection/Datum: NAD } 1983 \\
\text { UTM Zone 11N }\end{array}$ & \\
\hline \multirow[t]{4}{*}{$\begin{array}{l}\text { 4. Data } \\
\text { availability and } \\
\text { cost }\end{array}$} & $\begin{array}{l}\text { Percent coverage available now: } \\
100 \%\end{array}$ & \\
\hline & Currency: UNK & \\
\hline & Restrictions on use: none & \\
\hline & $\begin{array}{l}\text { Cost of dataset acquisition: Free } \\
\text { (download from NPS) }\end{array}$ & \\
\hline
\end{tabular}

\begin{tabular}{|l|l|l|}
\hline \multicolumn{1}{|c|}{ Component } & \multicolumn{1}{|c|}{ Details } & \multicolumn{1}{c|}{ Notes } \\
\hline \multirow{4}{*}{$\begin{array}{l}\text { 1. Data } \\
\text { Identification }\end{array}$} & Name: trails.shp & Designated_Trails \\
\cline { 2 - 3 } & Source Agency: NPS & JTNP \\
\cline { 2 - 3 } & Internet location: & \\
\cline { 2 - 3 } & Metadata: Complete & text file \\
\hline \multirow{4}{*}{$\begin{array}{l}\text { 2. Data volume } \\
\text { considerations }\end{array}$} & Digital data format: Shape file & \\
\cline { 2 - 3 } & Percentage available: $100 \%$ & \\
\cline { 2 - 3 } & Primary record type: digital & \\
\cline { 2 - 3 } & $\begin{array}{l}\text { Primary record volume: } 1 \\
\text { shapefile }\end{array}$ & \\
\cline { 2 - 3 } & Total data volume: $449.85 \mathrm{~KB}$ & \\
\hline
\end{tabular}




\begin{tabular}{|c|c|c|}
\hline \multirow[t]{3}{*}{ Digital Portion } & Size: $449.85 \mathrm{~KB}$ & \\
\hline & Scale: UNK & $\begin{array}{l}\text { GPS points collected and } \\
\text { digitized onto } 7.5 " \text { quads. }\end{array}$ \\
\hline & $\begin{array}{l}\text { Projection/Datum: UTM Zone } 11 \\
\text { NAD } 1983\end{array}$ & \\
\hline \multirow[t]{4}{*}{$\begin{array}{l}\text { 4. Data } \\
\text { availability and } \\
\text { cost }\end{array}$} & $\begin{array}{l}\text { Percent coverage available now: } \\
100 \%\end{array}$ & \\
\hline & Currency: January 2001 & \\
\hline & Restrictions on use: none & \\
\hline & $\begin{array}{l}\text { Cost of dataset acquisition: Free } \\
\text { (download) }\end{array}$ & \\
\hline
\end{tabular}

\begin{tabular}{|c|c|c|}
\hline Component & Details & Notes \\
\hline \multirow[t]{4}{*}{$\begin{array}{l}\text { 1. Data } \\
\text { Identification }\end{array}$} & $\begin{array}{l}\text { Name: Trail (within } \\
\text { JOTR_SocialTrails08.mdb) }\end{array}$ & GPS_SocialTrails \\
\hline & Source Agency: NPS & JTNP \\
\hline & Internet location: None & \\
\hline & Metadata: None & \\
\hline \multirow[t]{5}{*}{$\begin{array}{l}\text { 2. Data volume } \\
\text { considerations }\end{array}$} & $\begin{array}{l}\text { Digital data format: Geodatabase } \\
\text { feature class }\end{array}$ & \\
\hline & $\begin{array}{l}\text { Percentage available: Partial / } \\
\text { UNK }\end{array}$ & \\
\hline & $\begin{array}{l}\text { Primary record type: Feature } \\
\text { class }\end{array}$ & \\
\hline & Primary record volume: UNK & \\
\hline & Total data volume: UNK & \\
\hline \multicolumn{3}{|l|}{$\begin{array}{l}\text { 3. Data } \\
\text { Characteristics }\end{array}$} \\
\hline \multirow[t]{3}{*}{ Digital Portion } & Size: UNK & \\
\hline & Scale: UNK & \\
\hline & $\begin{array}{l}\text { Projection/Datum: UTM Zone } 11 \\
\text { NAD } 1983\end{array}$ & \\
\hline \multirow[t]{4}{*}{$\begin{array}{l}\text { 4. Data } \\
\text { availability and } \\
\text { cost }\end{array}$} & $\begin{array}{l}\text { Percent coverage available now: } \\
\text { UNK }\end{array}$ & \\
\hline & Currency: Fall 2008 & In progress \\
\hline & Restrictions on use: none & \\
\hline & $\begin{array}{l}\text { Cost of dataset acquisition: Free } \\
\text { (JTNP) }\end{array}$ & \\
\hline
\end{tabular}




\begin{tabular}{|c|c|c|}
\hline Component & Details & Notes \\
\hline \multirow[t]{4}{*}{$\begin{array}{l}\text { 1. Data } \\
\text { Identification }\end{array}$} & Name: rds_pub2.shp & Roads \\
\hline & Source Agency: NPS & JTNP \\
\hline & Internet location: None & \\
\hline & Metadata: $100 \%$ & text file \\
\hline \multirow[t]{5}{*}{$\begin{array}{l}\text { 2. Data volume } \\
\text { considerations }\end{array}$} & Digital data format: Shape file & \\
\hline & Percentage available: $100 \%$ & \\
\hline & Primary record type: shape file & \\
\hline & $\begin{array}{l}\text { Primary record volume: } 203.87 \\
\text { KB }\end{array}$ & \\
\hline & Total data volume: $203.87 \mathrm{~KB}$ & \\
\hline \multicolumn{3}{|l|}{$\begin{array}{l}\text { 3. Data } \\
\text { Characteristics }\end{array}$} \\
\hline \multirow[t]{3}{*}{ Digital Portion } & Size: $203.87 \mathrm{~KB}$ & \\
\hline & Scale: UNK & Digitized from USGS maps \\
\hline & $\begin{array}{l}\text { Projection/Datum: UTM Zone } 11 \\
\text { NAD } 1983\end{array}$ & \\
\hline \multirow[t]{4}{*}{$\begin{array}{l}\text { 4. Data } \\
\text { availability and } \\
\text { cost }\end{array}$} & $\begin{array}{l}\text { Percent coverage available now: } \\
100 \%\end{array}$ & \\
\hline & Currency: 2001 & \\
\hline & Restrictions on use: none & \\
\hline & $\begin{array}{l}\text { Cost of dataset acquisition: Free } \\
\text { (NPS) }\end{array}$ & \\
\hline
\end{tabular}

\begin{tabular}{|c|c|c|}
\hline Component & Details & Notes \\
\hline \multirow[t]{4}{*}{$\begin{array}{l}\text { 1. Data } \\
\text { Identification }\end{array}$} & Name: Parking_pullouts.shp & Parking_pullouts \\
\hline & Source Agency: NPS & JTNP \\
\hline & Internet location: & \\
\hline & Metadata: None & \\
\hline \multirow[t]{5}{*}{$\begin{array}{l}\text { 2. Data volume } \\
\text { considerations }\end{array}$} & Digital data format: Shape file & \\
\hline & Percentage available: $100 \%$ & \\
\hline & Primary record type: shapefile & \\
\hline & Primary record volume: $26.05 \mathrm{~KB}$ & \\
\hline & Total data volume: $26.05 \mathrm{~KB}$ & \\
\hline \multicolumn{3}{|l|}{$\begin{array}{l}\text { 3. Data } \\
\text { Characteristics }\end{array}$} \\
\hline Digital Portion & Size: $26.05 \mathrm{~KB}$ & \\
\hline
\end{tabular}




\begin{tabular}{|l|l|l|} 
& Scale: UNK & \\
\cline { 2 - 3 } & $\begin{array}{l}\text { Projection/Datum: NAD 1983 } \\
\text { UTM Zone 11N }\end{array}$ & \\
\hline $\begin{array}{l}\text { 4. Data } \\
\text { availability and } \\
\text { cost }\end{array}$ & $\begin{array}{l}\text { Percent coverage available now: } \\
\text { UNK }\end{array}$ & \\
\cline { 2 - 3 } & Currency: UNK & \\
\cline { 2 - 3 } & Restrictions on use: none & \\
\cline { 2 - 3 } & $\begin{array}{l}\text { Cost of dataset acquisition: Free } \\
\text { (NPS) }\end{array}$ & \\
\hline
\end{tabular}

\begin{tabular}{|c|c|c|}
\hline Component & Details & Notes \\
\hline \multirow[t]{4}{*}{$\begin{array}{l}\text { 1. Data } \\
\text { Identification }\end{array}$} & $\begin{array}{l}\text { Name: Trail_Intersection (within } \\
\text { JOTR_socialtrails08.mdb) }\end{array}$ & Trail_Intersection \\
\hline & Source Agency: NPS & JTNP \\
\hline & Internet location: & \\
\hline & Metadata: None & \\
\hline \multirow[t]{5}{*}{$\begin{array}{l}\text { 2. Data volume } \\
\text { considerations }\end{array}$} & Digital data format: Geodatabase & \\
\hline & Percentage available: $100 \%$ & \\
\hline & $\begin{array}{l}\text { Primary record type: Feature } \\
\text { class }\end{array}$ & \\
\hline & Primary record volume: $6.29 \mathrm{~KB}$ & \\
\hline & Total data volume: $6.29 \mathrm{~KB}$ & \\
\hline \multicolumn{3}{|l|}{$\begin{array}{l}\text { 3. Data } \\
\text { Characteristics }\end{array}$} \\
\hline \multirow[t]{3}{*}{ Digital Portion } & Size: $6.29 \mathrm{~KB}$ & \\
\hline & Scale: UNK & \\
\hline & $\begin{array}{l}\text { Projection/Datum: NAD } 1983 \\
\text { UTM Zone } 11 \mathrm{~N}\end{array}$ & \\
\hline \multirow[t]{4}{*}{$\begin{array}{l}\text { 4. Data } \\
\text { availability and } \\
\text { cost }\end{array}$} & $\begin{array}{l}\text { Percent coverage available now: } \\
\text { UNK }\end{array}$ & \\
\hline & Currency: UNK & \\
\hline & Restrictions on use: none & \\
\hline & $\begin{array}{l}\text { Cost of dataset acquisition: Free } \\
\text { (NPS) }\end{array}$ & \\
\hline
\end{tabular}

\begin{tabular}{|l|l|l|}
\hline \multicolumn{1}{|c|}{ Component } & \multicolumn{1}{c|}{ Details } & \multicolumn{1}{c|}{ Notes } \\
\hline \multirow{2}{*}{$\begin{array}{l}\text { 1. Data } \\
\text { Identification }\end{array}$} & $\begin{array}{l}\text { Name: Trail_Transect (within } \\
\text { JOTR_socialtrails08.mdb) }\end{array}$ & Trail_Transect \\
\cline { 2 - 3 } & Source Agency: NPS & JTNP \\
\cline { 2 - 3 } & Internet location: & \\
\cline { 2 - 3 } & &
\end{tabular}




\begin{tabular}{|c|c|c|}
\hline & Metadata: None & \\
\hline \multirow[t]{5}{*}{$\begin{array}{l}\text { 2. Data volume } \\
\text { considerations }\end{array}$} & Digital data format: Geodatabase & \\
\hline & Percentage available: UNK & \\
\hline & $\begin{array}{l}\text { Primary record type: Feature } \\
\text { class }\end{array}$ & \\
\hline & Primary record volume: $11.91 \mathrm{~KB}$ & \\
\hline & Total data volume: $11.91 \mathrm{~KB}$ & \\
\hline \multicolumn{3}{|l|}{$\begin{array}{l}\text { 3. Data } \\
\text { Characteristics }\end{array}$} \\
\hline \multirow[t]{3}{*}{ Digital Portion } & Size: $11.91 \mathrm{~KB}$ & \\
\hline & Scale: UNK & \\
\hline & $\begin{array}{l}\text { Projection/Datum: NAD } 1983 \\
\text { UTM Zone 11N }\end{array}$ & \\
\hline \multirow[t]{4}{*}{$\begin{array}{l}\text { 4. Data } \\
\text { availability and } \\
\text { cost }\end{array}$} & $\begin{array}{l}\text { Percent coverage available now: } \\
\text { UNK }\end{array}$ & \\
\hline & Currency: UNK & \\
\hline & Restrictions on use: none & \\
\hline & $\begin{array}{l}\text { Cost of dataset acquisition: Free } \\
\text { (NPS) }\end{array}$ & \\
\hline
\end{tabular}

\begin{tabular}{|c|c|c|}
\hline Component & Details & Notes \\
\hline \multirow[t]{4}{*}{$\begin{array}{l}\text { 1. Data } \\
\text { Identification }\end{array}$} & Name: Bouldering.shp & BoulderingSites \\
\hline & Source Agency: NPS & JTNP \\
\hline & Internet location: & \\
\hline & Metadata: $100 \%$ & \\
\hline \multirow[t]{5}{*}{$\begin{array}{l}\text { 2. Data volume } \\
\text { considerations }\end{array}$} & Digital data format: Shapefile & \\
\hline & Percentage available: $100 \%$ & \\
\hline & Primary record type: Shapefile & \\
\hline & $\begin{array}{l}\text { Primary record volume: } 27.85 \\
\text { KB }\end{array}$ & \\
\hline & Total data volume: $27.85 \mathrm{~KB}$ & \\
\hline \multicolumn{3}{|l|}{$\begin{array}{l}\text { 3. Data } \\
\text { Characteristics }\end{array}$} \\
\hline \multirow[t]{3}{*}{ Digital Portion } & Size: $27.85 \mathrm{~KB}$ & \\
\hline & Scale: UNK & \\
\hline & $\begin{array}{l}\text { Projection/Datum: NAD } 1983 \\
\text { UTM Zone } 11 \mathrm{~N}\end{array}$ & \\
\hline $\begin{array}{l}\text { 4. Data } \\
\text { availability and }\end{array}$ & $\begin{array}{l}\text { Percent coverage available now: } \\
\text { UNK }\end{array}$ & \\
\hline
\end{tabular}




\begin{tabular}{|l|l|l|}
\hline cost & \\
\cline { 2 - 3 } & Currency: 2004 & \\
\hline & Restrictions on use: none & \\
\hline $\begin{array}{l}\text { Cost of dataset acquisition: Free } \\
\text { (NPS) }\end{array}$ & \\
\hline
\end{tabular}

\begin{tabular}{|c|c|c|}
\hline Component & Details & Notes \\
\hline \multirow[t]{4}{*}{$\begin{array}{l}\text { 1. Data } \\
\text { Identification }\end{array}$} & Name: Rocks.shp & Rock_Sites \\
\hline & Source Agency: NPS & JTNP \\
\hline & Internet location: & \\
\hline & Metadata: Partial & \\
\hline \multirow[t]{5}{*}{$\begin{array}{l}\text { 2. Data volume } \\
\text { considerations }\end{array}$} & Digital data format: Shapefile & \\
\hline & Percentage available: UNK & \\
\hline & Primary record type: Shapefile & \\
\hline & Primary record volume: $69.05 \mathrm{~KB}$ & \\
\hline & Total data volume: $69.05 \mathrm{~KB}$ & \\
\hline \multicolumn{3}{|l|}{$\begin{array}{l}\text { 3. Data } \\
\text { Characteristics }\end{array}$} \\
\hline \multirow[t]{3}{*}{ Digital Portion } & Size: $69.05 \mathrm{~KB}$ & \\
\hline & Scale: UNK & \\
\hline & $\begin{array}{l}\text { Projection/Datum: NAD } 1983 \\
\text { UTM Zone } 11 \mathrm{~N}\end{array}$ & \\
\hline \multirow[t]{4}{*}{$\begin{array}{l}\text { 4. Data } \\
\text { availability and } \\
\text { cost }\end{array}$} & $\begin{array}{l}\text { Percent coverage available now: } \\
\text { UNK }\end{array}$ & \\
\hline & Currency: UNK & \\
\hline & Restrictions on use: none & \\
\hline & $\begin{array}{l}\text { Cost of dataset acquisition: Free } \\
\text { (NPS) }\end{array}$ & \\
\hline
\end{tabular}

\begin{tabular}{|l|l|l|}
\hline \multicolumn{1}{|c|}{ Component } & \multicolumn{1}{|c|}{ Details } & \multicolumn{1}{c|}{ Notes } \\
\hline \multirow{4}{*}{$\begin{array}{l}\text { 1. Data } \\
\text { Identification }\end{array}$} & & CampgroundSites \\
\cline { 2 - 3 } & Name: campg.shp & JTNP \\
\cline { 2 - 3 } & Source Agency: NPS & \\
\cline { 2 - 3 } & Internet location: & \\
\cline { 2 - 3 } & Metadata: Partial & \\
\hline \multirow{2}{*}{$\begin{array}{l}\text { 2. Data volume } \\
\text { considerations }\end{array}$} & Digital data format: Shapefile & \\
\cline { 2 - 3 } & Percentage available: UNK & \\
\cline { 2 - 3 } & &
\end{tabular}




\begin{tabular}{|c|c|c|}
\hline & Primary record type: Shapefile & \\
\hline & Primary record volume: $13.41 \mathrm{~KB}$ & \\
\hline & Total data volume: $13.41 \mathrm{~KB}$ & \\
\hline \multicolumn{3}{|l|}{$\begin{array}{l}\text { 3. Data } \\
\text { Characteristics }\end{array}$} \\
\hline \multirow[t]{3}{*}{ Digital Portion } & Size: $13.41 \mathrm{~KB}$ & \\
\hline & Scale: UNK & \\
\hline & $\begin{array}{l}\text { Projection/Datum: NAD } 1983 \\
\text { UTM Zone } 11 \mathrm{~N}\end{array}$ & \\
\hline \multirow[t]{4}{*}{$\begin{array}{l}\text { 4. Data } \\
\text { availability and } \\
\text { cost }\end{array}$} & $\begin{array}{l}\text { Percent coverage available now: } \\
\text { UNK }\end{array}$ & \\
\hline & Currency: 2001 & \\
\hline & Restrictions on use: none & \\
\hline & $\begin{array}{l}\text { Cost of dataset acquisition: Free } \\
\text { (NPS) }\end{array}$ & \\
\hline
\end{tabular}

